\title{
Young Adult Daughters and their Parents: Communication about WorkCareer and Family
}

\author{
Rita Daniels
}

Follow this and additional works at: https://researchrepository.wvu.edu/etd

\section{Recommended Citation}

Daniels, Rita, "Young Adult Daughters and their Parents: Communication about WorkCareer and Family" (2016). Graduate Theses, Dissertations, and Problem Reports. 5433.

https://researchrepository.wvu.edu/etd/5433

This Dissertation is protected by copyright and/or related rights. It has been brought to you by the The Research Repository @ WVU with permission from the rights-holder(s). You are free to use this Dissertation in any way that is permitted by the copyright and related rights legislation that applies to your use. For other uses you must obtain permission from the rights-holder(s) directly, unless additional rights are indicated by a Creative Commons license in the record and/ or on the work itself. This Dissertation has been accepted for inclusion in WVU Graduate Theses, Dissertations, and Problem Reports collection by an authorized administrator of The Research Repository @ WVU.

For more information, please contact researchrepository@mail.wvu.edu. 
Young Adult Daughters and their Parents: Communication about Work/Career and Family

\title{
Rita Daniels
}

\author{
Dissertation submitted to the \\ Eberly College of Arts and Sciences \\ at West Virginia University \\ in partial fulfillment of the requirements \\ for the degree of
}

\author{
Doctor of Philosophy \\ in \\ Communication Studies
}

\author{
Christine E. Rittenour, Ph.D., Chair \\ Scott A. Myers, Ph.D. \\ Matthew M. Martin, Ph.D. \\ Alan K. Goodboy, Ph.D. \\ Ann M. Oberhauser, Ph.D. \\ Department of Communication Studies \\ Morgantown, West Virginia \\ 2016
}

Keywords: young adult daughters, parent-child communication, communication theory of identity, memorable messages about work/career and family

Copyright 2016 Rita Daniels 


\section{ABSTRACT \\ Young Adult Daughters and their Parents: Communication about Work/Career and Family \\ Rita Daniels}

Employing adult daughters' $(N=254)$ perspectives of their communication, relational quality, and identities with and surrounding their relationships with parents, I bridge organizational and family communication's scholarship realms to address family socialization regarding work/career and family. Specifically, I examine: (a) the content and context of memorable messages about work and/or family; (b) the connection between daughters' closeness to parents and daughters' likelihood to transmit these messages; and (c) the impact of mothers' socialization messages about work/career and family on daughters' personal, relational, and enacted identities (identity layers within the Communication Theory of Identity (CTI; Hecht (1993)). Using both online and paper surveys, participants responded to opened-and closedended questions directed at either their mother or father who are biological or non-biological and alive or deceased. Quantitative responses were analyzed through regressions using SPSS and qualitative data was coded with Nvivo to examine memorable messages that young adult daughters receive from parents regarding work/career and family. Themes of work enjoyment and marriage prevailed across memorable messages about work and family respectively. Regarding memorable messages on work, fathers communicated messages about having priorities and work input whereas mothers communicated messages about attitudes towards work (i.e., working hard, not missing work, and treating people well), the value of work (i.e., education and financial empowerment), perseverance, and offered encouragement. Regarding memorable messages on family, mothers communicated messages about marriage/relationship (i.e., prioritization of work over family, readiness for marriage/family, and premarital rules), family responsibility, and support/love/unity whereas fathers communicated messages about the importance of family (i.e., family is everything, family is first), marriage, and father responsibility. Most messages were communicated in a private and informal/unplanned conversations. Results of the study indicated no significant difference between daughters and their target parent (i.e., mother or father) in terms of daughters' likelihood to transmit memorable messages and to engage in respectful accommodation, interpersonal closeness, and relational satisfaction. However, daughters reporting on fathers had greater self-disclosing than those targeting mothers. Daughters and parents' engagement in respectful accommodation and selfdisclosure positively predicted daughters' relational satisfaction. When daughters were relationally satisfied, they were likely to transmit parents' memorable messages. Daughters' receipt of mixed messages about work/family from parents was related positively to daughters' personal-relational and personal-enacted identity gaps which were in turn negatively related to daughters' life satisfaction. Generally, the findings provide additional content on memorable messages about work/family that parents communicate to their children and extend CTI by testing identity gaps in the context of an intersection of organizational and family communication while further examining the cause of identity gaps within a familial and personal relationship (among parents and young adult daughters). 


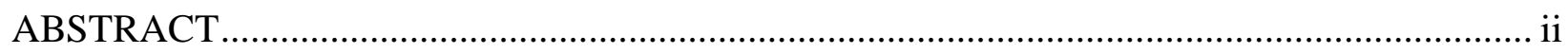

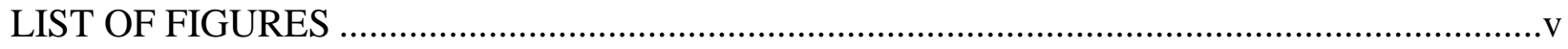

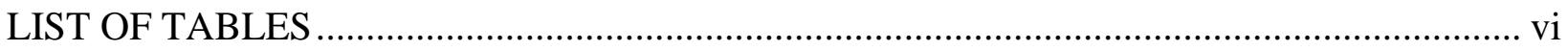

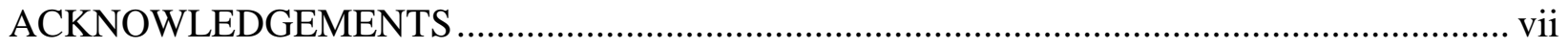

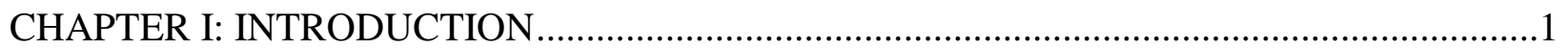

Parental Socialization about Work/Career and Family ...................................................5

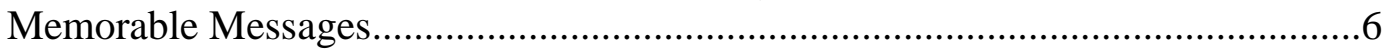

Gendered Socialization Messages and Parent-Daughter Relationships...........................10

Mother versus fathers: Trends in Parent-Child Relationship..............................11

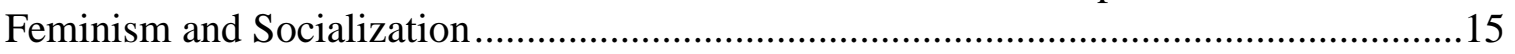

Communication Theory of Identity and Identity Gaps ............................................ 17

Communication Theory of Identity ….........................................................

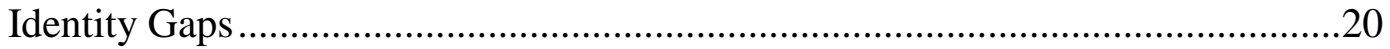

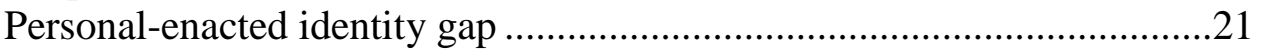

Personal-relational identity gap ..................................................22

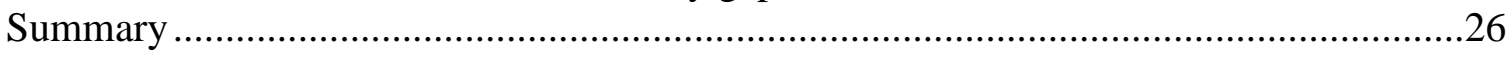

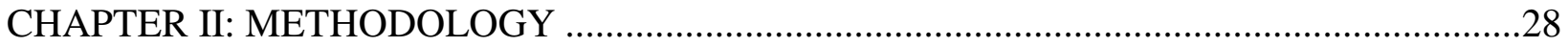

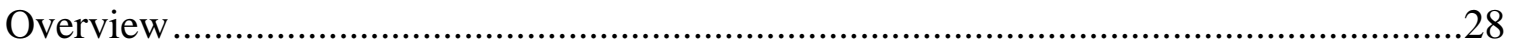

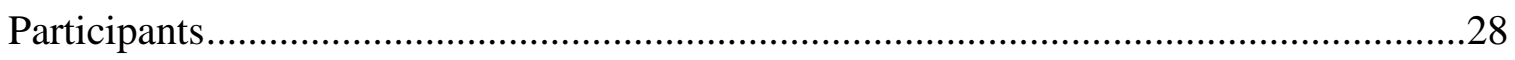

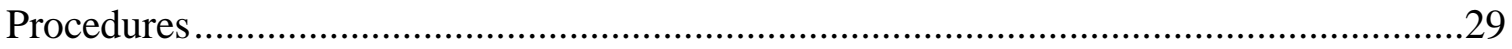

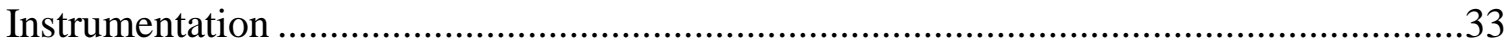

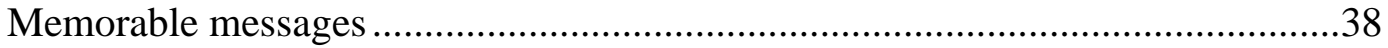

Likelihood to transmit memorable messages .................................................39

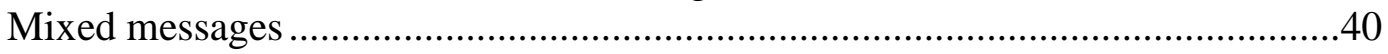

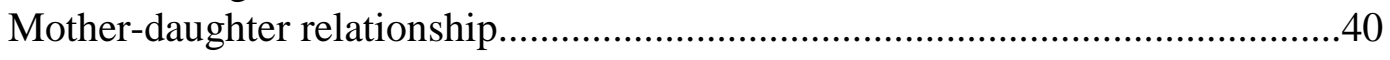

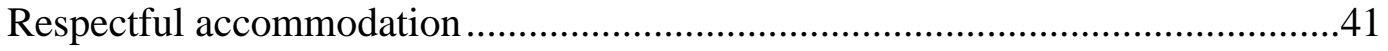

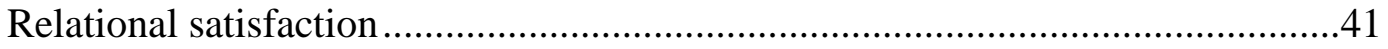

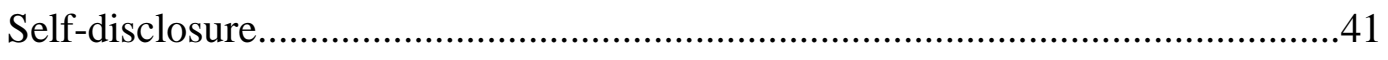

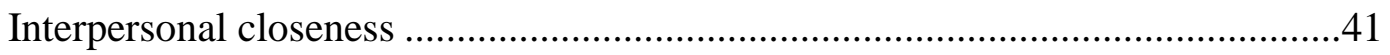

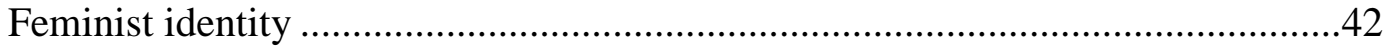

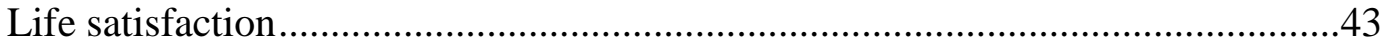

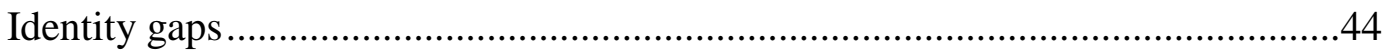

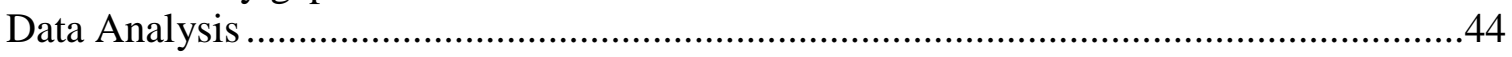

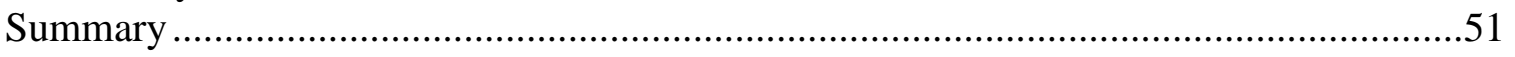

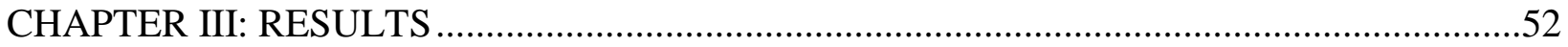

Research Question One: Content of Memorable Messages..........................................52 


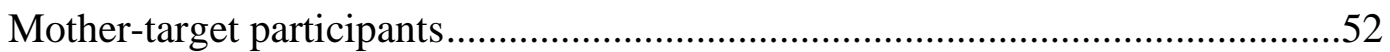

Messages about work …………………………………………….....5

Messages about family ......................................................................56

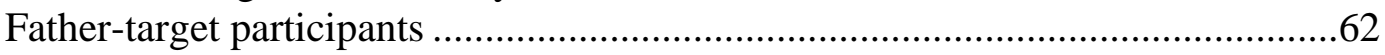

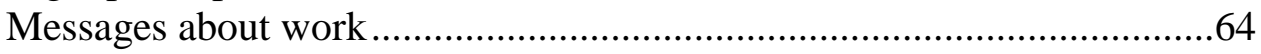

Messages about family.........................................................................64

Research Question Two: Context of Memorable Messages ...............................................68

Hypothesis One: Predictors of Daughter Relational Satisfaction ......................................68

Hypothesis Two and Three: The Likelihood of Transmitting Memorable Messages ........75

Hypotheses Four, Five, Six, and Seven: Dynamics in Daughter-Parent Relationship ......75

Hypotheses Eight and Nine: Mother and Daughter Feminist Identity...............................76

Hypothesis Ten: Mixed Messages and Identity Gaps .....................................................76

Hypotheses Eleven and Twelve: Identity Gaps, Likelihood to Transmit Messages, and

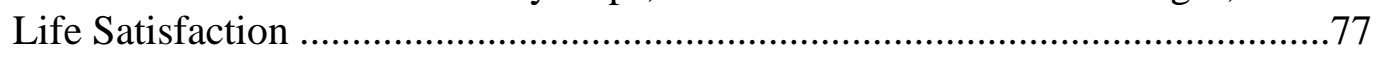

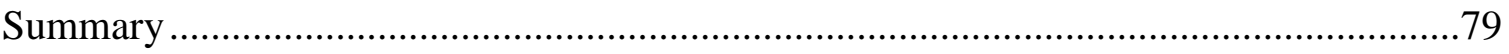

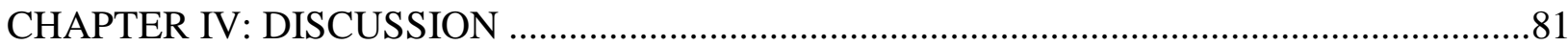

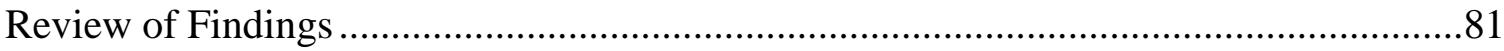

Parent-Daughter Relationships .........................................................................82

Memorable Messages about Work/Career and Family ........................................86

Memorable messages about work .............................................................87

Memorable messages about family.......................................................90

Context of memorable messages ..........................................................94

Theoretical and Practical Implications.......................................................................96

Theoretical Implications ………….............................................................96

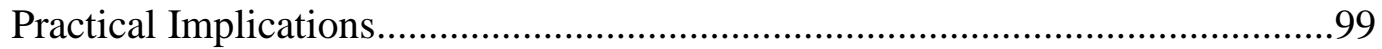

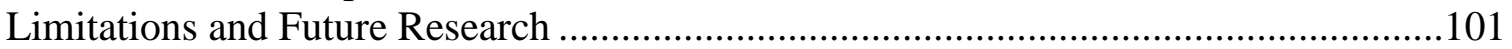

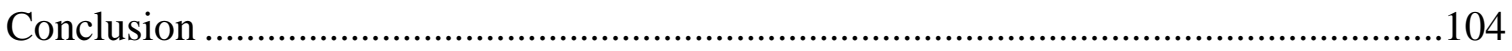

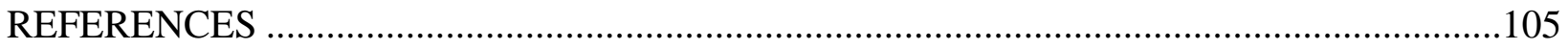

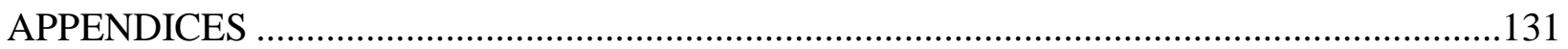

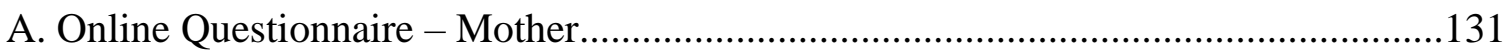

B. Online Questionnaire - Father ...........................................................................140

C. Paper Questionnaire - Mother................................................................................147

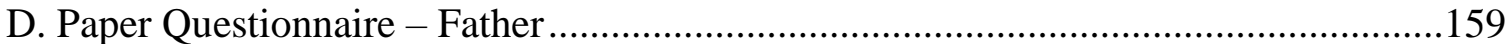

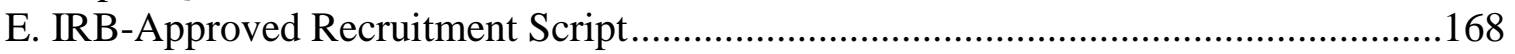

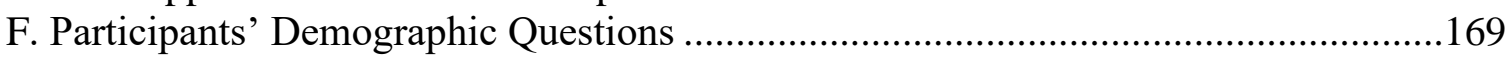

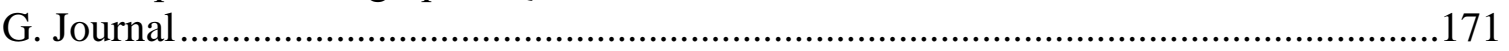




\section{List of Figures}

Figure 1. Qualitative Data Analysis Flow Chart: Creation of Nodes ............................................46

Figure 2. Word Cloud from Father Messages on Work/Family …….........................................49

Figure 3. Word Cloud from Mother Messages on Work/Family...................................................49

Figure 4. Themes from Memorable Messages Received from Mother-Target .............................54

Figure 5. Themes from Memorable Messages Received from Father-Target ................................63 


\section{List of Tables}

$\underline{\text { Page }}$

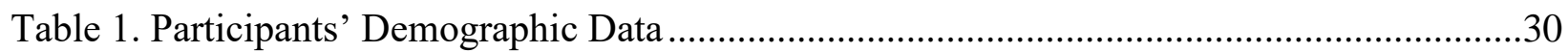

Table 2. Survey Distribution and Participants' Parents' Demographic Data ................................34

Table 3. Means, Standard Deviations, and Reliabilities for Variables .............................................36

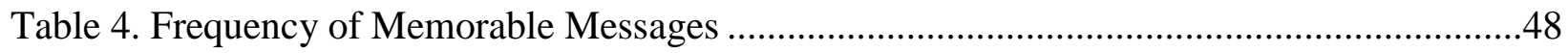

Table 5. Distribution of Target-Parent Messages that were Categorized into Themes ..................53

Table 6. Examples of Mother-Target Messages about Work: Attitude towards Work ..................57

Table 7. Examples of Mother-Target Messages about Work: The Value of Work, Work Enjoyment, Perseverance, and Encouragement .............................................................58

Table 8. Examples of Mother-Target Messages on Family ........................................................60

Table 9. Examples of Father-Target Messages about Work: Work Enjoyment, Having Priorities, Work Input, and Keeping a Balance

Table 10. Examples of Father-Target Messages about Family: Importance of Family, Marriage, and Father Responsibility .........................................................................................67

Table 11. Distribution of Type of Setting and Conversations for Memorable Messages..............69

Table 12. Correlations among Variables per Mother-Target......................................................

Table 13. Correlations among Variables per Father-Target ………..............................................72

Table 14. Correlations among Variables: Composite of both Target-Parents ................................73

Table 15. Multiple Regression Using Respectful Accommodation and Self-Disclosure to Predict Relational Satisfaction ...........................................................................................

Table 16. Multiple Regression Using Personal-Relational Identity Gap and Personal-Enacted Identity Gap to Predict Daughters' Likelihood to Transmit Mothers' Memorable Message.

Table 17. Multiple Regression Using Personal-Relational Identity Gap and Personal-Enacted Identity Gap to Predict Daughters' Life Satisfaction 


\section{ACKNOWLEDGEMENTS}

Habakkuk 2:2-3 (New International Version) "Then the Lord answered me and said, record the vision and inscribe it on tablets that the one who reads it may run. For the vision is yet for the appointed time; it hastens toward the goal and it will not fail. Though it tarries, wait for it; for it will certainly come, it will not delay."

I am most grateful to God for the abundant grace to witness this vision. My heart is filled with joy and profound appreciation to everyone who has contributed to my journey thus far. To those who have continually stuck with me through thick and thin, to those who watched me crawl, to those who watched me rise and fall in my earnest and ambitious desire to walk, and to those who provided running shoes or drinking water when I began to sprint, I share the joy of the fruition of my long standing dream. To the eyes that can read and the ears that can hear, be assured that though the vision tarries, it shall surely come without delay.

Of what good is family that doesn't share in your vision? When I held on to my vision for further studies, I was blessed with a family that has since said a prayer for me each morning. Those prayers each morning were drops of water on a seed planted in the desert that today has sprout as beautiful as the tree planted by the riverside. Thank you, Mummy, for your fervent prayers and the myriad sacrifices you made for me that held me high on wings like eagle. I share the glory of my dissertation with you. To the rest of my amazing family members, thank you immensely for every effort you have directed at my being. I am grateful to you. I wish my father lived long enough to read my dissertation.

Miles and miles away from home, I could not ask for any more support than what I have enjoyed and will continue to enjoy from my amazing advisor and friend, Christy. Thank you so much, Dr. Christine Elizabeth Rittenour. You always envisioned life beyond the now. You kept 
my hope alive and gave me enough reason to press ahead. You gave the word "challenge" a different meaning. You have been incredibly amazing. Had the world a thousand of you, evil minds will have no room to belabor great minds because sometimes, all that great minds need is an appropriate atmosphere. Every minute around you is always in an appropriate atmosphere. I will miss you dearly, but the thought of you and your family will forever bring fond memories and serve as a reminder and an anecdote to all that I shall encounter on my journey onward. My profound love goes to the Rittenours!!!

Thank you, Dr. Scott Myers, Dr. Matthew Martin, Dr. Alan Goodboy, and Dr. Ann Oberhauser for accepting to work with me on my dissertation. Your time and ideas invested in me and my work is invaluable. I am very grateful for your investment. Life as a Mountaineer couldn't have been any more enriching, had I not joined the Department of Communication Studies with the remarkable Chair of Department, Dr. Martin, and his team of faculty and staff. I am most grateful to have had the opportunity to study in the Department. I step out into the world with great confidence and a sense of fulfillment having known how much you all have invested in me and the great lessons I have learned while being a student of the Department. I am a proud and respectful Mountaineer!

Friends, as influential as they can be, finding the right friends can take you to the world's darkest hamlets, but I found true friends without hassle, here in the mountains. Melissa F. Tindage and Shaun Anderson, I am glad we found one another. Your true friendship is invaluable. Memories of our comprehensive exam preparations, all-nights of study, our travels to-and-from conferences, our good times over lunch and dinner (oh there were a couple of times we had breakfast together too), the joy we shared over our successes, and the times we brooded over our challenges will forever remain with me. I look forward to the many successes and 
celebrations to come while learning from my challenges to get better. Thank you for being a pillar, a strong one at that for me. You are family! You're always welcome to my home.

Finally, to all young adult daughters who participated in my study and all the people who supported me in recruiting participants for this dissertation, thank you. I appreciate you and I know you will find this dissertation useful in negotiating your identities in your communication with your parents. As you grow to take up parental roles, I hope that your involvement in this study would have raised your consciousness regarding the messages you communicate about work/career and family. Also, remember that though a vision tarries, wait for it, it shall surely come to pass. 


\section{CHAPTER I}

Introduction

"My father has told me it is important to always think of family while making decisions about work" (memorable message received from a participant's father).

"My mother said children are more important than work; a working mother is like a five legged dog, quite unnatural" (memorable message received from a participant's mother).

Whether it is about things one can unnaturally do or important things to always consider, messages from parents (or primary caregivers for that matter) play a significant role in the decisions one makes about work and family. As indicated in the two memorable messages above from the data of this dissertation, parents communicate varied messages about work and family to their children. Upon reflecting on one's cognitions and behaviors about work/career and family, chances are that they are influenced by messages about work/life issues received from parents.

Work-life issues have been studied with a focus on the intersection of employees' work and personal lives which primarily focused on work and family domains (e.g., Byron, 2005; Eby, Casper, Lockwood, Bordeaux, \& Brinley, 2005). Aiming to contribute to organizational and family communication's scholarship on work-life issues, the purpose of this dissertation is to examine the topics of conversation that parents engage in with their young adult daughters regarding work/career and family by specifically examining: (a) the connection between daughters' relationship with mothers and fathers, and daughters' likelihood to transmit parents' memorable messages regarding work/career and family; and (b) the impact of parents' mixed socialization messages about work/career and family on daughters' personal, relational, and enacted identities (identity layers within the Communication Theory of Identity; Hecht, 1993).

Work-life research increased in the early $21^{\text {st }}$ century to attend to global and societal 
changes in people's everyday behaviors that occurred based on demographic, economic, and moral changes. Work-life issues have received scholarly attention from communication studies, psychology, sociology, family studies, and political science. Organizational communication scholars contribute to research on work-life issues by examining how communication constitutes the sensemaking processes and structures surrounding work-life phenomena (for a review see Kirby, Golden, Medved, Jorgenson, \& Buzzanell, 2003).

Kirby and Buzzanell (2014) framed work-life communication research around five constitutive communicative processes - two of which pertain to this dissertation: (a) policy-ing work-life in organizations (b) norm-ing (or not) issues of work-life in organizations, (c) constructing (gendered) (working) identities, (d) acting practically and routinizing work and (personal) life, and (e) (re)producing ideal workers and the primacy of work.

The construction of gendered/working identities pertains well to this dissertation, with its focus on the complexity of women and men negotiating their worker (e.g., issues related to policies and practices such as maternity leave) and caregiving (e.g., parenthood, especially motherhood in academe) identities. There is a public/private distinction between men's and women's work and personal life which remains influential even though that may no longer be a given in Western culture (Kirby \& Buzzanell, 2014). While both men's and women's work and family life dually influence each other (Tracy \& Rivera, 2010), issues that involve a woman's family can impact other family members as well as organizational members because of the woman's pivotal (expectations for caregiving) and traditional role in the family. Thus, women are at the center of the work/family discourse.

Another framework (Kirby \& Buzzanell, 2014) that pertains to this dissertation is acting practically and routinizing work and (personal) life. This area of scholarship focuses on everyday 
routines that constitute work and personal life. Golden and Geisler (2007) examined the role of mobile communication technologies in everyday routines to construct boundaries between home and work. Other researchers explored the relationship between issues of routine domestic and family labor (e.g., care labor and household work), and organizational life (e.g., Medved, 2007, 2010).

The divisions of domestic labor are gendered (Alberts, Tracy, \& Tretheweay, 2011; Baxter, 2005; Baxter, Hewitt, \& Western, 2005; Medved, 2004, 2009). Clark’s (2000) work/family border theory explains how the nature of work and family domains as two different but interactive environments can be managed and negotiated to attain work-family balance. Clark's definition of work-family is "satisfaction and good functioning at work and home, with minimum role conflict” (p. 751). Hence, further research is necessary to examine how this state of satisfaction and good functioning at work and home can be achieved and promoted particularly amongst women who as a result of gender socialization are expected to play active roles in both domains.

According to Clark (2002), physical, temporal, and psychological parameters separate social roles and influence work and family responsibilities. The boundaries between these social roles are characterized by flexibility (i.e., the extent to which spatial and temporal parameters do not restrict one from accomplishing role-related tasks and responsibilities) and permeability (i.e., the extent to which elements from one domain may enter another domain; Clark, 2002). The lines of demarcation between the two domains are strengthened when an individual is able to blend role-related tasks and responsibilities of different but interactive domains.

Work and home are two different domains with different rules that demand different thought patterns and behavior from individuals engaged in these domains. Rokeach (1973) 
described the difference between work and family domains in terms of difference in value means and difference in value ends. Clark and Farmer (1998) as cited in Clark (2000) found that responsibility and capability are the means to attain desired ends at work whereas loving and giving are used to attain happiness at home. They also found that whereas home life satisfies the need for maintaining close and personal relationships, work life satisfies the need for selfaccomplishment and the need for a source of income.

Work-family issues have been studied extensively as issues of role conflict that arise particularly for women as a result of the intersection of women's managerial roles and the traditional gendered role of women in the home (e.g., Bedu-Addo, 2010; Delle \& Arkoful, 2014; Kissi-Abrokwah, Andoh-Robertson, Tutu-Danquah, \& Agbesi, 2015). This role conflict has been shown to have negative consequences (e.g., overwork and isolation; Baines \& Gelder, 2003; Chelsey, 2005); negative impact on job performance (Kossek, Lautsch, \& Eaton, 2006; OlsonBuchanan \& Boswell, 2006) for individuals as well as families and organizations (Frone, 2000; Shockley \& Singla, 2011). Ammons and Markham (2004) have shown that individuals engaged in long working hours are deprived of time to spend with their families.

Amidst these studies, there is limited research on how parental socialization produces and reproduces work/family norms (for an exception see Medved et al., 2006). This dissertation contributes to the literature on work-family socialization by examining the connection between daughter-parent relationships and daughters' likelihood to transmit parents' memorable messages regarding work/career and family, and proposing the connection to contribute to identity gaps within the Communication Theory of Identity framework (Hecht, 1993). Before delving into the theoretical framework, the following are reviewed: relevant literature on parental socialization messages about work/career and family; memorable messages and its gendered nature; the 
parent-daughter relationships; and daughter and mother feminist identity and ties to daughter life-satisfaction.

\section{Parental Socialization about Work/Career and Family}

Bullis (1993) defined socialization as a "central process through which individualsocietal relationships are mediated" (p. 10). Essentially, interactions are what shape and possibly transform one's social world over time. Socialization starts at those first moments of social contact and is most often experienced with one's parents. These interactions usually address the exploration, discovery, and judgment of appropriate behavior in a given context (Schieffelin \& Ochs, 1986). In the following sections, socialization from parents to children, particularly daughters, is reviewed using memorable messages as an analytical strategy for discourse analysis on socialization messages.

Parents, who are often primary caregivers, aim "to ensure that their children are able to display and understand behaviors appropriate to social situations" (Schieffelin \& Ochs, 1986, p. 470). This goal is primarily accomplished through language. Inasmuch as messages communicated by the media, coworkers, and friends contribute to the sensemaking of life issues in contemporary society, parents are the first to play an important role in the development of adult children's cognition and behaviors. According to Kellas (2010), parents' messages “might be embraced or rejected, but whether positive or negative, the content of the parent-child communication is often memorable and may have a lasting impression on children" (p. 459).

Pertinent to this dissertation, parents are key informants to young adults' future work/career and family issues (Csikszentmihalyi \& Schneider, 2000), but while there is evidence to suggest what these messages might entail (e.g., Rittenour, Colaner, \& Odenweller (2014) found that messages from mothers to daughters concern becoming a mother), researchers have 
yet to extensively examine the nature of the messages young adults receive specifically about work/career and family.

Honeycutt and Cantrill (2001) suggested that family communication is inherently a site for communicating memorable messages about important life lessons of which work/career and family is a part, given the crucial nature of one's well-being regarding these two realms. These memorable messages are heuristic frames that can have a carry-over effect on individuals' ongoing sensemaking processes of work/career and family issues (Knapp, Stohl, \& Reardon, 1981). Waldron, Kloeber, Goman, Piemonte, and Danaher (2014) described memorable messages as tools used by parents to transmit morals to their children. In this dissertation, memorable messages is used as an analytical strategy for discourse analysis on socialization messages.

\section{Memorable Messages}

Messages that are received very early in one's life, remembered for a long period of time, and have great influence on the sensemaking process of the receiver are known as memorable messages (Knapp et al., 1981; Stohl, 1986). As a "rich source of information about ourselves and our ways of communicating and socializing'” (Stohl, 1986, p. 232), memorable messages can guide self-assessment of behavior to maintain or enhance personal standards (Ellis \& Smith, 2004) because they prescribe the code of conduct for solving personal problems (Knapp et al.). They are communicated in the form of proverbs, colloquialisms, and rules of thumb (Barge \& Schlueter, 2004). Memorable messages are a powerful linguistic tool and have been used as a unit of communication analysis because they are used to interpret meaning in future communicative experiences.

Individuals receive thousands of messages from various sources, but a select few 
messages become memorable and such messages are legitimate and personal (Stohl, 1986), internalized and taken to heart (Knapp et al., 1981), retained in the memory's cache (Smith, Ellis, \& Yoo, 2001), and continue to influence receivers' lives long after the messages have been communicated (Ellis \& Smith, 2004). According to Stafford, Burggarf, and Sharkey (1987), most other messages we receive are quickly forgotten a few hours after receipt. " The only necessary and sufficient condition that distinguishes a memorable message from the thousands of others we receive each day is the retrospective judgment by the individual that the message was/is significant and can be precisely recalled" (Stohl, p. 234).

Knapp et al. (1981) identified the following as characteristics of memorable messages: they are brief and delivered verbally, personalized and important to the receiver, applicable to many contexts, delivered when the receiver is receptive, and the source of the message has esteemed respect. Other researchers have found that memorable messages are communicated usually in a serious nature (Ford \& Ellis, 1998), in private informal settings (Barge \& Schlueter, 2004; Stohl, 1986), and are usually positive (Stohl, 1986). Stohl (1986) —in a study on memorable messages in the process of organizational socialization—argued that a message communicated in a private setting becomes memorable because of the receiver's perception that the message was purposefully communicated.

Barge and Schlueter (2004) in a study on newcomer organizational socialization found that messages employees reported as memorable were mostly communicated face-to-face in private informal settings though Galvin (2000) noted that organizations have been increasingly using technology in the form of email. According to Knapp et al. (1981), the private and informal nature of a memorable message (i.e., individualized message) makes it more likely for the receiver to transmit the message to other individuals. 
There are several analytical strategies for discourse analysis but memorable messages as a strategy is well suited to the study of socialization because of the emphasis on message activity, its impact on the receiver's sensemaking process and behaviors (because memorable messages are salient enough to be so lodged in one's memories), and its use in previous socialization research in varied contexts.

Memorable messages have been used as a unit of communication analysis in a plethora of contexts. Examples are gender socialization of new university faculty (e.g., Dallimore, 2003), organizational newcomer socialization (e.g., Barge \& Sclueter, 2004; Stohl, 1986), volunteerism with nonprofit organization (e.g., Steimel, 2013), perceptions about aging (e.g., Fung \& Carstensen, 2003; Holladay, 2002), constructions of the sense of who one is as an individual (Heisler \& Ellis, 2008); college life (e.g., Dunleavy \& Yang, 2015; Johnson, Orbe, \& CookeJackson, 2014; Kranstuber, Carr, \& Hosek, 2012; Wang, 2012), nurses’ support messages (Ford \& Ellis, 1998), illness and healthcare (e.g., Cooke-Jackson, Orbe, Johnson, \& Kauffman, 2014; Lauckner et al., 2012; Smith et al., 2010), sports socialization (e.g., Colon, 2011; Cranmer, 2015; Kassing \& Pappas, 2007; Starcher, 2015;), end-of-life conversations about religious faith (e.g., Keeley, 2004), and — particularly useful and similar to this study_family and work (Medved, Brogan, McClanahan, Morris, \& Shepherd, 2006).

Medved et al. (2006) found that men and women received similar messages about the role that family should play in their lives; however, women were more frequently encouraged toward selecting work that would allow them to prioritize family needs, and were also advised to exit the workforce after the birth of a child. Inasmuch as Medved et al. reported similarities and differences in the content of messages that daughters and sons received from their parents regarding work and family, the frequency with which the messages are delivered can also 
symbolize agency and reinforce expectations for one gender. Rittenour et al. (2014) also reported that daughters received messages (in the form of requests, predictions, or instructions) about having children and about balancing work and personal life.

By studying workplace interactions, organizational communication scholars provide insights into the nature of messages constructed about paid labor (e.g., Barge \& Schlueter, 2004; Harter \& Krone, 2001). In this dissertation, I am extending memorable messages as a line of inquiry to examine adult daughters' socialization about work/career and family expecting that gendered patterns are bound to emerge but new cohorts and a specific look at memorable messages about work/career and family will offer further important insights. Participants of this study recalled specific memorable messages from their mother or father (either biological or non-biological).

As Giddens (1979) noted, socialization is representative of the construction process of meaning. Few researchers have examined the content of parent-child communication that socializes children about work/career and family, and those that have (e.g., Medved et al., 2006), did not examine (a) the connection between children's closeness to each parent and children's likelihood to transmit parents' memorable messages regarding work/career and family; and (b) the impact of parents' socialization messages about work/career and family on children's personal, relational, and enacted identities.

In knowing that memorable messages guide sense-making (Stohl, 1986), behavior (Smith et al., 2009), and self-assessment of behavior (Ellis \& Smith, 2004), the following questions are posed to glean insight from the content and context (i.e., whether in public/private setting or formal/informal conversations) of memorable messages from parents to daughters that address work/career and family issues: 
RQ1: What memorable messages regarding work/career and family do daughters receive from their parent?

RQ2: To what extent are these messages communicated in private/public or formal/informal conversations?

Gender socialization research in the context of family communication provides a "prescription for how parents should interact with children to bring about optimal development" (Stafford \& Bayer, 1993, p. 89). As Medved et al. (2006) posited, in family communication, the focus has greatly been on family communication styles and patterns and less on the transmission and reproduction of meaning. I aim to join others who are exceptions of this trend (i.e., research on family communication styles and patterns). My inspection of transmitted meanings is addressed alongside relationship characteristics and in doing so I place importance on the gender composition of the family members.

Even though previous work on this matter is limited, overlooking this aspect of socialization in trying to fully understand the construction of meaning of work/career and family will create a lacuna in academic and popular dialogues on the generational nature of work/career and family sensemaking. Sex of off-spring has been suggested to account for some differences in the focus of memorable messages (e.g., moral messages (Waldron et al., 2014) that may be as a result of cultural expectations regarding gender roles in family life; Hochschild, 1989) as well as work life.

\section{Gendered Socialization Messages and Parent-Daughter Relationships}

Dallimore (2003) and Heisler (2000) noted that socialization messages addressing work/career and family shape and are shaped by our interpretations of femininity and masculinity. For example, the ideal worker is generally gendered masculine with leadership and 
technical skills, upholds autonomy and competition, and spends unlimited time at work (Acker, 2004; Alvesson \& Billing, 2009) whereas the ideal woman is devoted and attentive to her family needs (Buzzanell \& D'Enbeau, 2009) and balances work and family without much evidence of physical and psychological strain (D'Enbeau \& Buzzanell 2010); the woman can be considered to have engaged in effortless perfection. Parents can be a source for some of these gendered messages and interpretations.

\section{Mothers versus Fathers: Trends in Parent-Child Relationship}

Heisler (2000) found sex differences in the nature and frequencies of socialization messages regarding work and family. Additionally, participants were quick to remember genderappropriate behaviors. Early work socialization messages validate gendered division of household labor (e.g., males are assigned the labor intensive chores such as mowing the lawn whereas females are assigned to cooking chores) and support stereotypes in traditional sex roles that pertain to particular kinds of work (e.g., in the profession of medicine, women are nurses whereas men are doctors). Research conducted under the rubric of anticipatory vocational socialization in organizational communication indicates that children may learn how to perform skills for use in their future workplace (e.g. delegating and soliciting assistance) through their parents in ways consistent with traditional gender norms (e.g., Goodnow, Bowes, Warton, Dawes, \& Taylor, 1991).

While fathers play a role in the cognitive development, well-being, and social competence of their children (Day \& Lamb, 2004), Kellas (2010) proposed that the motherdaughter relationship has contextual ripeness to provide insights into the transmission of family messages. Mothers rather than fathers are the primary source of memorable messages (Keating, Shaw, \& Smith, 2012) particularly regarding daughters' relational obligations (e.g., directing 
more attention from work to children after childbirth) and work and family (Medved \& Graham, 2006) - topics that are likely interwoven for women. Perhaps, this trend is as a result of gender similarities between mothers and daughters regarding their roles in the family (Martin \& Ruble, 2004). The gender makeup of the parent-child relationship is likely related to socialization power, and is likely responsible for Gordon (1998) and Orr's (2000) positions that mother-child interaction is important to transmitting worldviews to daughters.

There is some evidence that socialization messages change in content based on gender. For instance, Galvin (2006) and Bianchi, Robinson, and Milkie (2006) noted that mothers more than fathers tend to communicate with children. Research both supports children's greater likelihood to engage in conversation with their mothers than their fathers, and mothers' (more than fathers) greater likelihood to communicate with their children. I therefore expect that daughters experience relational satisfaction with their mothers because of their greater likelihood to engage in conversations and maintain relational closeness.

Existing research on parent-child relationship does provide some guidance. For instance, Piotrkowski and Stark (1987) found that fathers reported frequently engaging in conversations with their children about their jobs whereas mothers reported talking about paid labor experiences. There was also a positive correlation between parents' and their children's assessments of job satisfaction. These findings suggest gendered relationships where daughters identify more with their mothers than with their fathers on many issues of work, family, and well-being.

Mothers educate and socialize daughters on a plethora of topics spanning motherhood (Gilchrist \& Camara, 2012) and healthcare (Fischer, 2014). Hinton-Johnson (2004) described the mother-daughter relationship as most significant and enduring of women's relationships because 
of the wealth of information transmitted from mother to daughter which more often than not results in maternal modeling. The mother-daughter relationship is a central family relationship (Williams \& Nussbaum, 2001) because daughters like sons, spend more time with their mothers (Youniss \& Smollar, 1985) and because according to Miller-Day (2004), women co-author one another's lives as they engage in communication with each other as female family members to discursively construct their realities about life.

Mother-daughter relationships are significant to both women (i.e., mothers and daughters) in providing solidarity and support (La Sorsa \& Fodor, 1990). According to Fischer (1991), compared to other intergenerational relationships, these relationships have shown to be intense in emotional connection and interdependence that can be satisfying to both partners. When there is openness in the mother-daughter relationship and both women self-disclose, they will be more likely to benefit from the relationship and feel satisfied. However, not all motherdaughter relationships are of high quality given that the relationship quality differences coincide with differences in the messages exchanged between mother and daughter, and the impact of those messages.

According to Pearson (1989), satisfaction is the primary criterion for evaluating the quality of family communication. Rusbult, Martz, and Agnew (1998) described the extent to which people associate a feeling of happiness and contentment with the relationship they share with another person as relational satisfaction. Relational satisfaction in conjunction with memorable messages has been examined to provide insight into the gendered nature of parentchild relationships. Positive messages contribute to greater relational satisfaction (Starcher, 2015) that can then inform the transmission of memorable messages.

Herman (1989) argued for the centrality of the mother-daughter relationship in every 
woman's life and Bassoff (1987) suggested that daughters closely identify with their mothers such that the sameness bonds them. There is evidence of a positive correlation between motherdaughter closeness and the overall level of mother-daughter self-disclosure (e.g., Hernández \& Kahn, 2013). Given the bond between daughters and their mothers, I expect that interpersonal closeness will be indicative of relational satisfaction and with that satisfaction we might find other communication behaviors shown to enhance family bonds: self-disclosure and respectful accommodation.

Aiming to maintain a good relationship, family members may engage in respectful accommodation (i.e., showing respect for the opinions and perspectives of others; Harwood, 2000). This accommodative behavior is relevant in the context of this dissertation because of the likelihood of divergent perspectives regarding work/career and family. In the context of family members' disclosing their gay identity to the families, Soliz, Ribarsky, Harrigan, and TyeWilliams (2010) found a positive association between respectful accommodation and selfdisclosure, and respectful accommodation and relational satisfaction. This trend suggests the importance of respecting others' opinions and perspectives to encourage openness in communication and strengthen relationships with others.

If daughters have stronger bonds with their mothers than with their fathers and report greater relational satisfaction with mothers, I expect that daughters will be more likely to transmit their mother's messages than their father's messages. When daughters are satisfied with the mother-daughter relationship, they will tend to appreciate their mothers' messages. This and other predictions about parent-daughter relationships (i.e., how other communication behaviors shown to enhance family bonds can be gendered) and the likelihood for daughters to transmit parents' messages were forwarded within the following hypotheses: 
H1: Daughters' report of fathers' and mothers' respectful accommodation and selfdisclosure will be positive predictors of daughters' relational satisfaction.

H2: Daughters' relational satisfaction with parents will predict their likelihood to transmit a parent's memorable messages.

H3: Daughters will be more likely to transmit mothers' messages than fathers' messages.

H4: Daughters will engage in more respectful accommodation with mothers than with fathers.

H5: Daughters will self-disclose more to mothers than to fathers.

H6: Daughters will report greater interpersonal closeness with mothers than with fathers.

H7: Daughters will report greater relational satisfaction with mothers than with fathers.

\section{Feminism and Socialization}

Even among highly satisfied mother-daughter relationships, daughters often do not share their mothers' world views, particularly regarding women's roles and public perceptions of women. I examine the feminist identities of daughters and mothers to offer a communicative perspective on the development of the meaning of gender and provide one window into the socialization of daughters. Feminism promotes empowerment and supports women's development including the ability to identify acts of inequality and the desire to end such acts (Rittenour \& Colaner, 2012).

There are a myriad of personal variations to feminism and feminist identity (Allen, 2000). Contrary to hooks' (2000) assertion that feminism is for everybody (p. x), not all women identify 
as feminists or embrace feminism. College-aged adults for instance do not identify with feminism (Aronson, 2003) "Feminism" has negative connotations and stereotypes (e.g., feminists are men-haters) and there is a general distaste for the term (Toller, Suter, \& Trautman, 2004). Feminists are often construed as unfeminine, sexually unappealing, and unattractive (Alexander \& Ryan, 1997; Rubin, 1994; Rudman \& Fairchild, 2007). Given the pervasive nature of feminism and its ideals, it is possible that these negative stereotypes are being reframed or conceptualized differently because in a study conducted by Rudman and Phelan (2007), "there was no support for negative feminist stereotypes (i.e., that feminists are single, lesbians, or unattractive)" (p. 787).

Research has shown that one of the reasons for the backlash to feminism is that others' personal experiences and misperceptions of gender equality debunk the belief that gender equality is ideal and achievable (Swim \& Campbell, 2003). In an interview with women of various ages, Sigel (1996) noted women's concern that feminism has gone too far to interfere with traditional gender roles which has negatively affected women's relations with men. From this standpoint, it is possible that both mothers and daughters will not necessarily embrace a feminist identity or the same variation of a feminist identity, considering the prevalence of feminism and its ideals in contemporary society as well as the intergenerational nature of the mother-daughter relationship.

For those who embrace feminism though, they experience healthier relationships, greater relational stability, and sexual satisfaction (Rudman \& Phelan 2007; Schick, Zucker, \& BayCheng, 2008). They are able to recognize acts of inequality and advocate against inequality (Witte \& Sherman 2002). I infer from the relational benefits of feminist identity that daughters who identify with feminism will report greater overall judgment of the quality of their lives (i.e., 
life satisfaction) than those who do not identify with feminist ideals.

The following hypotheses were forwarded to explore mother and daughter feminist identities to examine the extent to which mothers and daughters identify with feminism as well as the relationship between feminist identity and life satisfaction as feminism relates to values of gender equality.

H8: Daughters will perceive their mothers' feminist identity as less than their own feminist identity.

H9: Daughter feminist identity will be positively related to daughter life satisfaction.

Upon addressing the topics of conversation that parents engage in with their young adult daughters regarding work/career and family, the relationship characteristics of parent-daughter relationships to determine the connection between daughters' relationship closeness to their parents, and the likelihood to accept or transmit their parents' messages, the focus of this dissertation shifts to examine the impact of parents' mixed socialization messages about work/career on daughters' personal-relational and personal-enacted identity gaps.

This dissertation draws upon the Communication Theory of Identity (CTI) (Hecht, 1993) framework that has been used in previous research to examine the notion of identity located in the individual and the nature of intra- and interethnic communication. The next section discusses CTI, previous research inspired by this framework, and the utility of the framework in this dissertation's new context.

\section{Communication Theory of Identity and Identity Gaps}

\section{Communication Theory of Identity}

Individuals differentiate and integrate themselves with others in their social world through the process of identity development (Erikson, 1968). The process of identity 
development involves a "simultaneous reflection and observation" in which individuals critically judge themselves and society from multiple perspectives (Erikson, p. 22). Additionally, individuals are influenced by psychological, social, historical, and developmental factors as they develop a concrete sense of self. Throughout the time of identity development, individuals explore possible options for personal identity and subsequently commit to or reject various options for defining the self. CTI further explains Erikson's identity development process from a communicative perspective.

CTI incorporates classical influences from African, Asian, and Greek cultures carved in perspectives from modernity and postmodernity (Hecht, Warren, Jung, \& Krieger, 2005). From the perspective of modernity, identity is an inward search for truth in order to represent one's true self (Bewes, 1997) whereas the postmodern perspective adorns a multiple representation of the modern self because of the recognition of unstable and rapidly mutating conditions in the postmodern world (e.g., immigration and advancement in technology and transportation systems which enable an individual to engage in social interactions with different people of different cultural backgrounds and in different places; Kellner, 1992).

CTI places communication as central to the study of identity. According to Hecht et al. (2005), "identity is formed when relevant symbolic meanings are attached to and organized in an individual in various situations through social interaction" (p. 262). Identity is formed, shaped, and maintained during social interactions. It is a product of layering schemata about the self and how an individual understands the social world and engages in social interactions within the social world (Hecht et al., 2005). Our identity emerges as a sense of self through four different frames of identity (Jung \& Hecht, 2004).

The first frame is personal identity. Personal identity captures the classical notions of 
self-concept, self-cognitions, spiritual sense of being, and feelings about oneself and/or selfimage (Hecht et al, 2005). In this frame, the individual is the locus of identity. Personal identity takes shape and becomes consolidated during an individual's adolescence and young adulthood (Tuck, Rolfe, \& Adair, 1994). According to Barber and Eccles (1992), the consolidation process involves the development of commitment to specific educational, occupational, marital, and parental goals. For example, daughters perceiving themselves as career-oriented, familyoriented, or independent are all aspects of the personal identity frame.

The second frame, enacted identity, is the part of a person's identity that is expressed through communication behaviors whereas the third frame, relational identity, frames identity as co-created though social interactions and role negotiation with people. In the enacted frame, the locus of identity is communication and the self is perceived as a performance. Relational identity is a mutual product of self and other and it emerges in three forms: (a) identity as ascribed by others through social interaction or social categorization and leads to an ongoing modification of an individual's identity as influenced by other people's views, (b) identity as defined by relational roles such as coworkers and parents, and (c) identity as the relational unit whereby the relationship itself is an identity (e.g., a couple as a unit can form an identity). The nature of linkages among gender, work, and family observed by an individual is a possible contributing factor to the individual's career aspirations and family plans (Riggio \& Desrochers, 2006). This observation can constitute one's relational identity regarding work/career and family. The relationship is the locus of identity.

Finally, communal identity is expressed through one's group affiliation such that characteristics shared with other ingroup members influence how an individual defines self (e.g., identifying with fellow employees of an organization or with other members of the family who 
are either family or career oriented). Identity exists within the group because group members share common memories and characteristics; the group is the locus of identity.

\section{Identity Gaps}

In the line of reasoning about the four frames of identity, communication is neither separate nor a precursor to identity; communication constitutes our identity. CTI conceptualizes identity from a postmodern perspective as "multilayered self as well as the dynamic interplay between stability and change... [and these] different aspects of self are interpenetrated - that is, infused into each other" (Hecht et al., 2005, p. 259). Sometimes, there are differences between and among the interpenetration of identity frames and this is referred to as identity gaps (Jung \& Hecht, 2004; Jung, Hecht, \& Wadsworth, 2007). Young adult daughters may succumb to their mothers' ideals or attempt to fulfill their mothers' expectations that are different from the daughters' own personal ideals or expectations. Such inconsistencies create identity gaps. This lens should aid my examining of the multiple sources converging and diverging as young adult daughters make sense of the messages they receive from their mothers regarding work/career and family to form their sense of self.

For the purpose of this dissertation, the personal-enacted and personal-relational identity gaps are the foci because they compare the traditional notion of identity (i.e., the personal frame) and two communication-based notions of identity (i.e., the enacted and relational frames). Emphasis will also be placed more on the mother-daughter relationship because of its known significance in daughter identity development (as explained in previous sections of this dissertation). Personal-relational and personal-enacted identity gaps are inherently communicative and research supports this communicative nature with findings of high correlations between the two identity gaps and communication outcome variables like 
communication effectiveness and appropriateness, feeling understood, and communication satisfaction (Jung \& Hecht, 2004).

Personal-enacted identity gap. A personal-enacted identity gap occurs when there is a discrepancy between the personal and enacted frames of identity such that an individual's perception of herself or himself is not the same as how the individual expresses herself or himself while interacting with others (Jung \& Hecht, 2004). Research has shown a variation in the size of the gap between personal and enacted identities because of an individual's tendency to suppress the authentic self to fit in a given context (Jack, 1999) or manipulate the authentic self to create a different impression (Petronio, 2000). Messages communicated do not all the time produce the exact intended meaning and so it is also possible to be perceived differently from how one intends to express oneself.

The personal-enacted identity gap emerges communicatively when a second party is involved and there is a discrepancy between what the sender perceives of herself/himself (personal identity) and what she/he conveys to the other person (enacted identity). According to Kohler, Grotevant, and McRoy (2002), individuals develop identity by "achieving a cohesive definition of the self while individuating from parents or family" (p. 93). However, young adult daughters may receive mixed messages from their mothers regarding work/career and family as a result of difference in mother and daughter values, and generational gap.

Mothers may communicate mixed messages because of the desire for their daughters to be successful and happy as individuals, but may also want their daughters to meet the social expectations for their gender. Despite the fact that we know that mothers generally engage in conversations with their children (particularly daughters) more than fathers engage their children, young adult daughters may not necessarily agree with their mothers' values. This disagreement 
in values is what causes an identity gap (personal gap) as mothers and daughters express themselves in communication (enacted gap).

As with any intergenerational relationship, the mother-daughter relationship may incur differences in life conditions and social expectations that demand an alteration in one's attitude and sensemaking of work/career and family issues. When life's conditions demand commitments to new values and/or goals throughout the lifespan, individuals undergo efforts of exploration to embrace the possibility for reformation of their personal identity. Consequently, identity is neither fixed nor are values and goals unchanging.

For instance, differences as a result of organizational policies and economic conditions may not permit a lower-income earning couple to take advantage of maternity and paternity leave, either of which may be paid or unpaid. Given the current pervasiveness of the ideals of feminism and the call for women's empowerment, young adult daughters may not necessarily validate the traditional roles of women both in the family and at the workplace, and the expectations for career. The next identity gap of relevance to the purpose of this dissertation is the personal-relational identity gap.

Personal-relational identity gap. This identity gap explains the condition in which an individual's self-view differs from the identity others ascribe to the individual, definition of relational roles differs from that of other relational partners, or definition of a particular relationship differs from that of other relational partners (Jung \& Hecht, 2004). The way an individual sees herself or himself may be different from others' perceptions perhaps as a result of stereotypes, inaccurate information, or misunderstandings between communication partners (Wadsworth, Hecht, \& Jung, 2008). This dynamics suggests the important role relationships have in creating the personal-relational identity gap and highlights the communicative nature of 
identity because this identity gap occurs in the process of or as a result of communication.

The mother-daughter relationship is significantly important to the development of daughter identity (Gordon, 1998) across the lifespan (Pecchioni \& Nussbaum, 2001). There is transmission of values and relational worldviews that can be both damaging and beneficial in the process of daughter identity development (Orr, 2000). There could also be transfer of values and relational worldviews from mother to daughter that are not consistent with daughter's personal values and worldviews, expectations, or mother's lifestyle. These possible inconsistencies are described in this dissertation as mixed messages (taking cues from Kirby; 2000) and may be related to daughter's personal-relational identity.

Kirby (2000), in an interpretive study, found that supervisors communicate mixed messages about work and family by saying one thing and doing another. For instance, one participant reported that "they [supervisors] definitely say, 'your home life is important and don't stress out about the job.' But then they [the supervisors] turn around and say, don't stress out, but you do have to have this done by Friday." This double bind of saying one thing and doing/meaning another thing is further explored in this dissertation as mixed messages.

In the context of this study, a daughter may view herself differently from how her mother views her because both hold different ideologies. For instance, when an adult daughter believes her mother perceives her as more family-oriented than career-oriented (relational identity) but she (the adult daughter) perceives herself as being more career-oriented than family-oriented (personal identity), the adult-daughter will experience a personal-relational identity gap. The experience of identity gaps is contextual in the sense that the extent to which a daughter perceives herself differently from how her mother perceives her depends on social appropriateness and the nature of her mother-daughter relationship (e.g., relationship closeness). 
Hence, the daughter who is close to her mother and receives mixed messages may be more likely to experience greater personal-relational identity gap than the daughter who is not close to her mother. Relational closeness between mother and daughter suggests affection and likeness such that the daughter will want to please her mother by communicating in ways that suggest a desirable personal identity to her mother when she (i.e., the daughter) knows very well that is not her real self.

According to Hecht and Jung (2004), identity gaps can become challenging for individuals' interpersonal relationships and overall sense of self when they perceive large and/or recurrent identity gaps. Therefore, for daughters reporting little to no identity gaps, I expect that they will transmit the messages regarding work/career and family that they receive from their mothers because the messages do not contradict daughters' views, expectations, or mother's lifestyle. Given the possibility of the dynamics discussed above on identity gaps, mothers' mixed messages, and mother-daughter relationships, the following hypotheses were forwarded to further explore the relationship between mixed messages regarding work/career and family, the two identity gaps (i.e., personal-enacted and personal-relational identity gaps), and the likelihood to transmit memorable messages.

H10: Parents' mixed messages regarding work/career and family will be positively related to daughters' identity gaps.

H11: Daughters' identity gaps will predict their likelihood to transmit their mothers' messages regarding work/career and family.

Since the emergence of CTI scholarship over two decades ago, it has been useful for studying the development, utility, and effects of identity for a plethora of social groups. Research has employed CTI to understand issues of identity among international students (e.g., Jung et al., 
2007; Wadsworth et al., 2008), first generation college students (e.g., Orbe, 2004), immigrants (e.g., Jung \& Hecht, 2008; Urban \& Orbe, 2010), and in family relationships (e.g., adoptive family relations: Colaner, Halliwell, \& Guignon, 2014; between grandparents and grandchildren: Kam \& Hecht, 2009; relationships with stepfathers: Pettigrew, 2013), and in interracial encounters (e.g., Drummond \& Orbe, 2009). In all these studies, researchers have found identity gaps to have effects on individuals who experience the gaps.

Regarding the effects of identity gaps, Jung and Hecht (2004) found high negative correlations between two identity gaps (i.e., personal-relational and personal-enacted identity gaps) and communication appropriateness, feeling understood, interpersonal communication satisfaction, and communication effectiveness. Although the concept of identity gaps has not been applied to daughter work/career and family identity, there is empirical support for the idea that mother socialization messages regarding work/career and family could conflict and create challenges for developing daughter identity. Contradictions related to the daughters' work versus family identity could cause interference with daughters' ability to come to terms with their daughter status, career preference, and employee status as they pertain to their personal identity. The degree to which identity gaps may be present and have implications for daughters' work/career and family identities are unknown.

As noted by Rittenour and Colaner (2012), scholars' vigorous exploration of the degrees to which work and family roles intersect in women's complex lives and the nature of women's multiple roles has shown an effect on women's physical, emotional, and relational health. Inasmuch as the description for these multiple roles are a social construction, the intersection of work and family roles for any woman depends on the extent to which the woman identifies with 
the role descriptions. Work identities for women have shifted increasingly whereas the role of motherhood for instance has remained relatively constant (Raskin, 2006).

Life satisfaction may be realized when young women develop an individual career identity while simultaneously satisfying the social expectations associated with women and family. According to Raskin (2006), women enter the workforce for economic necessity rather than personal identity. For other women, life satisfaction may be realized through career identity that also serves the purpose of an economic necessity, at the expense of family obligations and expectations if not balanced. Either way, when individuals perceive a discrepancy between their authentic self and the version they consider to be appealing (possibly an inauthentic version of themselves) based on social expectations and the expectations of significant others or family members, they are experiencing identity gaps. Such identity gaps have shown to have negative effects on individuals' levels of competent communication and satisfaction (Jung \& Hecht, 2004). To further this line of research, I explore the relationship between identity gaps and adult daughters' life satisfaction, guided by the following hypothesis.

H12: Daughters' identity gaps will be related negatively to their life satisfaction.

\section{Summary}

The main purpose of this dissertation is to illuminate connections between memorable messages young adult daughters receive from parents regarding work/career and family; the messages and relationship characteristics, and their connection to daughters' relationship closeness to either parent; the likelihood of daughters transmitting parents' messages regarding work/career and family; and these messages' relationship to daughters' identity gaps. Two research questions were posed and 12 hypotheses were proposed toward achieving this goal. Specifically, the research questions focus on the content and context of memorable messages 
regarding work/career and family that adult daughters receive from their parents. In the first through seventh hypotheses (H1-H7), predictions related to daughter-parent relational satisfaction, and how that will predict daughters' likelihood to transmit memorable messages regarding work/career and family. In the eighth and ninth hypotheses (H8 and H9), predictions about mother and daughter feminist identities as they relate to values regarding work and family, and daughter life satisfaction were asserted. The predictions for the tenth and eleventh hypotheses (H10 and H11) focused on the relationship between mixed messages and daughters' identity gaps (i.e., personal-enacted and personal-relational identity gaps), and the likelihood of daughters to transmit the messages. Given the uniqueness of the mother-daughter relationship as previously discussed, in the eleventh hypothesis (H11), only predictions about that relationship (and not the father-daughter relationship) were made. In the final hypothesis (H12), I predicted a negative relationship between daughters' identity gaps (i.e., personal-enacted and personalrelational identity gaps) and life satisfaction. 


\section{CHAPTER II}

Methodology

\section{Overview}

This dissertation was designed to examine parents' socialization messages about work/career and family, and the impact on daughters' personal-relational and personal-enacted identity gaps as discussed in the preceding chapter. I gathered both quantitative and qualitative data that were analyzed using IBM SPSS Statistics and computer-assisted qualitative data analysis software (CAQDAS), NVivo 11 Pro for Windows software respectively. In this chapter, I outline my method through describing participants, procedures, instrumentation, and data analysis. Participants responded to questions directed at either their mother or father. With the exception of the set of questionnaire on mothers that included questions directed at learning about daughters' and mothers' feminist identity, both the mother-targeted (see Appendix A) and father-targeted (see Appendix B) questionnaires had the same questions, but adapted for the target parent. I utilized both online (see Appendix A and B) and paper (see Appendix C and D) surveys in data collection.

\section{Participants}

Participants of the study were 254 females within the age range of 18 to 35 years old ( $M$ $=23.93, S D=5.10)$. Six participants did not report their age. To qualify for participation in this dissertation, participants had to meet the following criteria: (a) be female, (b) be at least 18 to 35years old as this is the designated age for "young adult" (Petry, 2002), and (c) must have had contact with either mother or father to be able to report on their relationship. Ecological validity is maintained through including relationships of biological and non-biological ties and those with living or deceased parents. There was no restriction on the how many years the parent/parental figure may have been deceased because in the study of memorable messages, these messages are 
received very early in one's life and remembered for a long period of time (Knap et al., 1981). Other demographic data provided by participants are listed in Table 1.

\section{Procedures}

Following Institutional Review Board (IRB) approval, I utilized purposive sampling, snowball sampling, volunteer sampling, and network sampling as the four nonprobability sampling procedures to solicit for participation in this dissertation.

The first sampling procedure used was purposive sampling which allows for the use of a predetermined criteria in selecting a sample (Vogt, 2005). Given the focus of this dissertation on young adult daughters, the use of purposive sampling allowed for the use of the predetermined criteria participant selection (Hussey, 2010) in order to glean insight from the memorable messages young adult daughters receive from their parents about work/career and family and how these messages shape daughters' identity. With this procedure, participants were recruited from three upper-level communication courses (two large lecture courses of Nonverbal Communication; and one small lecture course of Family Communication) taught in the Department of Communication Studies and two introductory women and gender studies courses (small lecture courses) at West Virginia University (WVU). In all the classes, the researcher read the IRB-approved recruitment script (see Appendix E) aloud to the class. The recruitment script detailed an introduction to the researcher, the purpose of the research, as well as the participation criteria, how to participate in the study, acknowledgement of research approval from WVU's IRB, and contact information for both the principal investigator and the co-investigator. In the large lecture classes, participants were given the recruitment script and requested to send an email to the researcher; the response to which included the online survey link generated through the Qualtrics website. By placing this responsibility on the participants, I aimed to reduce 
Table 1

Participants' Demographic Data

Variable
Race/ethnicity

$10.20 \%$

$11 \quad 4.30 \%$
Black/African American

26

Asian/Pacific Islander

Hispanic/Latino

Native American/American Indian

White/Caucasian

Please specify if not listed

No response

$n$

7

2

201

4

3

132

10

155

5

7

Out of work but currently looking for work

Unable to work

Out of work and not looking for work
$\%$

$2.80 \%$

$.80 \%$

$79.10 \%$

$1.60 \%$

$1.20 \%$

$52.00 \%$

$3.90 \%$

$61.00 \%$

$2.00 \%$

$2.80 \%$

$-\quad \overline{1.60 \%}$

$11 \quad 4.30 \%$

2

128

44

66

3

$.80 \%$

$50.40 \%$

$17.30 \%$

$26.00 \%$

Graduate degree (e.g., master's, Ph.D.)

No response

$1.20 \%$

Relationship status

Single

Engaged

11

2

128

44

66

3

$4.30 \%$

$.80 \%$

$50.40 \%$

$17.30 \%$

$26.00 \%$

$1.20 \%$

No response

Residential area

Urban

87

54

111

2
$34.30 \%$

$21.30 \%$

$43.70 \%$

$.80 \%$
Rural

No response 
incomplete and incredible data from unwilling participants. This method yielded 205 out of the total of 254 participants. In the small lecture classes, participants were given the recruitment script and then those eligible and interested in doing so completed the paper version of the survey. This method yielded 49 out of the total of 254 participants. In the small lecture course of Family Communication, participants took the surveys home to be completed and returned a week later because the instructor of the class could not give students time to complete the surveys in class. In the other two introductory women and gender studies courses, the instructor agreed to give students time to complete the surveys in class that day.

The second sampling procedure used was snowball sampling, the recruitment of successive participants by initial participants (Chromy, 2008). People in the large lecture and Family Communication course who did not meet the criteria were invited to recruit someone who meets the criteria. Upon their recruitment, successive participants followed the same procedure of sending an email to the researcher; the response to which included the online survey link generated through the Qualtrics website. When students recruited someone else for the study, they did so using blank envelopes that the participant could use to return their paper responses and protect their confidentiality. The paper version of the survey had a cover letter which introduced the researcher, described the study, stated the criteria for participation and what the participation in the study entails, acknowledged the approval from WVU's IRB for this study, and provided contact information for both the principal investigator and the coinvestigator. Upon receipt of paper questionnaires, the researcher manually entered this data in to SPSS.

The third sampling procedure utilized was volunteer sampling. Volunteer sampling involves the solicitation of participants who willingly decide to respond to research questions 
(Lefever, Dal, \& Matthiasdottir, 2007). The researcher sent a call for research participation to academic group LISTSERV lists (i.e., Communication Research and Theory Network (CRTNET), a service of the National Communication Association); and the LISTSERV list for Women and Gender Studies majors, minors, and graduate certificate students; as well as online chatrooms (i.e., momsnet.com and imgur.com). The call for research participation had the same content as the IRB-approved recruitment script. Members of the academic groups on the LISTSERV lists were also encouraged to share the call for participation.

Finally, network sampling was used to solicit participants for this study through the use of friends or acquaintances and family to gain access to potential participants the researcher may otherwise not have been able to reach (Lee, 2008). The researcher sent a call for research participation as private messages to friends and colleagues on Facebook who agreed to help solicit participants and participate as well if they fit the research criteria.

Prior to participants responding to questions related to the research questions and hypotheses of this study, they provided their demographic data (see Appendix F). Research participants were presented with one of the two sets of questionnaire (i.e., mother-targeted and father-targeted questionnaires) containing several relevant measures (described in the instrumentation section) and open-ended questions to address the proposed hypotheses and research questions respectively. Participants responded to the question, "which of the following best describes your parent/s (either biological/non-biological) who are primarily responsible for raising you?" For participants who completed the online survey, this question served as the randomizer for targeted parent. The options to this question were: (a) father and father, (b) mother and father, (c) mother and mother, (d) father, and (e) mother. If participants selected options A and D, they were directed to father-targeted questions. Participants were directed to 
respond to questions directed at gleaning information on their mother if they selected options $\mathrm{C}$ and E. If participants selected option B, they were directed randomly to either father-targeted or mother-targeted questions.

Across online and paper surveys, 132 participants reported on mothers (target-age range $36-68 ; M=52.94, S D=7.09$ ) and 122 reported on fathers (target age range $37-95 ; M=55.45$, $S D=8.49$ ). There were no responses on the ages of 12 participants' fathers and 10 participants' mothers. A full account of this distribution from all participants and their parents' demographic data is detailed in Table 2. See items on parents' demographics in Appendix D (items 93-96) and E (items 76-79).

For this dissertation, I deemed using questionnaires with open-ended questions as appropriate and convenient. Previous research on memorable messages (e.g., Ford \& Ellis, 1998; Keeley, 2004; Knap et al., 1981; Nazione et al., 2011; Stohl, 1986) used face-to-face interviews to gather data because interviews are advantageous for greater control over the data collection process, as the researcher is able to probe into responses. However, interviews have the potential to pose face-threats. Other researchers have successfully employed questionnaires to gather data on memorable messages (e.g., Dunleavy \& Yang, 2015; Holladay, 2002; Steimel, 2013).

\section{Instrumentation}

The descriptive statistics (i.e., means, standard deviations, and Cronbach's alpha coefficients) for the instruments (with the exception of the one item-measurement of likelihood to transmit memorable message, and the Inclusion of Self and Other (IOS) scale which measured interpersonal closeness) discussed in this section are detailed in Table 3. Unless otherwise noted, possible responses for all items range from (1) strongly disagree to (7) strongly agree and high scores indicate high levels of that construct (following any necessary reverse coding). The 
Table 2

Survey Distribution and Participants' Parents' Demographic Data

\section{Variable \\ Parent}

Father and father

Mother and father

Mother and mother

Father

Mother

Demographic data on mothers

Relationship status

Single

Engaged

Married

Divorced

Widowed

In a long term relationship

No response

State of life

Alive

Deceased

No response

Ties to mother

Biological

Non-biological

No response
119

2

11

$n$

1

199

3

51

$20.10 \%$
$.40 \%$

$78.30 \%$

$1.20 \%$

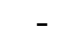

9

4

85

12

8

4

10

$6.80 \%$

$3.00 \%$

$64.40 \%$

$9.10 \%$

$6.10 \%$

$3.00 \%$

$7.60 \%$

120

2

10

$90.90 \%$

$1.50 \%$

$7.60 \%$
$90.20 \%$

$1.50 \%$

$8.30 \%$ 
Table 2 (Continued)

\begin{tabular}{|c|c|c|}
\hline Variable & $n$ & $\%$ \\
\hline \multicolumn{3}{|l|}{ Demographic data on fathers } \\
\hline \multicolumn{3}{|l|}{ Relationship status } \\
\hline Single & 3 & $2.50 \%$ \\
\hline Engaged & 1 & $.80 \%$ \\
\hline Married & 88 & $72.10 \%$ \\
\hline Divorced & 9 & $7.40 \%$ \\
\hline Widowed & 3 & $2.50 \%$ \\
\hline In a long term relationship & 5 & $4.10 \%$ \\
\hline No response & 13 & $10.70 \%$ \\
\hline \multicolumn{3}{|l|}{ State of life } \\
\hline Alive & 105 & $86.10 \%$ \\
\hline Deceased & 7 & $5.70 \%$ \\
\hline No response & 10 & $8.20 \%$ \\
\hline \multicolumn{3}{|l|}{ Ties to father } \\
\hline \multicolumn{3}{|l|}{ Biological } \\
\hline Non-biological & 105 & $86.10 \%$ \\
\hline \multirow{2}{*}{ No response } & 7 & $5.70 \%$ \\
\hline & 10 & $8.20 \%$ \\
\hline
\end{tabular}


Table 3

Means, Standard Deviations, and Reliabilities for Variables

\begin{tabular}{|c|c|c|c|}
\hline Variables & $M$ & $S D$ & $\alpha$ \\
\hline \multicolumn{4}{|l|}{ Mother-Target } \\
\hline Mixed message* & 2.08 & 1.07 & .90 \\
\hline \multicolumn{4}{|l|}{ Mother-daughter relationship $* *$} \\
\hline Connectedness & 4.16 & .82 & .93 \\
\hline Interdependence & 4.01 & 1.14 & .91 \\
\hline Respectful accommodation* & 4.77 & 1.27 & .82 \\
\hline Relational satisfaction* & 2.85 & .67 & .88 \\
\hline Self-disclosure** & 3.98 & .85 & .91 \\
\hline \multicolumn{4}{|l|}{ Feminist identity* } \\
\hline \multicolumn{4}{|l|}{ Daughter feminist identity } \\
\hline Passive acceptance & 5.25 & 1.30 & .92 \\
\hline Social dominance orientation & 2.26 & 1.13 & .72 \\
\hline \multicolumn{4}{|l|}{ Mother feminist identity } \\
\hline Passive acceptance & 4.79 & 1.18 & .88 \\
\hline Social dominance orientation & 2.59 & 1.15 & .76 \\
\hline Life satisfaction* & 5.22 & 1.31 & .89 \\
\hline \multicolumn{4}{|l|}{ Identity gaps* } \\
\hline Personal-relational identity & 3.15 & 1.20 & .89 \\
\hline Personal-enacted identity & 2.58 & 1.36 & .94 \\
\hline
\end{tabular}


Table 3 (Continued)

\begin{tabular}{llll}
\hline Variables & $M$ & $S D$ & $\alpha$
\end{tabular}

Father-Target

Mixed message*

1.72

.91

.93

Father-daughter relationship**

Connectedness

4.03

.75

.90

Interdependence

3.98

1.11

.81

Respectful accommodation*

1.24

.89

Relational satisfaction*

2.95

.65

.92

Self-disclosure**

3.61

.88

.92

Life satisfaction*

5.44

1.14

.87

Identity gaps*

$\begin{array}{lccc}\text { Personal-relational identity } & 2.87 & 1.13 & .87 \\ \text { Personal-enacted identity } & 2.53 & 1.29 & .94\end{array}$

Note. * Items range from (1) strongly disagree to (7) strongly agree. ** Items range from (1) strongly disagree to (5) strongly agree. 
wording of scale items was also adapted to suit the assessment of participants' relationships with either parent. All composite scores were computed using mean scores.

Memorable messages. Memorable messages participants received from their parents regarding work/family were examined by asking participants to write one memorable message they received from either parent depending on the target-parent. The target-parent could be biological or non-biological, and alive or deceased. Either way, participants were asked to report on the same person throughout the rest of the survey.

The directions defined a memorable message as one that is "vividly remembered and believed to have had a large impact on how we behave, the attitudes we hold, and the decisions we make or anticipate making in the future" (Medved et al., 2006). This definition was followed with two examples of memorable message formats (i.e., piece of advice, and words of wisdom; Steimel, 2013; Stohl, 1986) and the possibility of those memorable messages to have influenced behavior at work, organizational expectations, career decisions, and the interpretation of work and family.

As posited by Kellas (2010), providing participants with specific examples of memorable messages may influence participants' responses. Hence, participants were not provided with specific examples. Participants were restricted to a 500-word long message for the online survey and one page (with double-space lines) for the paper survey. Prior to completing the questionnaire, participants were instructed to take a moment to reflect on their conversations with their target parent. For instance, the instruction for the questionnaire on mother read: "please go ahead and write the details of one memorable message you recall your mother giving you about work/family. Be sure to include where the message was communicated and who said what." The wording was changed for the father-targets to read "father" instead of "mother." 
Given that participants' writing of a memorable message forms an integral part of this study, the validation option of force response was activated in Qualtrics for this question.

Once participants identified a specific message, they answered 13 questions about the message (see items 1-13 of Appendix A and B). This set of questions asked about participants' confidence in the sameness of the wording of the memorable message their parent provided and what they wrote. Majority of participants reported being very confident or confident that the wording of the message they wrote is the same as the wording of the source message (mothertarget: $M=3.83, S D=1.04$; father-target: $M=3.77, S D=1.19)$. This high level of confidence validates the messages as indeed memorable (Waldron et al., 2014).

Participants were also asked about the setting in which the message was communicated (i.e., public/private and formal/planned or informal/unplanned) and participants' perception of why the message was communicated (this information was not analyzed in the dissertation, but included in the questionnaire to help participants reflect on the memorable message); their likelihood to transmit the message to their 18year old daughter; the inconsistency among memorable message and sender's lifestyle, expectations, actions, behavior, expressions/sayings, attitude, and participant's own personal values; and how participants think the memorable message has shaped their expectations and/or values about work/family (this information was also not analyzed in the dissertation but included to serve reflective purposes).

Likelihood to transmit memorable message. The likelihood of participants to transmit the memorable messages they received from either parent was examined by asking participants to rate on a 5-point Likert type scale the likelihood of passing the messages onto their 18year old daughters (this is a projection, as none of the participants had 18-year old daughters of their own at the time of data collection). See item 5 of Appendix A and B. The Cronbach's alpha 
coefficient of the instrument could not be computed because the measure is a single item. A mean score of $4.32(S D=1.07)$ and $4.27(S D=1.08)$ was obtained for the measure for both father and mother sets of data, respectively.

Mixed messages. Mixed messages from parents was measured with seven items to examine the inconsistency among memorable message and sender's lifestyle, expectations, actions, behavior, expressions/sayings, attitude; and participant's own personal values. These items were adapted from Kirby's (2000) interpretive study. See items 6 to12 of Appendix A and B. All scale items were reverse recoded for both sets of data.

Mother-daughter relationship. Mother-daughter relationship was measured using the Mother-Adult Daughter questionnaire (MAD; Rastogi, 1995) to assess participants' perception of their relationship with their mother. The scale items were adapted to suit the assessment of participants' relationship with parent-targets. Given that expectations and norms of intergenerational relationships vary across cultures, the MAD attempts to capture these differences in the mother-daughter relationship. The 25-item questionnaire assesses connectedness, interdependence, and trust in hierarchy in the mother-daughter relationship from a daughter's perspective. For the purpose of this study, only the 3-item interdependence subscale (see items 22, 23, and 25 of Appendix A and B) and the 9-item connectedness subscale (see items 14-21 and 24 of Appendix A and B) were used. The interdependence subscale measures the extent to which the daughter expects her mother to be available either emotionally or physically whereas the connectedness measures closeness, intimacy, and attachment in the mother-daughter relationship. Previous researchers have found this version to be reliable, with Cronbach's alphas between .87 and .92 for the connectedness subscale and between .74 and .86 for the interdependence subscale (Onayli \& Erdur-Baker, 2013; Rastogi, 2002; Wiggins, 2014). 
Respectful accommodation. Respectful accommodation was measured using 2-items adapted from Soliz, Ribarsky, Harrigan, and Tye-Williams's (2010) measurement of respectful accommodation (see items 26 and 27 of Appendix A and B) and four items adapted from Harwood's (2000) measurement of grandchild reluctant accommodation and grandchild accommodating role-relations (see items 28-31 of Appendix A and B). Respectful accommodation refers to the show of respect for others' perspectives and opinions particularly in situations where communication partners may have divergent views. Negatively-keyed items were reverse coded.

Relational satisfaction. Relational satisfaction was measured using the adapted version of the Marital Opinion Questionnaire (Huston, McHale, \& Couter, 1986) that has ten semantic differentials (see items 32-41 of Appendix A and B). The ten semantic differentials assess specific and global dimensions of satisfaction over the last month. Previous researchers have found this version to be reliable, with Cronbach's alphas between .85 and .96 (Rittenour \& Soliz, 2009; Soliz et al., 2010; Soliz, Thorson, Rittenour, \& Murry, 2009). Negatively-keyed items were reverse coded.

Self-disclosure. Self-disclosure was measured using a six-item scale (Laurenceau, Barrett, \& Pietromonaco, 1998) adapted to assess the reciprocal self-disclosure in the parentdaughter relationship regarding work/family. See items 42 to 47 of Appendix A and B for scale items. Possible responses for all items ranged from (1) not at all to (5) a great deal. Previously, researchers have found this scale to be reliable, with Cronbach's alphas between .83 and .93 (Harwood, Hewstone, Paolini, \& Voci, 2005; Rittenour \& Soliz, 2009; Soliz et al., 2009).

Interpersonal closeness. Interpersonal closeness was measured using Aron, Aron, and Smollan's (1992) single item Inclusion of Self and Other (IOS) scale (see items 48 of Appendix 
A and B) to assess the closeness of bi-lateral personal and social relationships between young adult daughters and either parent. Though the use of one-item scales is not standard practice in the field of Communication Studies, Postmes, Haslam, and Jans (2013) suggested that a single item can bear clarity and transparency about the construct of interest. The single-item scale consists of seven overlapping circles, representing self and other, with gradually increasing degrees of overlap. In Qualtrics, the validation option of force response was activated for this scale in order to ensure complete data for analysis. The Cronbach's alpha coefficient of the instrument could not be computed because the measure is a single item. However, a mean score of $4.38(S D=1.76)$ and $4.15(S D=1.74)$ was obtained for the measure of both mother and father sets of data respectively.

Feminist identity. Feminist identity was measured using the passive acceptance subscale of the Feminist Identity Scale (FIDS; Downing \& Roush, 1985) and five items from the Social Dominance Orientation (SDO) Scale (Pratto, Sidanius, Stallworth, \& Malle, 1994) that were adapted for the purpose of this dissertation. Participants reported on their feminist identity (see items 49-60 of Appendix A) as well as their perception of their mother's feminist identity (see items 97-108 of Appendix A). In order to clearly distinguish between the targets for feminist identity, the two sets of questions were placed apart in the questionnaire. The set of questions about participants' perception of their mother's feminist identity was the last set of questions on the questionnaire (see items 97-113 of Appendix A). These sets of questions were only administered to participants who completed the mother-target questionnaire.

Passive acceptance is the first stage in the feminist development model (which is a continuum from complete unawareness of feminist values to commitment to feminism through social action) and represents a lack of identification (Flores, Carrubba, \& Good, 2006). The focus 
of this dissertation was to examine the degree to which participants identified as feminists and perceived their mothers to embrace the same feminist ideals. As such, I used the 12-item passive acceptance (FIDS-PA) scale as an indicator of feminist identity to assess the degree to which both women accept traditional gender roles and assume that male dominance is normal and acceptable. All scale items from the FIDS-PA were reverse coded such that agreement with the items indicated a stronger identification as a feminist. Previous researchers have found this subscale to be reliable, with Cronbach's alphas between .74 and .85 (Gerstmann \& Kramer, 1997; Moradi \& Subich, 2002; Rittenour \& Colaner, 2012).

Based on the concerns of this dissertations' committee members about cohort's knowledge of issues referenced on the FIDS-PA scale such as equal rights amendment, some additional items were adapted from the SDO scale to supplement this limitation. The scale was originally developed to examine individual differences in the desire to subordinate certain groups over others in attempt to create and maintain social hierarchies (Etchezahar, Jaume, PradoGascó, \& Brussino, 2014). Participants reported on their social dominance orientation (see items 61-65 of Appendix A) as well as the perception of their mother's social dominance orientation (see items 109-113 of Appendix A). The SDO scale complemented the feminist ideals regarding traditional gender roles. Negatively-keyed items on the adapted SDO scale were reverse coded before composite scores were created.

Life satisfaction. Life satisfaction was measured using the Satisfaction with Life Scale (SWLS; Diener et al., 1985). The five-item scale (see items 66-70 of Appendix A and items 4953 of Appendix B) was used to assess participants' overall judgment of the quality of their life. Previous researchers have found this scale to be reliable, with Cronbach's alphas between .74 and .85 (Athay, 2012; Diener et al., 1985; Rittenour \& Colaner, 2012). 
Identity gaps. Personal-enacted (PE) identity gap (see items 71-81 of Appendix A and items 54-64 of Appendix B) and personal-relational (PR) identity gap (see items 82-92 of Appendix A and items 65-75 of Appendix A) were measured using a modified version of the Identity Gap Scale (Jung \& Hecht, 2004) to assess participants' perceptions about their identity gaps during interactions with parents. The identity gap scales included 11 items each. Hecht and Jung (2004) reported Cronbach's alpha of .86 for the PR scale and .89 for the PE scale.

Negatively-keyed items were reverse coded before composite scores were created.

\section{Data Analysis}

This dissertation was guided by two research questions and 12 hypotheses. The research questions focused on the memorable messages regarding work/career and family that young adult daughters received from their parents and the extent to which these messages are communicated in private/public and formal/informal conversations. The qualitative data on these research questions were analyzed using Nvivo 11 Pro for Windows software to organize the data more efficiently and develop category systems to classify the content and context of memorable messages. The use of CAQDAS provides quantitative analysis of qualitative data, facilitates a transparent and an accurate procedure for qualitative data analysis, and provides a general picture of the data that can be reliable (Morrison \& Moir, 1998). As Creswell (2013) noted, in using CAQDAS, the researcher identifies a text segment, "assigns a code label, searches through the database for all text segments that have the same code label, and develops a printout of these text segments for the code" (p. 201). Likewise in my qualitative data analysis, I employed the following steps: organizing data, coding and querying, and modifying node structures.

First, I organized the data into six different MS-Word documents based on memorable messages from mothers and fathers, reasons for the messages from mothers and fathers, and the 
influence of the messages from mothers and fathers. These six documents were exported to Nvivo. A journal was also created in the memo section of Nvivo to document how I have moved from the initial forays in this project to have arrived at the conclusions. Richards (2005) compared this process of journaling to a ship's log of careful account of journey. Bazeley (2007) added that keeping a journal in qualitative research analysis helps to keep track of how and when insights were gained and developed, as evidence to support conclusions. Taking cues from Bazeley's advice, I created the journal by writing "freely without worrying about formality of style or 'correctness' of thoughts" (p. 29). This journal also served as a document for my selfreflexivity, indicating biases, affective commentary, as well as fleeting ideas as data were analyzed (see Appendix G).

Second, I read through the data twice using an emic approach (Saldana, 2009; Tracy, 2013), which asks the question, "what is happening here?" to create analytic memos and initial codes represented by nodes in NVivo (Bernauer, Lichtman, Jacobs, \& Robinson, 2013). I created nodes in three levels (see Figure 1). At the first level, I created four nodes to categorize the dataset on memorable messages (from fathers and mothers) into messages about work and messages about family. At the second level, I created two nodes to categorize a single message (from fathers and mothers) that focused on both work and family (one node for such messages from mothers and another for such messages from fathers). At the third level, I created two nodes. A node was created each for messages from fathers and messages from mothers that were not directly related to work and family (because it was not specifically stated or that I could not infer that those messages were related to work and/or family) but other life issues. An example of such messages (from a father-target) is "at a sporting event, my father said: pain is temporary pride forever." Given the focus of the dissertation, I did not analyze nodes at the third level. The 
Figure 1. Qualitative Data Analysis Flow Chart: Creation of Nodes

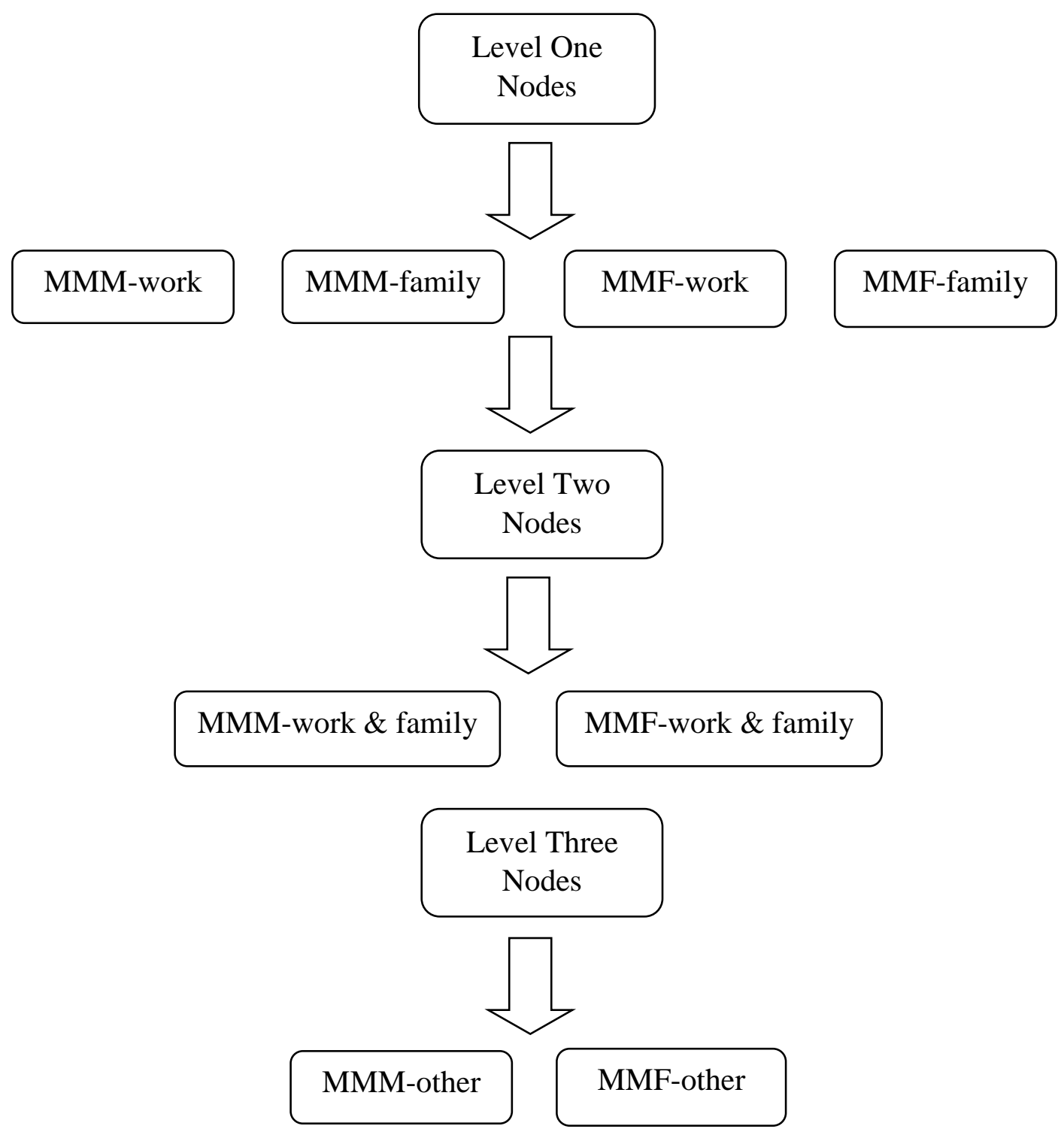

Note. $\mathrm{MMM}=$ memorable message from mother; $\mathrm{MMF}=$ memorable message from father. Level three nodes were not analyzed 
total number of messages considered for analysis from the two levels of nodes is detailed in Table 4.

Third, all nodes were reviewed. Messages initially categorized as other that did not specifically have a direct relation to work and family but I could infer the relationship of the message to family/work or both, were categorized as such (see Table 4 for details). I used query tools in Nvivo to obtain a word cloud of the nodes (i.e., messages from mothers and messages from fathers; see Figure 2 and 3 for the word cloud from target-parent messages) to examine overlaps and discrepancies in the data to give me a fair idea of possible themes across the data. Non-essential words such as "always" and "ever" were eliminated in generating the word cloud. Progressively, the codes were modified to go beyond description of data to explanations and concepts to include interpretation and identification of patterns. At this phase of the data analysis, theoretical saturation was reached; no new data appeared and all concepts were well developed.

Prior to exploring the 12 hypotheses forwarded in this study, Pearson product-moment correlations were computed among all variables for each target-parent and a composite of both target-parents; these correlations are included in Chapter III as they include several of the results. H1 predicted that daughters' report of fathers' and mothers' respectful accommodation and selfdisclosure will be positive predictors of daughters' relational satisfaction. Multiple regression analysis was used to test the hypothesis using daughters' report of parents' respectful accommodation and self-disclosure as the predictor variables and relational satisfaction as the outcome variable (for each parent-target).

$\mathrm{H} 2$ and $\mathrm{H} 3$ predicted daughters' relational satisfaction with their parents and how that will predict daughters' likelihood to transmit parents' messages regarding work/career and 
Table 4

Frequency of Memorable Messages

\begin{tabular}{|c|c|c|c|c|}
\hline \multirow[t]{2}{*}{ Variable } & \multicolumn{2}{|c|}{ Frequency } & \multicolumn{2}{|c|}{$\%$} \\
\hline & $\begin{array}{c}1^{\text {st }} \\
\text { Approach }\end{array}$ & $\begin{array}{c}2^{\text {nd }} \\
\text { Approach }\end{array}$ & $\begin{array}{c}1^{\text {st }} \\
\text { Approach }\end{array}$ & $\begin{array}{c}2^{\text {nd }} \\
\text { Approach }\end{array}$ \\
\hline
\end{tabular}

Messages from mothers

$\begin{array}{lcccc}\text { Work messages } & 43 & 59 & 32.82 \% & 45.04 \% \\ \text { Family messages } & 21 & 21 & 16.03 \% & 16.03 \% \\ \text { Family and work messages } & 20 & 20 & 15.27 \% & 15.27 \% \\ \text { Other } & 47 & 31 & 35.88 \% & 23.66 \% \\ \text { Total } & & \mathbf{1 3 1} & & \end{array}$

Messages from fathers

$\begin{array}{lcccc}\text { Work messages } & 61 & 63 & 53.98 \% & 55.75 \% \\ \text { Family messages } & 19 & 19 & 16.81 \% & 16.81 \% \\ \text { Family and work messages } & 16 & 16 & 14.16 \% & 14.16 \% \\ \text { Other } & 17 & 15 & 15.04 \% & 13.27 \% \\ \text { Total } & & \mathbf{1 1 3} & & \end{array}$

Note. Total number of messages from each target-parent in bold. 
Figure 2. Word Cloud from Father Messages on Work/Family

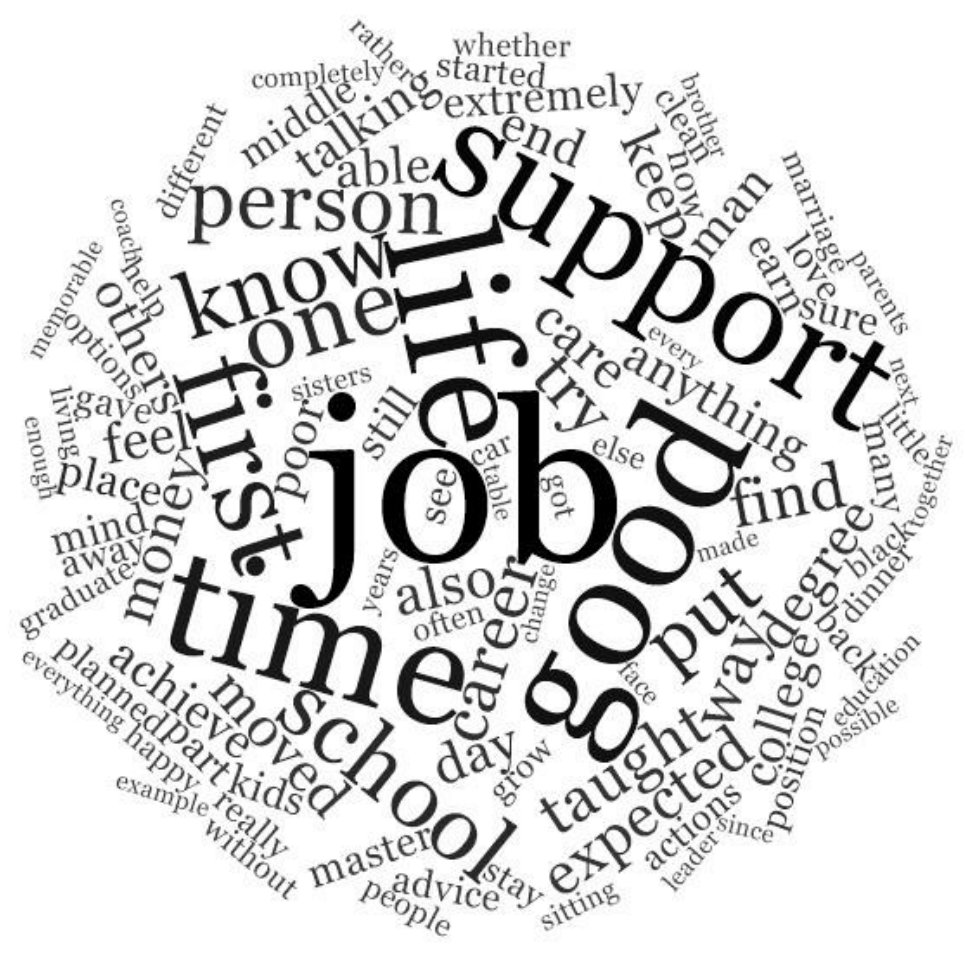

Figure 3. Word Cloud from Mother Messages on Work/Family

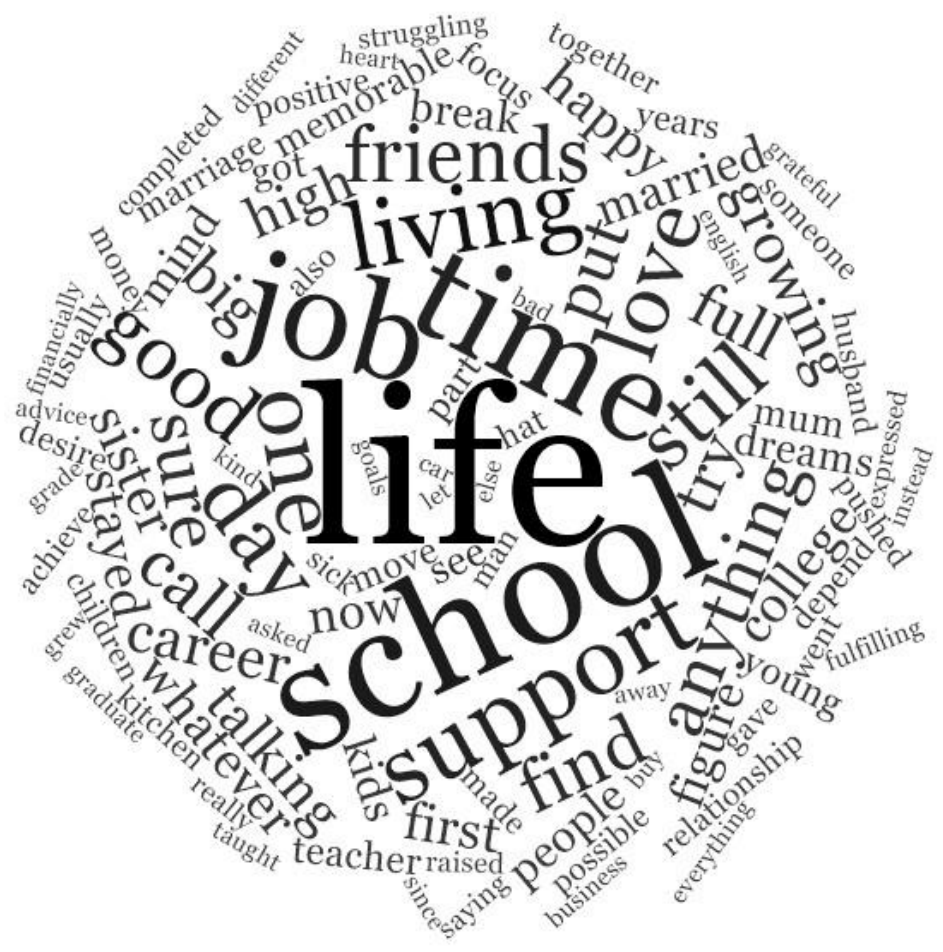


family. Pearson product-moment correlations was computed among the variables (i.e., daughters' report of relational satisfaction, and likelihood to transmit memorable message) to answer $\mathrm{H} 2$. For H3, one-tailed independent samples $t$-test was computed to compare the two groups' (i.e., daughters' report on fathers and mothers) mean scores on the likelihood to transmit message.

H4 through $\mathrm{H} 7$ were focused on the nature of daughter-parent relationships. Using a series of one-tailed independent samples $t$-tests, the mean scores of two groups (i.e., daughters' report on fathers and mothers) on respectful accommodation, self-disclosure, interpersonal closeness, and relational satisfaction were compared. H8 and H9 were predictions about mother and daughter feminist identities as they relate to traditional gender roles and male dominance, and daughter life satisfaction. Paired samples $t$-tests was used to compare two groups' (daughter self-report and daughter report on mother) mean scores on feminist identity to answer H8 whereas Pearson product-moment correlations was computed among the variables (i.e., daughter feminist identity and life satisfaction) to answer H9.

H10 focused on the relationship between mixed messages and daughters' identity gaps. Pearson product-moment correlations among the following variables: mixed messages (from each parent target), personal relational identity gap, and personal-enacted identity gap was used to answer H10.

H11 predicted the likelihood of daughters to transmit their mother's messages regarding work/career and family. Multiple regression analysis was used with personal-enacted identity gap and personal-relational identity gap as the predictor variables and likelihood to transmit mother's message as the outcome variable. Finally, H12 predicted a negative relationship between daughters' identity gaps and life satisfaction. Multiple regression was used with personal-enacted identity gap and personal-relational identity gap as predictor variables and life 
satisfaction as the outcome variable (for each parent target).

\section{Summary}

This dissertation was guided by two research questions and 12 hypotheses to examine the work/career and family messages parents give their adult daughters, determine the connection between daughters' relationship closeness to each parent and daughters' likelihood to transmit the messages, and examine the impact of parents' socialization messages about work/career and family on daughters' personal-relational and personal-enacted identities. This chapter reviewed the methodology under the following main headings: overview, participants, procedures, instrumentation, and data analysis. Both quantitative and qualitative data were used in the study and analyzed using IBM SPSS Statistics and computer-assisted qualitative data analysis software (CAQDAS), NVivo 11 Pro for Windows software respectively. Results of these analyses are reported in Chapter III followed by a discussion in Chapter IV. 


\section{CHAPTER III}

Results

This dissertation was guided by two research questions and 12 hypotheses to explore memorable messages that young adult daughters receive from their parents regarding work/career and family, address the parent-daughter relationship and its influence on daughters' likelihood to transmit the memorable message, and examine the impact of these memorable messages on daughters' personal-relational and personal-enacted identities. The results are presented in this section based on the order of research questions and hypotheses as posed in Chapter I.

\section{Research Question One: Content of Memorable Messages}

Research question one inquired about the memorable messages regarding work/career and family that young adult daughters receive from parents. Overall, nine mother-target participants did not record a memorable message from their mother and two father-target participants did not record a memorable message from their father. All message exemplars presented in the results and discussion were edited solely for spelling and simple grammatical errors to enhance readability. Detailed information on the distribution of target-parent messages that were categorized into themes is presented in Table 5. The next section presents results based on target-parent.

Mother-target participants. From mother-target participants, five themes emerged under memorable messages about work $(n=54)$, three themes under messages about family $(n=$ 23 ), and one theme $(n=7)$ about keeping a balance between work and family (see Figure 4). Participants were prompted to write one memorable message about work/family and so this "either/or" versus "and" distinction is an important first-step in reviewing the themes of these 
Table 5

Distribution of Target-Parent Messages that were Categorized into Themes

\begin{tabular}{|c|c|c|c|c|}
\hline & \multicolumn{2}{|l|}{ Mother-target } & \multicolumn{2}{|l|}{ Father-target } \\
\hline & Theme & Frequency & Theme & Frequency \\
\hline & & $N=84$ & & $N=91$ \\
\hline & & $n(\%)$ & & $n(\%)$ \\
\hline \multirow[t]{5}{*}{ Work message } & Attitude towards work & $14(16.67 \%)$ & Having priorities & $12(13.19 \%)$ \\
\hline & Value of work & $9(10.71 \%)$ & Work enjoyment & $14(15.38 \%)$ \\
\hline & Work enjoyment & $13(15.48 \%)$ & Work input & $45(49.45 \%)$ \\
\hline & Perseverance & $11(13.10 \%)$ & & \\
\hline & Encouragement & $7(8.33 \%)$ & & \\
\hline \multirow[t]{3}{*}{ Family message } & Marriage or relationship & $11(13.10 \%)$ & Importance of Family & $10(10.99 \%)$ \\
\hline & Family responsibility & $3(3.57 \%)$ & Marriage & $4(4.40 \%)$ \\
\hline & Support/love/unity & $9(10.71 \%)$ & Father responsibility & $5(5.49 \%)$ \\
\hline \multicolumn{2}{|c|}{ Keeping a balance between work and family } & $7(8.33 \%)$ & & $1(1.10 \%)$ \\
\hline
\end{tabular}


Figure 4. Themes from Memorable Messages Received from Mother-Target

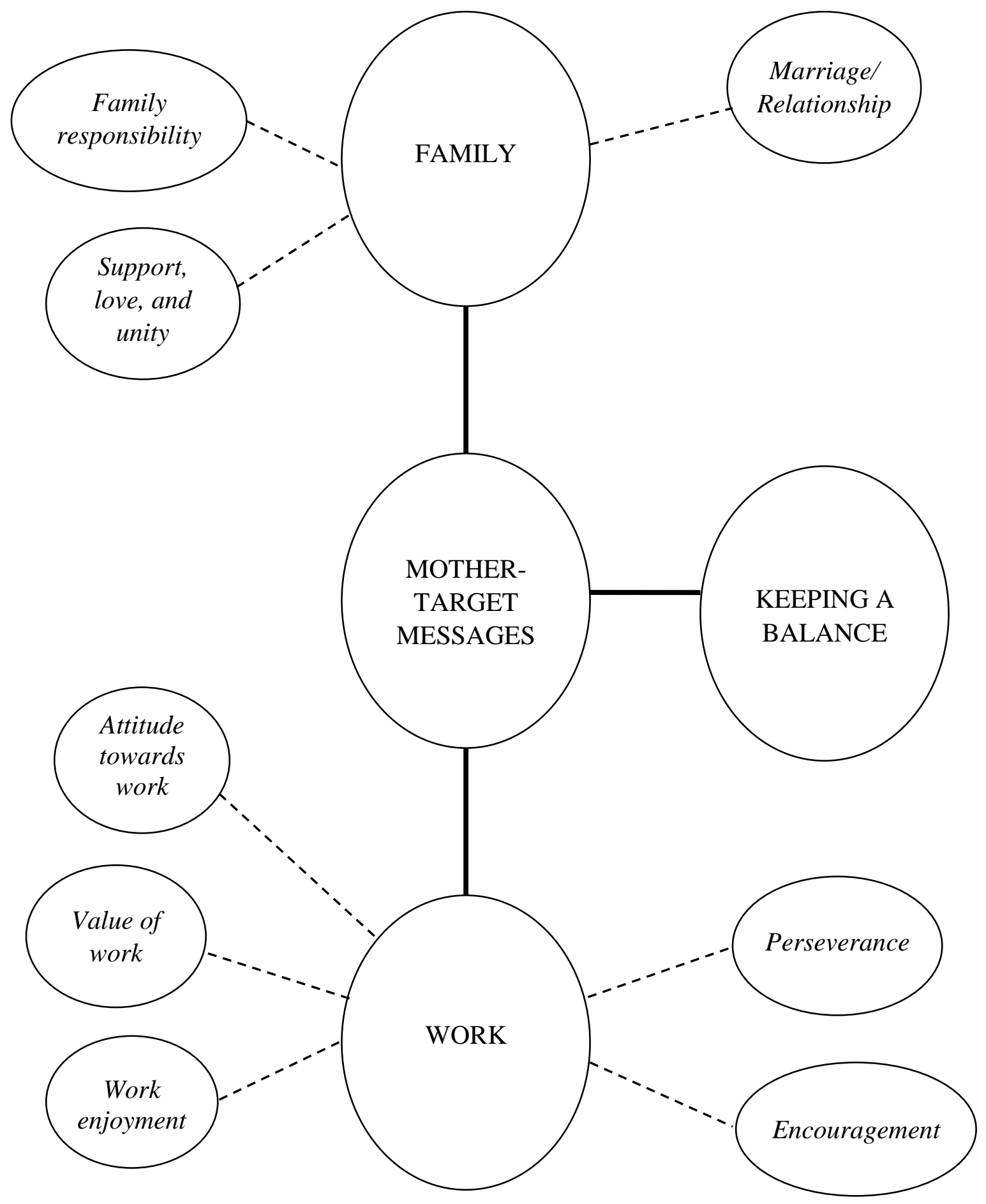


messages. Of the 131 memorable messages recorded by mother-target participants, 84 were categorized into themes. The remaining messages were not categorized because they were not directly related to work (in traditional terms) and family, but academic work or other life issues. Examples of such messages are:

My grandmother passed away and I was very emotional over this. At my grandma's funeral, my mom would not let me go up and see her body. I asked her why and she said because if I did it would be a big mistake I would regret for years to come. She told me that I need to remember my grandma with color and a smile. She said everyone dies, but only after they lived the amount of life God planned for them.

Don't be influenced by grades. Even if you've failed, remember that what you know, you know. No one can take that away from you.

A message my mother often communicated to me was not necessarily spoken in direct words, as much as through many interactions/examples. The basic message is "You are responsible for yourself/your actions." I remember her always making me come all the way upstairs to clean up even the tiniest mess: my shoes not put in the closet, a spoon and bowl left in the sink, and crumbs from toast not wiped up. She made me practice taking responsibility for myself.

Messages about work. The five themes from the mother-target participants' memorable messages about work are attitude towards work, importance of work, work enjoyment, perseverance, and encouragement. Memorable messages categorized as attitude towards work refer to messages that encourage participants to behave a certain way at work or have a certain mindset towards work. Such behaviors include (a) working hard, (b) not missing 
work and (c) treating people well. Examples of messages that exemplify attitudes toward work are given in Table 6.

With regard to messages about the value of work that mothers communicated to their daughters, the messages emphasized (a) the importance of education and the fact that (b) work provides financial empowerment. Examples of messages that exemplify messages about the importance of work and education are given in Table 7. Messages about work enjoyment referenced the need for daughters to choose a job/career that makes them happy.

Mothers also communicated messages about perseverance. Such messages framed daughters' achievement of goals on the condition that daughters work hard and stay focused. Exemplars are provided in Table 7. Finally, messages in the form of encouragement were communicated to daughters in times of despair, as a way of helping daughters to believe in themselves and their ability. These messages of encouragement came in the form of the expression of love and support. Other messages of encouragement were presented about what nature presents to an individual or the advantage of a social construction in favor of daughters (for instance, in the discourse on non-traditional gender roles, one of the social constructions of gender is that women can be functional in both family and work domains). Exemplars of messages of encouragement can be found in Table 7.

Messages about family. Three themes emerged from mother-target participants' memorable messages about family: marriage/relationship, responsibility, and support/love/unity. Memorable messages categorized as marriage/relationship refer to messages that ask young adult daughters to (a) prioritize work over family, (b) be ready for marriage/family, and (c) observe pre-marital rules. Examples of messages categorized under marriage/relationship that exemplify mothers' messages about family are given in Table 8 . 
Table 6

Examples of Mother-Target Messages about Work: Attitude towards Work

Categories Exemplars

Working hard

Every day she works 10+ hours as she owns her businesses. She has sent a message nonverbally; to be a hard worker.

My mother struggles with depression. Through the last 8 years the severity of her depression has worsened. The message that I can remember most vividly wasn't very direct. I just remember her always comparing her high school self to my sisters and I. She had huge aspirations, but could never follow through. Her message was to always strive for great things and work for the results we desire.

Not missing work $\quad$ My mother told me that you NEVER miss work-work is an obligation and a responsibility. This happened when I asked her if I could call in sick to work when I worked retail at age 16. She said; "Absolutely not. Calling in sick to work is not okay_you let down your supervisors and other colleagues."

One day, my mother was very sick, but she would not call in to work. When I asked her why she was unwilling to call in, she said it was because hard workers didn't do that. If you wanted your employer and other employees to respect you, you went to work come hell or high water. I think we were in the kitchen. I really didn't want her to leave that day because I could tell how awful she felt. She went anyway.

Treating people well My mother was in management for most of her career, and I remember one time she was talking about how to be an effective leader and how to deal with subordinates effectively. She said, "You've got to give people the benefit of the doubt. Most of the time, they're trying really hard."

My mom told me to always "kill people with kindness" when I'm at work to prevent losing my job. 
Table 7

Examples of Mother-Target Messages about Work: The Value of Work, Work Enjoyment, Perseverance, and Encouragement

Categories Exemplars

Value of work

Education $\quad$ My mom worked several different jobs when I was growing up. She also took housekeeping jobs on the side. From time to time she would help a friend who cleaned a dentist office in the evenings. My kid sister and I tagged along and could earn a few bucks by washing walls and emptying trash cans. Afterward, she advised me to work hard at school so that I wouldn't have to scrub peoples' floors like she did.

My mom completed her Bachelor's degree with 3 small children at home. This showed us the importance of hard work and education.

Financial My mom has always told me to go to college, get an education, and make a living for myself so I do not need to Empowerment depend on anyone else for financial stability.

My mom has shared with me a message about there being specific challenges in the workforce for women. She shared this as we discussed my future and what she hoped for us and she explained that despite these challenges she does whatever she can to be innovative and provide for us kids a better life than she had herself.

Work enjoyment One memorable message was classic: "Do what you love, follow a career that makes you happy." This message is memorable since it came at such a young age when I was 5 or 6 . We were at home, and she really spent some time trying to impress the significance of the thought.

Find a job that makes you happy.

Perseverance $\quad$ My mother always taught me that I can accomplish anything I want with hard work and determination.

My mother has always encouraged me to work hard no matter what type of job I am involved in, as it could be a stepping stone to something better. She also instilled in me to be grateful for whatever job I can land because it will help provide for myself and one day my family. 
Table 7 (Continued)

Category Exemplars

Encouragement

when I was doubting my ability to obtain a job in the dental hygiene profession my mother calmly gave me words of encouragement saying "you can do anything you put your mind to."

What's for you won't go by you. She said this message on the breakdown of a relationship and countless times since for things like missing out on jobs.

Keeping a balance I didn't receive the message in words; I simply watched my mother both raise children and work part time or full time throughout her life. I learned that it is possible to do both, but also that it is difficult to do both well.

When I was in high school, I was living in a small rural area in which "helicopter moms" were a commonality. One afternoon, my mother told me that she never wanted to be that mother for two reasons: it's not healthy for the child or the mother. That day my mom told me that a woman's children don't have to be her entire life. She spoke passionately about living a full life as both a worker and a mother. 
Table 8

Examples of Mother-Target Messages on Family

Category Exemplars

Marriage/relationship

Prioritization of work over family/relationship

Readiness for marriage/family

Pre-marital rules
Make sure you have a steady job before you have a family.

The most memorable advice my mom gave me was to be independent. I was supposed to value work more than interpersonal relationships, because depending on men is a big mistake women "make."

I had said that I didn't think I wanted kids because I want a fulfilling career. My mom told me that you should be sure you want kids and a family, before you have them. She told me this at my parents' house.

She told me to pursue my dreams and education, and not to rush into marriage which might stop me. She gave me this advice because I wanted to get married at 22 and she was concerned my husband wouldn't support my desire to get a Ph.D.

After my mother and father divorced, she relayed to me that her primary regret was not living together before they got married. She told me my father had stopped "courting her" immediately after the wedding, and that she hadn't realized how incompatible their lives were until they had moved in together after the honeymoon. Her advice was "whatever you do, live together before you get married."

My mother always brought the Bible up. Everything had to do with the Bible. She drilled into my head that you cannot have sex before you're married, and alcohol is sinful. 
Table 8 (Continued)

Category Exemplars

Family responsibility

My mother didn't begin working until I was in first grade. When I would ask her why, my mother would always tell me that raising me was the "most important thing" either she or my father would do in their lives. To make sure they raised me instead of an outside party, she stayed home until I was well into elementary school.

My mother always says that your name is all you ever have and it is all our family ever has so make sure whatever you do, do it to the best of your abilities because it is a direct reflection of your name.

Support/love/unity

Our family is so closely knit. You know that no matter what you do, good or bad, family will always be there to support you. I will always love you. She said this to me the night before I left to start my freshman year at WVU.

We were sitting in the living room and I was telling my mom that my friends and I were fighting and that my sister took their side instead of mine. My mom said that she was very disappointed because it is always important to support and stand up for your family because they are the only ones who have your best interest at heart. Friends come and go, but family is forever. 
With regard to messages about the family responsibility that mothers communicated to their daughters, the messages emphasized the need for daughters to make family their top priority. Family in this case was inclusive of both nuclear and extended families. With the extended family, the message had to do with portraying a positive image of the family through acceptable behavior whereas with the extended family, the message had to do with making sacrifices for the success of the family. Examples of messages that exemplify family responsibility themed messages about family are listed in Table 8. Mothers also communicated messages about support/love/unity. Such messages requested young adult daughters to be supportive of their families, ensure unity, and show love to family members. Exemplars are provided in Table 8.

Father-target participants. From father-target participants, three themes each emerged under memorable messages about work and family (see Table 5 in the first section of this chapter for further distribution). Only one message was communicated about keeping a balance between work and family. Of the 113 memorable messages recorded by father-target participants, 91 were categorized into themes (see Figure 5). The remaining messages were not categorized because they were not directly related to work (in the traditional sense) and family but academic work or other life issues. Examples of such messages are:

When I got into Cornell for undergrad my dad was so proud, he started calling family members and telling them I was going to be the first female president. He had always encouraged me to do well in school, but my mom was always the one who pushed me in that area-I think Dad felt because he never did well in school, he didn't have the right to tell me to do better; but after I got into Cornell, he started asking me more about my studies and telling me how I can be whatever I want to be.

At a sporting event, my father said: "pain is temporary; pride is forever." 
Figure 5. Themes from Memorable Messages Received from Father-Target

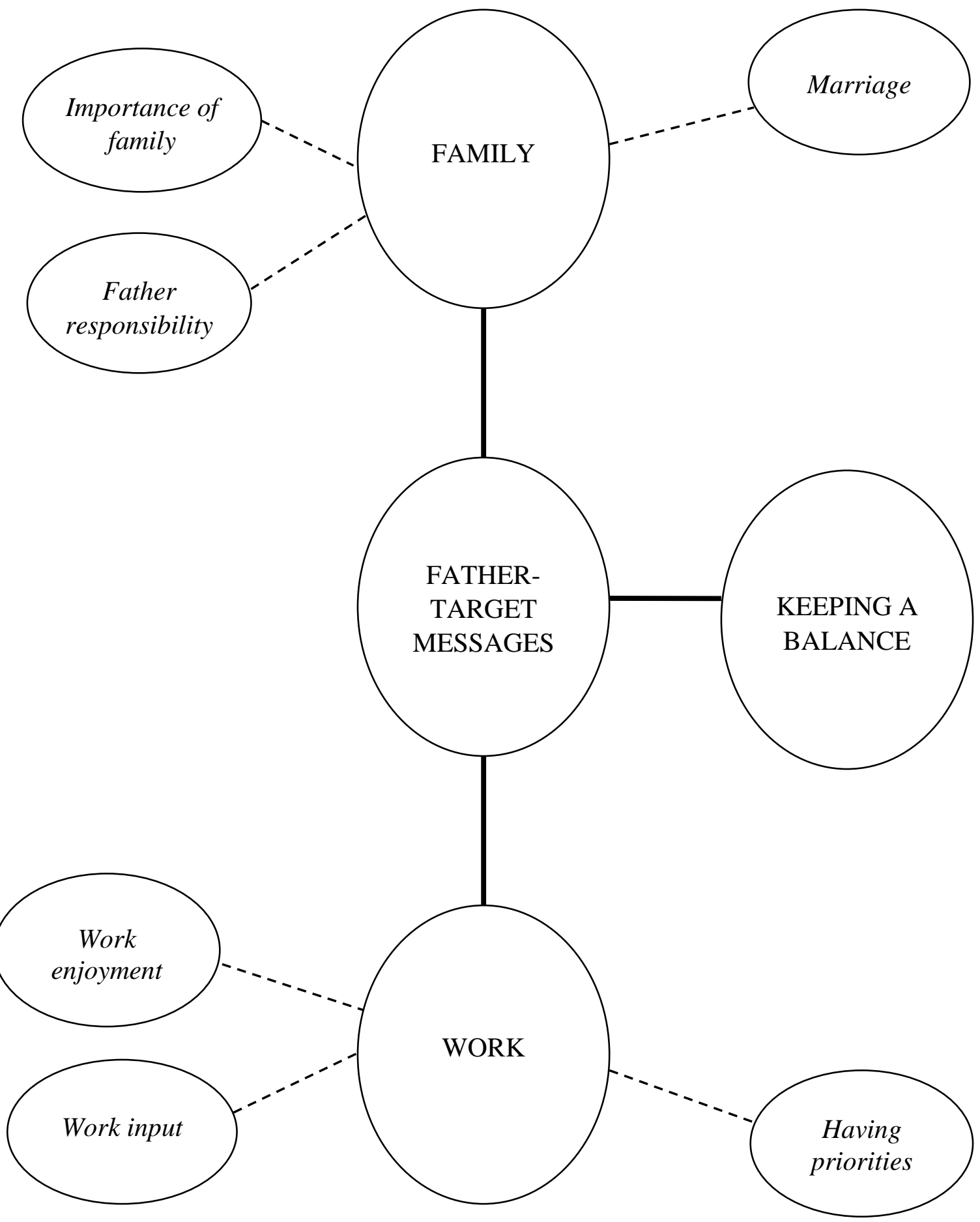


We were driving in the car on our way to the orthodontist; the song "Jack and Diane" came on. Once it ended, he got emotional and began to cry. He told me to not grow up too fast and to appreciate all of the life's "little moments." At the time, I'm sure I didn't fully understand the lyrics and was even a little freaked out because he was crying. I won't forget it though. I was 15 ; my parents were divorced so I only saw him mostly on weekends. I saw him once more; he died less than a week later.

Messages about work. The three themes from the father-target participants' memorable messages about work are work enjoyment, having priorities, and work input. Memorable messages categorized as work enjoyment include the call for the kind of work that will make daughters unique and happy, and a job that pays well. Examples of messages that exemplify messages about work enjoyment are given in Table 9. Messages under having priorities are about daughters making certain choices over others. Such choices include having a work/life balance, making academic work a top priority in order to get a good job in the future and to provide for family. Examples of messages that exemplify messages about having priorities are given in Table 9. With regard to messages about work input, fathers asked daughters to (a) work hard and (b) be influential at work.

Messages about family. Three themes emerged from father-target participants' memorable messages about family: importance of family, marriage, and father responsibility. Fathers communicated the importance of family by emphasizing that (a) family is everything and the most important thing to ever have and that (b) family is first. Examples of messages that exemplify family responsibility themed messages about family are given in Table 10. Memorable messages categorized as marriage refer to messages that describe the union of marriage and give daughters expectations about marriage. Examples of messages categorized 
Table 9

Examples of Father-Target Messages about Work: Work Enjoyment, Having Priorities, Work Input, and Keeping a Balance

Categories Exemplars

Work enjoyment

Do something that makes you unique. It's not enough just to be good at one thing; you have to have something that makes you different from others in your field.

My father always told me to choose a career that I truly enjoyed, but I must be able to fend for myself one day if that's the case.

Having priorities

When I first began my graduate program for my MA degree, my father gave me advice on maintaining a work/life balance that would allow for me to complete my course requirements without becoming overwhelmed. He told me to work hard on my classes and research and treat graduate school like it's a 9-5 traditional job, but to be sure to leave time for relaxation and family/friends on the weekends and in the evening. This advice has helped me to find personal time for relaxation and relationships.

My dad has always told me to focus on my schooling and get a good job. For as long as I can remember my dad has always emphasized his desire for me to be successful. He always tells me to put boys second and if I ever get married to never depend on a man. He has always been someone who works really hard to provide the best for his family. He's a very hard worker and expects the same from me. In contrast though, he provides completely for my mother and insists on giving me money and support because "I'm his little girl." 
Table 9 (Continued)

Categories Exemplars

\section{Work input}

Work hard

Be influential

Keeping a balance
In my father's house, he told me as we were sitting in the living room to always work hard because nothing is just handed to you in life.

My dad started working when he was 16 so hard work and dedication are something I grew up with engrained in my mind. From when I was a very little girl I started going to work with my dad putting pens in holders, talking to customers and pretending I was a saleswoman.

Always leave a place or person better than you found it.

One memorable message that I recall my father giving me about work/family is that there are opportunities to positively impact people in every part of life; having a positive effect on other people doesn't have to only come from a formal position. It is possible to positively impact others in everything we do. By being a leader, mentoring others, or just offering friendship to another person, you can positively change their lives.

My father's actions as a business man and an amazing father always balancing out work and family time, making sure to provide us with anything he can, is a message. My father has told me it is always important to always think of family while making decisions with work. 
Table 10

Examples of Father-Target Messages about Family: Importance of Family, Marriage, and Father Responsibility

Categories Exemplars

Importance of family

Family is everything I remember when I was a little girl, my dad and I were at our home. I was sitting on his lap playing with our dog and he said "XXX" (my nickname), family is the most important thing you'll ever have. Always remember that."

My dad told me, "family is everything. If you don't have family, then you don't have anything." He told me this at our house while we were discussing an issue with my brother.

Family is first

Family is first. Don't procrastinate. Go after it.

Family comes first.

Marriage

Marriage is something "you have to gut it out."

Marriage is not just about the good times but sticking by each other in the hard times and that in the end, the hard times bring you closer.

Father responsibility

Family is the most important thing. A man is to take care of his family always. Fathers should provide for their family. This message was communicated at home over dinner.

My dad once told me that he could not imagine a husband who did not split housework with his wife. He says he knows so many men who assume it is women's work and that this upsets him greatly. He was a stay at home dad for years. This was said various times throughout my life when I still lived at home.

Note. *Pseudonym 
under marriage that exemplify fathers' messages about family are given in Table 10. Finally, with regard to messages about father responsibility that fathers communicated to their young adult daughters, the messages emphasized the role of a father in the family — to provide for the family (see Table 10 for exemplars).

\section{Research Question Two: Context of Memorable Messages}

Research question two inquired about the extent to which memorable messages about work/career and family are communicated in private/public settings and in formal/planned or informal/unplanned conversations. Participants reported that majority of messages irrespective of the target-source were communicated in private settings and through informal/unplanned conversations. Table 11 has detailed information about this distribution.

\section{Hypothesis One: Predictors of Daughter Relational Satisfaction}

Prior to exploring the 12 hypotheses forwarded in this study, Pearson product-moment correlations were computed among all variables for each target-parent (see Table 12: mothertarget; Table 13: father-target) and a composite of both target-parents (see Table 14). The first hypothesis predicted that daughters' report of parent's respectful accommodation and selfdisclosure would be positive predictors of daughters' relational satisfaction with the target parent. Pearson product-moment correlations showed that respectful accommodation $(r=.69)$ and self-disclosure $(r=.25)$ were significantly $(p<.001)$ and positively related to relational satisfaction (see Table 14). Multiple regression analysis was computed to predict daughters' relational satisfaction based on their report of parent's respectful accommodation and selfdisclosure (see Table 15). A significant model was obtained $F(2,238)=115.04, p<.001, R^{2}=$ .49 with both respectful accommodation $(\beta=.67, p<.001)$ and self-disclosure $(\beta=.11, p=.02)$ serving as predictors. Hypothesis one was supported. 
Table 11

Distribution of Type of Setting and Conversations for Memorable Messages

\begin{tabular}{|c|c|c|c|c|}
\hline & \multicolumn{2}{|c|}{ Mother-target } & \multicolumn{2}{|c|}{ Father-target } \\
\hline & Frequency & $\%$ & Frequency & $\%$ \\
\hline \multicolumn{5}{|l|}{ Setting } \\
\hline Private & 115 & $87.12 \%$ & 87 & 71.31 \\
\hline Public & 12 & $9.09 \%$ & 26 & 21.31 \\
\hline No response & 5 & $3.79 \%$ & 9 & 7.38 \\
\hline \multicolumn{5}{|l|}{ Conversation } \\
\hline Formal/planned & 9 & $6.82 \%$ & 11 & 9.02 \\
\hline Informal/unplanned & 120 & $90.91 \%$ & 103 & 84.43 \\
\hline No response & 3 & $2.27 \%$ & 8 & 6.56 \\
\hline
\end{tabular}


Table 12

Correlations among Variables per Mother-Target

\begin{tabular}{|c|c|c|c|c|c|c|c|c|c|c|c|c|c|c|}
\hline Variables & 1 & 2 & 3 & 4 & 5 & 6 & 7 & 8 & 9 & 10 & 11 & 12 & 13 & 14 \\
\hline 1. Mixed message & - & & & & & & & & & & & & & \\
\hline $\begin{array}{l}\text { 2. Likelihood to } \\
\text { transmit memorable } \\
\text { message }\end{array}$ & $-.26^{* *}$ & - & & & & & & & & & & & & \\
\hline $\begin{array}{l}\text { 3. Interpersonal } \\
\text { Closeness }\end{array}$ & $-.25^{* *}$ & $.34^{* *}$ & - & & & & & & & & & & & \\
\hline $\begin{array}{l}\text { 4. Respectful } \\
\text { accommodation }\end{array}$ & $-.22^{*}$ & $.30^{* *}$ & $.48^{* *}$ & - & & & & & & & & & & \\
\hline $\begin{array}{l}\text { 5. Relational } \\
\text { satisfaction }\end{array}$ & $-.26^{* *}$ & $.28^{* *}$ & $.60^{* *}$ & $.74^{* *}$ & - & & & & & & & & & \\
\hline 6. Self-disclosure & $-.24^{* *}$ & $.42^{* *}$ & $.58^{* *}$ & $.54^{* *}$ & $.60^{* *}$ & - & & & & & & & & \\
\hline 7. Life satisfaction & -.09 & .01 & $.23^{*}$ & $.27^{* *}$ & $.30^{* *}$ & $.32^{* *}$ & - & & & & & & & \\
\hline \multicolumn{15}{|l|}{$\begin{array}{l}\text { Feminist identity } \\
\text { (Daughter feminist } \\
\text { identity) }\end{array}$} \\
\hline 8. Passive acceptance & -.02 & -.08 & $-.26^{* *}$ & .05 & -.03 & -.07 & -.04 & - & & & & & & \\
\hline $\begin{array}{l}\text { 9. Social dominance } \\
\text { orientation }\end{array}$ & .04 & .07 & $.32^{* *}$ & .02 & .05 & .04 & -.04 & $-.80^{* *}$ & - & & & & & \\
\hline
\end{tabular}

Note. ${ }^{*}$ Correlation is significant at the 0.05 level (2-tailed). $* *$ Correlation is significant at the 0.01 level (2-tailed). 
Table 12 (Continued)

\begin{tabular}{|c|c|c|c|c|c|c|c|c|c|c|c|c|c|c|}
\hline Variables & 1 & 2 & 3 & 4 & 5 & 6 & 7 & 8 & 9 & 10 & 11 & 12 & 13 & 14 \\
\hline \multicolumn{15}{|l|}{$\begin{array}{l}\text { Feminist identity } \\
\text { (Mother feminist } \\
\text { identity) }\end{array}$} \\
\hline 10. Passive acceptance & $-.21^{*}$ & $-.77^{* *}$ & .10 & $.36^{* *}$ & $.28^{* *}$ & .12 & -.00 & $.51^{* *}$ & $-.44^{* *}$ & - & & & & \\
\hline $\begin{array}{l}\text { 11. Social dominance } \\
\text { orientation }\end{array}$ & .09 & -.10 & .01 & $-.25^{* *}$ & $-.18^{*}$ & -.16 & -.07 & $-.51^{* *}$ & $.53^{* *}$ & $-.77^{* *}$ & - & & & \\
\hline \multicolumn{15}{|l|}{$\begin{array}{l}\text { Mother-daughter } \\
\text { relationship }\end{array}$} \\
\hline 12. Connectedness & $.28^{* *}$ & $.41^{* *}$ & $.61^{* *}$ & $.71^{* *}$ & $.70^{* *}$ & $.75^{* *}$ & $.23^{* *}$ & -.04 & .21 & $.29^{* *}$ & $-.19^{*}$ & - & & \\
\hline 13. Interdependence & $-.28^{* *}$ & $.39^{* *}$ & $.69^{* *}$ & $.61^{* *}$ & $.70^{* *}$ & $.60^{* *}$ & $.24^{* *}$ & $-.19^{*}$ & $.28^{* *}$ & .15 & -.04 & $.76^{* *}$ & - & \\
\hline \multicolumn{15}{|l|}{ Identity gaps } \\
\hline $\begin{array}{l}\text { 14. Personal-relational } \\
\text { identity gap }\end{array}$ & .12 & $-.24^{* *}$ & $-.47^{* *}$ & $-.73^{* *}$ & $-.51^{* *}$ & $-.51^{* *}$ & $-.40^{* *}$ & -.00 & -.00 & $-.29^{* *}$ & $.30^{* *}$ & $-.66^{* *}$ & $-.56^{* *}$ & - \\
\hline $\begin{array}{l}\text { 15. Personal-enacted } \\
\text { identity gap }\end{array}$ & .16 & $-.29^{* *}$ & $-.43^{* *}$ & $-.75^{* *}$ & $-.56^{* *}$ & $-.56^{* *}$ & $-.31^{* *}$ & -.02 & -.06 & $-.27^{* *}$ & $.30^{* *}$ & $-.74^{* *}$ & $-.58^{* *}$ & $.79^{* *}$ \\
\hline
\end{tabular}

Note. ${ }^{*}$ Correlation is significant at the 0.05 level (2-tailed). $* *$ Correlation is significant at the 0.01 level (2-tailed). 
Table 13

Correlations among Variables per Father-Target

\begin{tabular}{|c|c|c|c|c|c|c|c|c|}
\hline Variables & 1 & 2 & 3 & 4 & 5 & 6 & 7 & 8 \\
\hline 1. Mixed message & - & & & & & & & \\
\hline $\begin{array}{l}\text { 2. Likelihood to transmit } \\
\text { memorable message }\end{array}$ & $-.27^{* *}$ & - & & & & & & \\
\hline 3. Interpersonal Closeness & $-.34^{* *}$ & $.35^{* *}$ & - & & & & & \\
\hline 4. Respectful accommodation & $-.37^{* *}$ & $.29^{* *}$ & $.52^{* *}$ & - & & & & \\
\hline 5. Relational satisfaction & $-.48^{* *}$ & $.53^{* *}$ & $.64^{* *}$ & $.59^{* *}$ & - & & & \\
\hline 6. Self-disclosure & $-.35^{* *}$ & $.31^{* *}$ & $.51^{* *}$ & $.45^{* *}$ & $.53^{* *}$ & - & & \\
\hline 7. Life satisfaction & $-.27^{* *}$ & $.23^{*}$ & $.31^{* *}$ & $.26^{* *}$ & $.36^{* *}$ & $.27^{* *}$ & - & \\
\hline $\begin{array}{l}\text { 8. Personal-relational identity } \\
\text { gap }\end{array}$ & $.45^{* *}$ & $-.32^{* *}$ & $-.55^{* *}$ & $-.75^{* *}$ & $-.67^{* *}$ & $-.43^{* *}$ & $-.39^{* *}$ & - \\
\hline $\begin{array}{l}\text { 9. Personal-enacted identity } \\
\text { gap }\end{array}$ & $.44^{* *}$ & $-.26^{* *}$ & $-.46^{* *}$ & $-.71^{* *}$ & $-.55^{* *}$ & $-.48^{* *}$ & $-.43^{* *}$ & $.81^{* *}$ \\
\hline
\end{tabular}

Note. $*$ Correlation is significant at the 0.05 level (2-tailed). $* *$ Correlation is significant at the 0.01 level (2-tailed). 
Table 14

Correlations among Variables: Composite of both Target-Parents

\begin{tabular}{|c|c|c|c|c|c|c|c|c|c|}
\hline Variables & 1 & 2 & 3 & 4 & 5 & 6 & 7 & 8 & 9 \\
\hline 1. Mixed message & - & & & & & & & & \\
\hline $\begin{array}{l}\text { 2. Likelihood to transmit } \\
\text { memorable message }\end{array}$ & $-.25^{* *}$ & - & & & & & & & \\
\hline 3. Interpersonal Closeness & $-.26^{* *}$ & $.35^{* *}$ & - & & & & & & \\
\hline $\begin{array}{l}\text { 4. Respectful } \\
\text { accommodation }\end{array}$ & $-.26^{* *}$ & $.31^{* * *}$ & $.50^{* *}$ & - & & & & & \\
\hline 5. Relational satisfaction & $-.34^{* *}$ & $.40^{* *}$ & $.61^{* *}$ & $.69^{* *}$ & - & & & & \\
\hline 6. Self-disclosure & $-.17^{* *}$ & $.15^{*}$ & $.30^{* *}$ & $.20^{* *}$ & $.25^{* *}$ & - & & & \\
\hline 7. Life satisfaction & $-.14^{*}$ & .12 & $.27^{* *}$ & $.32^{* *}$ & $.36^{* *}$ & .12 & - & & \\
\hline \multicolumn{10}{|l|}{ Identity gaps } \\
\hline $\begin{array}{l}\text { 8. Personal-relational } \\
\text { identity gap }\end{array}$ & $.28^{* *}$ & $-.25^{* *}$ & $-.47^{* *}$ & $-.67^{* *}$ & $-.61^{* *}$ & $-.19^{* *}$ & $-.34^{* *}$ & - & \\
\hline $\begin{array}{l}\text { 9. Personal-enacted } \\
\text { identity gap }\end{array}$ & $.29^{* *}$ & $-.26^{* *}$ & $-.42^{* *}$ & $-.67^{* *}$ & $-.58^{* *}$ & $-.20^{* *}$ & $-.30^{* *}$ & $.80^{* *}$ & - \\
\hline
\end{tabular}

Note. ${ }^{*}$ Correlation is significant at the 0.05 level (2-tailed). $* *$ Correlation is significant at the 0.01 level (2-tailed). 
Table 15

Multiple Regression Using Respectful Accommodation and Self-Disclosure to Predict Relational Satisfaction

\begin{tabular}{llllll}
\hline Predictor variables & B & SEB & $\beta$ & $t$ & $p$ \\
\hline Respectful accommodation & .67 & .05 & .67 & 14.18 & .00 \\
Self-disclosure & .12 & .05 & .11 & 2.42 & .02 \\
\hline
\end{tabular}




\section{Hypothesis Two and Three: The Likelihood of Transmitting Memorable Messages}

The second hypothesis predicted that daughters' relational satisfaction with their parent would be related positively with daughters' likelihood to transmit their parent's memorable messages. Pearson product-moment correlations revealed that relational satisfaction and likelihood to transmit memorable message were significantly $(p<.001)$ and positively related $(r$ $=.40 ;$ see Table 14). Hypothesis two was supported.

The third hypothesis predicted that daughters would be more likely to transmit mothers' messages than fathers' messages. Results of a one-tailed independent samples t-test $(t(244)=-$ $.14, p=.89$ ) showed no significant difference between daughters' likelihood to transmit memorable messages from mothers $(M=4.30, S D=1.08)$ and fathers $(M=4.32, S D=1.08)$. Hypothesis three was not supported.

\section{Hypotheses Four, Five, Six, and Seven: Dynamics in Daughter-Parent Relationship}

Hypotheses four through seven focused on the nature of daughter-parent relationships. Hypothesis four posited that daughters and mothers would engage in more respectful accommodation with mothers than with fathers. Results of a one-tailed independent samples ttest $(t(243)=-.71, p=.75)$ showed no significant difference between daughters' engagement in respectful accommodation with mothers $(M=4.81, S D=1.34)$ and fathers $(M=4.93, S D=$ 1.25). Hypothesis four was not supported.

Hypothesis five posited that daughters and mothers would engage in more self-disclosure than daughters and fathers. Results of a one-tailed independent samples t-test $(t(241)=-10.15, p$ $<.001$, Cohen's $d=1.31)$ showed that daughters disclose significantly more to fathers $(M=3.61$, $S D=.88)$ than mothers $(M=2.28, S D=1.14)$. Hypothesis five was not supported.

Hypothesis six posited that daughters would report greater interpersonal closeness with 
mothers than with fathers. Results of a one-tailed independent samples t-test $(t(242)=1.17, p=$ .24) showed no significant difference between daughters' report of interpersonal closeness with mothers $(M=4.41, S D=1.77)$ in comparison to fathers $(M=4.15, S D=1.74)$. This hypothesis was not supported.

Hypothesis seven posited that daughters report greater relational satisfaction with mothers than fathers. Results of a one-tailed independent samples t-test $(t(240)=-1.01, p=.31)$ showed no significant difference between daughters' report of relational satisfaction with mothers $(M=5.69, S D=1.34)$ in comparison to fathers $(M=5.87, S D=1.27)$. Hypothesis seven was not supported.

\section{Hypotheses Eight and Nine: Mother and Daughter Feminist Identity}

Hypotheses eight and nine were predictions about mother and daughter feminist identities as they are related to traditional gender roles, male dominance, and daughter life satisfaction. Hypothesis eight predicted that daughters perceive their mothers' feminist identity as less than their own feminist identity. Results of a paired samples t-test $(t(118)=1.63, p=.11)$ showed that daughters did not perceive their mother's feminist identity $(M=3.69, S D=.41)$ as less than their own feminist identity $(M=3.76, S D=.40)$. Hypothesis eight was not supported.

Hypothesis nine predicted that daughter feminist identity is positively related to daughter life satisfaction. Pearson product-moment correlations showed that daughter feminist identity is not significantly related $(p=.19)$ to daughter life satisfaction (see Table 12). Hypothesis nine was not supported.

\section{Hypothesis Ten: Mixed Messages and Identity Gaps}

Hypotheses ten focused on the relationship between mixed messages and daughters' identity gaps. Proposing that parents' mixed messages regarding work/family would be 
positively related to daughters' identity gaps (i.e. personal enacted and personal-relational identity gaps). Pearson product-moment correlations (see Table 14) showed that mixed messages regarding work/family was significantly $(p<.001)$ and positively related to personal-relational identity gap $(r=.28)$ and personal-enacted identity gap $(r=.29)$. Hypothesis ten was supported. Hypotheses Eleven and Twelve: Identity Gaps, Likelihood to Transmit Messages, and Life

\section{Satisfaction}

Hypothesis eleven posited that daughters' identity gaps (i.e. personal enacted and personal-relational identity gaps) will predict their likelihood to transmit their mothers' messages regarding work/career and family. Pearson product-moment correlations (see Table 12) revealed that likelihood to transmit mothers' messages was significantly $(p<.05)$ and negatively related to personal-relational identity gap $(r=-.24)$ and personal-enacted identity gap $(r=-.29)$. Hypothesis eleven was supported. Multiple regression analysis was computed to predict daughters' likelihood of transmitting their mothers' memorable message based on daughters' personal-relational identity gap and personal-enacted identity gap. See Table 16. A significant model was obtained $\left(F(2,119)=5.70, p<.05, R^{2}=.09\right)$. However, neither personal-relational identity gap $(\beta=-.04, p=.77)$ nor personal-enacted identity gap $(\beta=-.26, p=.07)$ was a significant predictor.

Hypothesis twelve posited that daughters' identity gaps (i.e. personal enacted and personal-relational identity gaps) would be related negatively to their life satisfaction. Pearson product-moment correlations (see Table 14) showed that life satisfaction was significantly $(p<$ .001) related to personal enacted identity gap $(r=-.30)$ and personal-relational identity gap $(r=-$ .34). Hypothesis twelve was supported. As indicated in Table 17, multiple regression analysis was computed to predict daughters' life satisfaction based on their personal-relational identity 
Table 16

Multiple Regression Using Personal-Relational Identity Gap and Personal-Enacted Identity Gap to Predict Daughters' Likelihood to Transmit Mothers' Memorable Message

\begin{tabular}{lccccc}
\hline Predictor Variable & B & SEB & $\beta$ & $t$ & $p$ \\
\hline & & & & & \\
Personal-relational identity gap & -.04 & .13 & -.04 & -.30 & .77 \\
Personal-enacted identity gap & -.21 & .12 & -.26 & -1.84 & .07 \\
\hline
\end{tabular}

Table 17

Multiple Regression Using Personal-Relational Identity Gap and Personal-Enacted Identity Gap to Predict Daughters' Life Satisfaction

\begin{tabular}{llclll}
\hline Predictor Variable & B & SEB & $\beta$ & $t$ & $p$ \\
\hline Personal-relational identity gap & -.22 & .11 & -.21 & -1.97 & .05 \\
Personal-enacted identity gap & -.13 & .10 & -.14 & -1.29 & .20 \\
\hline
\end{tabular}


gap and personal-enacted identity gap. A significant model was obtained $(F(2,229)=13.42, p<$ $\left..001, R^{2}=.11\right)$ with personal-relational identity gap $(\beta=-.22, p=.05)$ serving as the only significant predictor.

\section{Summary}

The results presented in this chapter were obtained through frequency counts, coding, and bivariate analyses leading to themes of memorable messages that young adult daughters received from parents regarding work/career and family, as well as increased understanding of parentdaughter relationship and how this relationship influences daughters' likelihood to transmit the memorable message, and evidence of the impact of these memorable messages on daughters' personal-relational and personal-enacted identities. Memorable messages regarding work that young adult daughters reported receiving from mothers were based on attitudes towards work (i.e., working hard, not missing work, and treating people well), the value of work (i.e., education and financial empowerment), the work enjoyment, perseverance, and encouragement.

Conversely, fathers communicated messages on work enjoyment, having priorities, and work input. On family-related messages, mothers communicated messages about

marriage/relationship (i.e., prioritization of work over family, readiness for marriage/family, and premarital rules), family responsibility, and support/love/unity whereas fathers communicated messages about the importance of family (i.e., family is everything, family is first), marriage, and father responsibility. Most participants confidently recalled memorable messages from their parent regarding work/career and family and most of these messages were communicated in a private setting and informal/unplanned conversations. Results of the study did not reveal any significant differences based around target-parent (i.e., mother or father) in terms of daughters' likelihood to transmit memorable messages and to engage in respectful accommodation, 
interpersonal closeness, and relational satisfaction. However, daughters reported self-disclosing more to fathers than to mothers. Daughters' report of their parent's respectful accommodation and self-disclosure were positive predictors of their relational satisfaction with their parent. This relational satisfaction predicted daughters' likelihood of transmitting memorable messages received from their parent. An examination of the difference between daughters' feminist identity and their mothers' feminist identity did not emerge as significant. Daughters did not perceive their mother's feminist identity as less than their own feminist identity nor did daughter feminist identity positively relate to daughter life satisfaction. Finally, in examining the relationship between parents' mixed messages and daughters' identity gaps (i.e., personalrelational identity gap and personal-enacted identity gap), results indicated a positive relationship. Relatedly, daughters' identity gaps predicted their likelihood to transmit parent's memorable messages, and were negatively related to the daughters' life satisfaction. 


\section{CHAPTER IV}

\section{Discussion}

The purpose of this dissertation was to explore the content of work/career and family messages that parents communicate to their young adult daughters as well as daughters' likelihood of transmitting these messages and the impact on daughters' personal, relational, and enacted identities (identity layers within the Communication Theory of Identity; Hetch (1993)). Drawing from daughters' reported experiences with parents of biological or non-biological ties, and those who are alive or deceased, the parent-daughter relationship with regard to respectful accommodation, relational satisfaction, interpersonal closeness and self-disclosure was examined to explain daughters' likelihood of transmitting parents' messages. Given that this dissertation aimed at contributing to the development of daughter identity, the influence of feminism in general and contemporary terms was considered because of the relational benefits of feminist identity (e.g., life satisfaction: Rittenour \& Colaner, 2012; increased self-esteem and selfefficacy: Morley, 1993) but unfortunately it performed less successfully in this particular dissertation. This chapter is organized as follows: first, I review findings; second, I examine theoretical and practical implications; third, I address limitations, and fourth, conclude. Throughout this chapter, I offer potential directions for future research on memorable messages about work/career and family as well as daughter-parent relationships and identity gaps.

\section{Review of Findings}

Study results are summarized based on: parent-daughter relationships and memorable messages, respectively. Each set of findings is reviewed by providing explanations and implications for the findings. These findings culminate to paint a fuller picture of the power of parent-child communication in adult children's identity as well as parents' intentions to enhance 
their own children's identity through future communication.

\section{Parent-Daughter Relationships}

Through my sample of young adult daughters, there is evidence that the communication of both mothers and fathers is moderately high with regard to issues of work and family. While the hypotheses prioritized the dynamics between communication, relational quality, and identity, and were less concerned with the differences between mothers' and fathers' behaviors as reported by adult daughters, there are several meaningful points to be made about the "mother versus father" trends that emerged.

Daughters' report of their target-parent relationship with regard to respectful accommodation, interpersonal closeness, and relational satisfaction had similarly high mean scores (mother-target means ranged from 4.81 to 5.87 whereas father-target means ranged from 4.93 to 5.87). Daughters reported self-disclosing more to fathers than to mothers and this finding should be interpreted while considering the nature of the data collection (i.e., the fact that only daughters self-reported on the father-daughter relationship).

The high-father-disclosure trend could be due to participants' choosing to report on their closest parent and so this trend may not necessarily be a true depiction of general father-daughter and general daughter-mother relationships. While I asked participants to begin the questionnaire by identifying their parental figures, they may have omitted low-closeness parenting figures altogether, which prohibited such members from being included as one of the conditions of which they could have been randomized. Fathers and mothers who are not close to their daughters may have been omitted from this study as participants were randomly placed into only close parent relationships. Thus, the dynamics of the daughter- parent relationships may be skewed to the more positive end. 
Across previous studies, mothers have emerged as more highly involved than fathers.

Keating et al. (2012) found that mothers rather than fathers are the primary source of memorable messages. Nielsen (2007) in a longitudinal study over the period of 15 years indicated that the mother-daughter relationship is comparatively more intimate, communicative, and more comfortable as mothers and daughter were more involved in each other's lives. Despite mothers' long history of heightened involvement with their adult children, particularly young adult daughters, the findings of this study suggest a similar trend of the "changing culture of fatherhood" (i.e.; when men's relationships with their fathers and sons shift toward the nature of a nurturant father rather than society's image of an authoritarian and emotionally detached father; Morman \& Floyd, 2002, p. 400) with father-daughter relationships.

It is possible that there is more communication happening between daughters and fathers. This changing culture as a result of cultural prescriptions may as well apply to the fatherdaughter relationship in terms of self-disclosure and relational closeness on the whole. It is also likely, however, that what is changing is the propensity to report a higher amount of selfdisclosure from fathers, and-given the expectation that fathers (and men more generally) communicate less about themselves and their feelings - fathers may have to self-disclose less in order to be considered "high self-disclosers" whereas mothers' heightened expectations have the opposite effect; a similar point was made by Morman and Floyd (2002) and Odenweller, Rittenour, Myers, and Brann (2013).

According to McKinney and Renk (2008), fathers tend to have a more authoritative style of parenting (i.e., high control and low warmth) as compared to mothers, and if this held true for our participants (note that such data was not collected), it may have influenced the impact of fathers' messages about work/career and family (Nelson \& Coyne, 2009). Given the focus of this 
dissertation on memorable messages about work/career and family, if the content of the messages truly created the context for which daughters responded, then daughters may have evaluated the father-daughter relationship based on the specific period in which these memorable messages were communicated rather than in general terms. Still, the point should not be forgotten that overall, reports on mothers and fathers were comparable regarding the majority of the closed-ended measures, just as was largely true of the responses to the open-ended questions about the message itself. For instance, across target-parent, there was no difference in terms of whose messages are intended to be embraced and passed onward.

Consistent with the "changing culture" trend of heightened involvement (and subsequent influence), the findings highlight a need to further examine the father-daughter relationship to better understand the relationship dynamics in different communication contexts as well as examine message content and how the content impacts the nature of the relationship. Doing so would fill the gap in literature that tends to target mothers, often overlooking fathers. Fathers provide human capital (e.g., professional skill sets and strong work ethic), financial capital (e.g., income and its resources and experiences), and social capital (i.e., beneficial family and social relations; Amato, 1998) and are significant in the development of daughters' identity. Previous research has primarily focused on mother-daughter relationships. However, there is ample empirical support for the great contribution of fathers in the development of their children in areas such as academic achievement (which is also highlighted in the memorable messages daughters reported - in this dissertation - receiving from their fathers) and socioeconomic status which of course pertain to work/career related issues (see Flouri (2005) for a review), both of which complement this dissertation's focus on work and family socialization. Given that both mothers and fathers play a role in communicating memorable messages 
to adult daughters, I turn to the extent to which memorable messages regarding work and family might predict the likelihood that messages daughters receive from parents would be transmitted to the next generation. Findings indicate that daughters' experience of respectful accommodation and self-disclosure in daughter-parent relationships result in relational satisfaction. In turn, this relational satisfaction predicted daughters' likelihood to transmit parent's memorable messages. These findings are suggestive of the fact that it is not enough for messages to be communicated, but that the quality of the relationship contributes to the effectiveness (in terms of likelihood to transmit communicated messages) of the communicated message. Certainly, this quality is likely built on a consistent high-quality communication exchange between the daughter and her parent, but the relational quality should not be ignored. Two ways to develop effective parent-daughter relationship are through respectful accommodation and self-disclosure.

Respectful accommodation and self-disclosure are two communication behaviors that are ongoing so as to really serve as a backdrop for the more targeted memorable messages. Previous studies have shown the effectiveness of the two communication behaviors, particularly in intergroup communication contexts, which is applicable to this dissertation given its intergenerational context (e.g., Cayanus, Martin, \& Goodboy, 2009; Fowler \& Soliz, 2013; McCann, Ota, Giles, \& Caraker, 2003; Rittenour \& Soliz, 2009; Soliz, 2007). In intergroup communication between parents and daughters, interaction and perceptions are shaped by intergroup factors including, but not limited to, such contexts as gender, age or worldview (Harwood, Giles, \& Palomares, 2005; Harwood, Soliz, \& Lin, 2006). Inasmuch as young adults may be more conscious of their age difference with their grandparents (Soliz, 2007), they may also be conscious of the age difference between them and their parents. As Miller-Day (2008) argued, adult children between the ages 18 to 25 years negotiate between developing adult 
identity and family interdependence which would make such age salience quite feasible.

Looking across intergroup communication contexts, it is vital to relational quality and individual well-being that both parties recognize the need to be respectful of the intergroup factors to which they may be bound. As Soliz and Harwood (2006) posited, the personalized nature of accommodative behaviors (e.g., supportive communication, respectful accommodation, self-disclosure, or storytelling) puts the interlocutors in an optimum position in which they may move beyond social distancing intergroup factors to the highly personalized interactions that are based on the characteristics of the two engaged individuals. Accommodative behaviors have been linked to positive outcomes of relationships (Soliz et al., 2010; Soliz \& Rittenour, 2009, 2012; Williams \& Harwood, 2004) and so it is unsurprising that in this sample, it was linked to heightened parent-child relationship quality.

\section{Memorable Messages about Work/Career and Family}

Alongside trait-like communication behaviors of respectful accommodation and selfdisclosure, interesting trends emerged regarding the communication of memorable messages. Research has well established the power of communication within the family and the fact that such communication serves as the original source of socialization for children (e.g. BoothButterfield \& Sidelinger, 1998; Socha \& Yingling, 2010). Inasmuch as research on general family communication patterns are essential and particularly useful among family members of different genders (e.g., Punyanunt-Carter, 2008), it is also important to examine the content of the message shared (in this case, messages that daughters find memorable). Memorable messages are messages "often transmitted in family settings from parent to child and have a lasting impact beyond the parent-child interaction" (Kellas, 2010, p. 461). This section reviews the content of memorable messages that young adult daughters received from parents about work and family. 


\section{Memorable messages about work}

One message that was consistent from mothers and fathers was for daughters to pay attention to the choice of the work in which they (daughters) got themselves involved. For both mothers and fathers, the happiness of daughters is salient and happiness should be the driving force for the kind of jobs that daughters will have eventually. Indeed, most people value happiness and society in general rates happiness as a highly valued goal (Diener, 2000).

Although organizational researchers have not extensively studied happiness as an employee experience in organizations, other related constructs (e.g., task enjoyment and emotion at work) have been studied and shown to have vital consequences for individuals and organizations alike (see Fisher (2010) for a review). Results from this study can help us glean insights into the meaning of happiness and the reason behind the quest for happiness from work. One of the ways social scientists define happiness is from a eudaemonic perspective that involves doing something that is true to oneself, meaningful, and growth producing (Fisher, 2010).

The eudaemonic perspective of happiness is explicit in fathers' messages such as "do something that makes you unique. It's not enough just to be good at one thing, you have to have something that makes you different from others in your field" as well as mothers' messages such as "money can't buy you happiness, but it does buy you comfort and security." The first message defines a happy job as one that is growth producing whereas the second message defines a happy job as one that is meaningful (i.e., "able to buy comfort and security").

From one father's message, the quest for happiness from work is because "work is where you make friends. Work is where you find fulfillment." Inasmuch as some messages about work were consistent with parents' values, lifestyle, expectations, actions, behavior, 
expressions/sayings, and attitude, other parents' messages were inconsistent and served as mixed messages. The two excerpts below are evidence. The first except exemplifies consistency whereas the second excerpt exemplifies inconsistency.

I don't recall when exactly a particular message was shared, but rather the idea that I should choose a job that I enjoy was communicated to me throughout my childhood. This advice was also demonstrated in how my parents felt about their careers.

Although my mother made it clear I could do whatever I wanted, she did not always follow through on that. Honestly, I don't believe she thought that. She is a teacher and always expected me to be one. I never wanted to be a teacher, but always felt that's what I had to do. This left me with little career focus and no path in higher education. When a message is not consistently communicated, daughters are less likely to report favorably about themselves and their relationship with their parent. Mixed messages regarding work/career and family as manifested in the above exemplar (note, though, that mixed messages were examined through a separate measure and this particular memorable message happens to capture this phenomenon), are positively related to daughters' personal-relational and personalenacted identity gaps. Additionally, the experience of identity gaps prevent daughters the likelihood to transmit the memorable message communicated to them, which coincides with lower life satisfaction; the overall judgment of the quality of her life.

As may be expected among such a satisfied group of daughters, many work-related memorable messages from parents have a warm and consistent tone. For mothers, this was indicative of traditional nurturing and caring characteristics of women. With this tone came messages of encouragement and perseverance such as "you can be whatever your heart desires." Mothers were reassuring of their support for their daughters and mothers highlighted daughters' 
potential for success at work: "you can do anything you set your heart and mind to! I am proud of you!" and "my mother has always encouraged me to work hard no matter what type of job I am involved in, as it could be a stepping stone to something better.

Conversely, fathers' work-related memorable messages were not communicated through direct expressions of their own love and care but instead were presented more as a directive. Examples of such messages are "when I first started working, my dad would say, do more than what is expected from you because that will go a long way," "growing up, my dad often told me to dress for the job I want, not the job I have," "working for someone else is a mug's game [a foolish activity to engage in because of the high likelihood of one's failure]," and My father has told me since I was little (6 or 7) to "always be honest, even if the truth is hard to say." Usually he communicated these messages in the home while discussing his own work experiences. He was (and still is) known for being brutal and having no filter. One participant may have attempted to save the face of her father to further explain what her father meant by the message in order not for her father to appear "rude" as she puts it below: "You're certainly not going to be a model." My father said this in the car on the way to church one week ago. It seems rude, but he meant I wasn't going to have jobs and tuition money handed to me for being pretty. He meant I'd have to put in effort to get the things that middle class kids have handed to them. He said I could work hard now or I could stay poor as an adult.

The elaborations above on the different ways in which mothers and fathers express their care and love to young adult daughters suggest gender differences in parenting styles. While there was great similarity across the groups, there is evidence that mothers and fathers can communicate advice/guidance differently (e.g., through encouragement and instructions/directives 
respectively). Work related messages that young adult daughters reported receiving from mothers were based on attitudes towards work (i.e., working hard, not missing work, and treating people well), the value of work (i.e., education and financial empowerment), work enjoyment, perseverance, and encouragement. Conversely, messages from fathers about work were based on work enjoyment, having priorities, and work input.

\section{Memorable messages about family}

Generally, both mothers and fathers were reported to have communicated messages about marriage/relationship but with different concerns. Research on marriage has established clear gains economically, socially, and psychologically (Liu, Elliott, \& Umberson 2010; Williams \& Umberson 2004) as well as a decrease in stress levels upon the termination of the relationship. All the same, relationship termination is not what mothers and fathers wish for their daughters. Hence, parents' messages are generally aimed at preparing daughters for marriage/relationship as some mothers sensitize daughters to be ready for marriage as other mothers caution daughters about pre-marital engagement with relational partners. Some fathers paint a very beautiful picture of marriage and other fathers do not hesitate to add the potential challenges daughters are inevitably likely to encounter.

Findings of the study indicate that whereas mothers communicated the need for daughters to prioritize work over family, fathers communicated the importance of family. As one participant explained, "the most memorable advice my mom gave me was to be independent. I was supposed to value work more than interpersonal relationships, because depending on men is a big mistake women make." For this participant, the message is not only memorable but the most memorable, indicating that this message is the most legitimate and personal (Stohl, 1986), internalized and taken to heart (Knapp et al., 1981), and reserved in the memory's cache (Smith, 
Ellis, \& Yoo, 2001). This memorable message is non-traditional because it shifts attention from relationship-mindedness as a core characteristic of being female to a more action-oriented masculine characteristic of work-mindedness. It is however not surprising given that Kaufman (2005) suggested that "work is now an integral part of women's lives" (p. 59).

Mothers' messages about daughters prioritizing work over family may be for the sake of independence not to solely depend on one's relational partner for livelihood (as indicated in the memorable message quoted above) and self-actualization where daughters can live their dreams of a lifetime career and not be confined to private spaces like the home. For some mothers, independence and self-actualization don't matter as one mother says to her daughter "why don't you just be married and have a normal 9-5 job." Perhaps, a "normal" job implies nothing exceptional, not a dream job but a job that matches the current trend of women entering the workforce (Kaufman, 2005) so that one would have also satisfied the traditional expectation for marriage.

According to Etaugh and Folger (1998), full-time work has shown to be perceived as an impediment for mothers' more than fathers' family-oriented image. Despite the fact that women are entering the workforce, the traditional expectations still hold of women as family-oriented. Women are still expected to put their families first - though there is no such indication from memorable messages gathered from mothers (but from fathers) in this dissertation. Memorable messages from fathers emphasize this traditional expectation of women to put their families first: "ever since I was young, my father has always stressed that family is the most important thing. Family comes before anything," "family is first. Don't procrastinate. Go after it," and "family comes first." From this dissertation, it can be concluded that fathers reinforce the traditional expectation of daughters to be family-oriented. Admittedly, sons may also receive similar 
messages from fathers to be family-oriented or rather, responsible in carrying out traditional masculine duties such as the breadwinner role in the family.

Fathers remind daughters that though marriage/family is to be desired in all earnest, it has its challenges. The following are examples of messages in which fathers communicate the challenges that marriage/family may present: "that marriage is not just about the good times but sticking by each other in the hard times and in the end the hard times bring you closer," "marriage is something you have to have the guts for," and "in marriage, there's never a 'good time' to have kids - and there's always a 'good time' to have kids." When it comes to the responsibility of family members, some fathers' present traditional gender roles: "family is the most important thing. A man is to take care of his family always. Fathers should provide for their family and other fathers advocate equality in which both man and woman are assumed to fulfill work and family roles:

My dad once told me that he could not imagine a husband who did not split housework with his wife. He says he knows so many men who assume it is women's work and that this upsets him greatly.

Though data from this dissertation did not focus on within-family differences (each participant would have to provide data for her mother and father), it can be inferred that if mothers are giving different messages about family (i.e., mothers talk about prioritizing work over family whereas fathers emphasize the importance of family), this can be a source of mixed messages for young adult daughters. Future research should compare mothers' and fathers' (within family units) memorable messages about family and how these messages conform to traditional gender roles. Given that feminism as a movement advocates for the self-actualization and empowerment of women to be able to be self-reliant, it would also be beneficial to the cause 
of the movement, to explore the extent to which feminism has been able to influence this discourse and avert the creation of a double standard for women who are functional in both family and work domains.

Mothers, in their memorable messages about family, did not discourage their daughters from marriage/family. They emphasized the idea about being ready for marriage/family. The following is an example of such memorable messages from mothers:

I had said that I didn't think I wanted kids because I want a fulfilling career. My mom told me that you should be sure you want kids and a family, before you have them. She told me this at my parents' house.

The excerpt above also suggests that the daughter perceived that having children/family was indeed an impediment to her realization of a fulfilling career. This perception is not very different from what another mother expressed in her message to her daughter:

My mom told me to always put my goals before a relationship, no matter how serious it may seem. She told me this after she and my biological father split right as I was entering into high school. They didn't have the best marriage and she admitted to me that he had held her back from her accomplishing a lot of the goals in her life. She didn't want to see the same thing happen to me.

Additionally, in this dissertation, mothers $(n=7)$ more than fathers $(n=1)$ communicated memorable messages about balancing work and family which supports earlier findings of fathers' messages highlighting traditional gender roles of women taking particular concern in family/marriage. If women are not expected to engage in work and do so excellently, then the discourse on keeping a balance and the benefit of such balance to the woman and her family does not suffice. This memorable message suggests the benefit of balancing work and family. 
When I was in high school, I was living in a small rural area in which "helicopter moms" were a commonality. One afternoon, my mother told me that she never wanted to be that mother for two reasons: it's not healthy for the child or the mother. That day my mom told me that a woman's children don't have to be their entire life. She spoke passionately about living a full life as both a worker and a mother, "To live that full life you have to figure out what you want by ignoring what others want."

Family related messages that young adult daughters reported receiving from mothers were based on marriage/relationship (i.e., prioritization of work over family, readiness for marriage/family, and premarital rules), family responsibility, and support/love/unity. Conversely, messages from fathers about family were based on the importance of family (i.e., family is everything, family is first), marriage, and father responsibility.

\section{Context for memorable messages}

In addition to exploring memorable messages that adult daughters receive from mothers and fathers about work/career and family, the context of the memorable messages were also examined. Irrespective of the target-source, most messages were communicated in private and informal/unplanned conversations (for example: in the kitchen (for target-mothers), house, car, over dinner, and on phone). This finding supports previous research finding (e.g., Barge \& Schlueter, 2004; Cramer, 2015) that memorable messages are communicated in private settings.

Other memorable messages were not verbally communicated. Across themes that emerged from memorable messages received from parents, there were both verbal/explicit messages and nonverbal/behavioral messages. Although participants of the study were not directed to indicate whether the memorable messages were communicated verbally or nonverbally, some participants found it necessary to indicate that their memorable message was 
communicated through parents'actions. As Brim and Wheeler (1966) posited, the salience of a memorable message can be attributed to the fact that the message inculcates appropriate behaviors to socialize the recipient. Memorable messages can be communicated nonverbally/behaviorally but for the most part, they tend to be communicated verbally/explicitly (Lucas, 2011). Examples of nonverbal/behavioral memorable messages from participants' parents are:

I didn't receive the message in words; I simply watched as my mother both raised children and worked, part time or full time, throughout her life. I learned that it is possible to do both, but also that it is difficult to do both well.

My father wasn't one to voice many opinions. He never came out and said: "never give up," but my father definitely gave those messages. My parents have had a rough marriage and have put the family through a lot of turmoil, but my father never stops trying to keep the family together. So, to him, family is very important and he gave me those messages not through words but through action.

Participants' mention of the form (i.e., whether verbal/ explicit or nonverbal/ behavioral) in which memorable messages were communicated also support one of the fundamental ways in which parents are communicating mixed messages to their daughters. For instance, if a parent verbally/explicitly communicates the message of balancing work and family but does not do so herself/himself (nonverbally/behaviorally), the parent is communicating a mixed message about work and family. While both direct statements and behaviors are useful in teaching children, behaviors are more easily modeled (either due to an observed behavior - the modeling hypothesis, or to compensate for an experience one did not have- the compensation hypothesis; 
see Floyd and Morman (2009) for a review) and thus more likely to truly influence how (adult) children behave (Bandura, 1977).

Ekman and Friesen (1974) conceptualized the relationship between verbal and non-verbal modes of communication as a link of congruence and incongruence. This conceptualization further supports the propensity for parents to send mixed messages when there is a discrepancy between simultaneous verbal and nonverbal messages (i.e., link of incongruence) rather than a relationship of similarity between the messages (i.e., link of congruence). The next section of this chapter further examines the theoretical and practical implications of the study, focusing on how the nature of communication, particularly mixed messages create consequential gaps in the identities of daughters.

\section{Theoretical and Practical Implications}

This dissertation's findings have both theoretical implications for Communication Theory of Identity (CTI) and memorable message studies as well as practical implications for daughterparent communication about work/career and family.

\section{Theoretical Implications}

This dissertation is heuristically valuable in its contribution to the scholarly work on identity gaps conducted to examine how individuals with different social identities (e.g., Jewish Americans, Korean Americans, international students, contemporary U.S. immigrants, and intraracial encounters: Hecht \& Faulkner, 2000; Hecht et al., 2002; Jung \& Hecht, 2008; Jung et al., 2007; Urban \& Orbe, 2010; Drummond \& Orbe, 2009) negotiate multiple forms of identity. Kam and Hecht (2009) have also examined the influence of identity gaps (i.e., the relationalenacted, personal-enacted, and personal-relational identity gaps) on communication and relational outcomes within the context of family and personal relationships (i.e., the grandparent- 
grandchild relationship as a family relationship and as a personal relationship). Previous research on identity gaps has suggested an association between identity gaps and negative outcomes like depression (Jung \& Hecht, 2008), and decreased levels of communication satisfaction and misunderstanding (Jung \& Hecht, 2004).

This dissertation is the first to consider and test CTI its subsumed identity gaps in the intersectional context of organizational and family communication; it is also further articulates a cause of identity gaps within a familial relationship (among parents and young adult daughters). This dissertation also advances theoretical understanding of the role of family communication processes in work and family identity development. In addition to the known negative outcomes of identity gaps, we now know that identity gaps can exist in daughter-parent communication when parents communicate messages that are inconsistent with parents' lifestyle, expectations, actions, behaviors, expressions/sayings, and attitude or children's personal values.

Findings of this dissertation showed that when young adult daughters receive mixed messages about work/career and family from parents (though not many participants of the study reported having received mixed messages), daughters experience personal-relational identity gaps and personal-enacted identity gaps. Personal-relational identity gap is experienced when there is a discrepancy between daughters' view of themselves and how they are viewed by parents in the daughter-parent relationship. Personal-enacted identity gap is experienced when daughters behave in ways that are inconsistent with their perception of themselves. Considering extant literature as well as findings of this dissertation on the general closeness of motherdaughter relationships, daughters stand a risk of the effect of personal-relational identity gaps on their life satisfaction as satisfaction with life encapsulates the essence of one's being. Future research should explore other effects of mothers' mixed messages on daughters' personal- 
relational identity gap. Though interdependence between daughters and fathers was not examined, considering the possible changing culture of fatherhood as discussed earlier, the effect of mixed messages from fathers can be expected to have the same effect based on the level of interdependence existent in the father-daughter relationship

The approach to the study of personal-relational and personal-enacted identity gaps based on communication and relational outcomes may be extended to the content of other messages communicated in organizations among organizational members or in the family context among familial members (e.g., immigrant families, interracial relationships). For instance, superiors and subordinates as well as peer and coworkers are constantly engaged in verbal and nonverbal communication within and about the workplace. For subordinates upon whom authority compliance is laid, when superiors act differently or express incongruent ideals with organizational values, this may contribute to subordinates' organizational identity gaps (i.e., in the context of enacted and relational identity gaps). The experience of identity gaps in superiorsubordinate relationships may be apparent considering the inherent relational power at play.

Personal-relational and personal-enacted identity gaps may further impact negatively on organizational members' job satisfaction, organizational commitment, organizational identification and other positive organizational attributes thereby leading to issues of employee turnover and attrition. The power relationship around which the superior-subordinate relationship is carved could also be examined as a moderator of the extent to which the communication of mixed messages from superiors may contribute to the personal-relational and personal-enacted identity gaps of subordinates. This proposition may be informed by the tenets of Leader Member Exchange theory (LMX, Graen \& Uhl-Bien, 1995) which takes a relationship based approach to leadership. 
In addition to adding to CTI literature and its application, this dissertation expands research on the use of memorable messages in the field of organizational communication and family communication in two ways. First, results of this dissertation prove useful in a comparative sense, in evaluating whether memorable messages on work/family tend to be associated with circumstances (e.g., in the home or in public places) and sources (e.g., mothers or fathers) different from those reported in studies of other communication context (e.g., Cranmer, 2015; Holladay, 200).

Second, this dissertation has provided additional content of memorable messages that children (particularly young adult daughters) receive from parents about work/family (i.e., attitude towards work: how to treat people at work, not missing work, working hard) and supported the notion that memorable messages are communicated in private and informal/unplanned contexts which are fundamental across varied communication contexts (Knapp et al., 1981; Stohl, 1986).

\section{Practical Implications}

The content and context of memorable messages regarding work and family may inform parents and educators, helping them understand the circumstances that give rise to memorable messages. For instance, the knowledge that daughters do not only take in verbal messages as memorable, but also implicitly communicated messages could be useful to educators in designing family education programs that facilitate communication about work/career and family such that the focus will not only be on verbal but behavioral cues as well.

In that same regard, parents can be cautioned about giving mixed (and negative) messages across various communication channels. It is important for parents to aim at consistency in the messages about work/career and family that they give or rather acknowledge 
their deviation from the practice of the message, given that this incongruence in messages have the tendency to positively impact daughters' personal-enacted and personal relational identity gap. Aiming at maintaining a cordial daughter-parent relationship, parents also engage in respectful accommodation and self-disclosure. Even though this dissertation did not examine young adult daughters' likelihood of engaging in topic avoidance, it is possible that they may engage in topic avoidance as a relationship maintenance strategy with parents whose values and ideals about work/career and family may not be the same as that of daughters.

Avoidance of conflict or uncomfortable situations can be a form of relationship maintenance and a strategy for relational satisfaction. Young adult daughters may strategically avoid certain topics of conversation in order to present appealing versions of oneself. Taboo topics are known to serve as face-saving tools and contribute to relational satisfaction but it may also mare relational closeness. Harwood (2000) and Williams and Giles (1996) argued that when individuals engage in topic avoidance as a strategy for discourse management, they purport constrained communication. Topic avoidance is negatively associated with perceptions of relational satisfaction (e.g., Roloff \& Ifert, 1998) in many relational contexts such as in marriage (e.g., Finkenauer \& Hazam, 2000) and family (e.g., transracially adoptive families; DocanMogan, 2010). When daughters and parents experience topic avoidance, it can keep the parentdaughter relationship from growing deeper even though the communication partners may express relational satisfaction. Relational partners may express relational satisfaction because they engage in topic avoidance to avert conflict or uncomfortable situations.

One interesting point to note that may be relevant to the discourse on communication behaviors and attempts made by both parents and daughters to maintain the parent-daughter relationship is the fact that though participants of the study were not instructed to write a 
memorable message on work or family but work/family, most participants wrote the former. This trend also suggests that work/family messages are indeed intertwined for both parents and children.

Finally, young adult daughters and parents may also find this dissertation useful to know more about messages regarding work/career and family that prove memorable. For instance, messages about work were focused on work enjoyment, attitude towards work, and how to treat people at work whereas messages about family were focused on marriage, responsibility, and premarital rules. In terms of the context of these memorable messages, findings of this dissertation support previous research (e.g., Barge \& Schlueter, 2004; Cramer, 2015) findings about memorable messages being communicated in private and informal/unplanned conversations. Hence, daughter-parent conversations about work/career and family should continue to occur in private and informal/unplanned conversations. According to Knapp et al. (1981), the private and informal nature of a memorable message makes the message individualized and thus, more likely for the receiver to transmit the message to other individuals.

\section{Limitations and Future Research}

There are four limitations that should be considered when interpreting the results of this dissertation. These limitations suggest several directions for future research. First, the sample was largely comprised of Caucasian females $(n=201)$. This characteristic of the sample limits the generalization of findings in terms of the content of memorable messages regarding work and family to the experiences of females in minority ethnic groups or of different cultural backgrounds. Extant research on work-life issues has been conducted in Western countries (e.g., United States, Canada, and United Kingdom). However, the socio-economic patterns, cultural values, national policies, family structures, and employment opportunities may not necessarily 
allow a fine application of models developed from the Western countries (Bagger \& Love, 2010). Yang (2005) argued that individuals may have different interpretations and implications of participating in work and family roles.

Future research should extend the study of memorable messages to include minority populations, taking into consideration the influence of culture on the interpretation of memorable messages. As noted by Annor (2014), lack of research from non-Western contexts is a major limitation in the literature on work-life issues and conspicuously absent from the literature is research on sub-Saharan Africa. However, the diversification of the contemporary workforce (e.g., organizational restructuring, work time scheduling, organizational policies, and the use of information technology at work) and an increase in female participation is a global development that has been well documented (Bedu-Addo, 2012).

Second, this dissertation only focused on the perspectives of daughters to assess the dynamics of the daughter-parent relationship. Seeking parents' perspectives on their relationship satisfaction, interpersonal closeness, and respectful accommodation may illuminate the specific dynamics of the daughter-parent relationship. Knowing which memorable message parents think they may have given their daughters and the contexts for communicating those messages would also shed light on the congruence or incongruence in communicated messages and provide practical recommendations on how to avert communicating mixed and perhaps negative messages. Also, daughters reported perceptions of their mothers' feminist identity could be misleading in the sense that daughters' report may not accurately represent mothers' feminist identity. This potential inaccuracy may have contributed to findings of the study that showed that daughters did not perceive their mothers' feminist identity as less than their own feminist identity despite the penetration of feminist values in contemporary times as compared to a decade ago, 
and also the fact that the mother-daughter relationship is intergenerational. Future studies should consider using dyadic data (i.e., mothers-daughters and fathers-daughters) in examining this trend. Relatedly, future studies may also extend the scope of this dissertation to focus on young adult sons to fill the gap in the literature on memorable messages about family/career and work that parents communicate to sons.

Third, despite the fact that data collection for this dissertation was done in two folds (i.e., online and paper surveys), majority of participants turned out to be college students. As such, their interpretation of traditional work included academic work. Although all memorable messages that focused on academic work were excluded from the analysis, this exclusion reduced the potential number of memorable messages from which further insight could have been gleaned. Just as a memorable message was defined for participants, "work" may also be conceptualized in future studies that examine memorable messages about work that young adult daughters receive from parents. Given the age range stipulated for young adulthood (i.e., 18-35; Petry, 2005), college students may not necessarily be avoided but in addition to conceptualizing work, another selection criterion can be that participants should have ever worked in an organization. The college student sample may have skewed findings on feminist identity given that they may not necessarily have ventured the traditional workforce and be delusional about work conditions and traditional gender roles in contemporary times.

Finally, the online and paper survey data collection methods did not allow for probing of results despite its advantages of timeliness in completing this dissertation and easy access to a large pool of participants. Face-to-face interviews and focus group discussion would have allowed for probing of results and perhaps the clarification of what work means in the context of this dissertation. Researchers should consider interviews and focused group discussions in data 
collection to glean more insight on the content of memorable messages that parents communicate to their young adult daughters.

\section{Conclusion}

Using memorable messages as a communicative tool to analyze messages that parents communicate to daughters about work and family has provided insight into the content as well as the context of memorable messages that young adult daughters receive from their parents. Findings of this study showed the tendency for parents to communicate messages both verbally/explicitly and nonverbally/behaviorally, and mixed messages. This dissertation is the first to initiate the application the Communication Theory of Identity outside the context of intercultural communication and instructional communication into the realms of intersecting organizational and family communication and the specific behavior of mixed messages. This initiative supports the potency of CTI and its applicability even in intersectional communication contexts. As such, the role of communication, particularly identity gaps and mixed messages can be further explored in areas of organizational communication such as superior-subordinate relationships and peer/coworker relationships to fully understand the contextual relationship between mixed messages and identity gaps. The world would be a better place without having to experience personal-relational and personal-enacted identity gaps at all; granted that we spend most of our time with family and/or other employees of our workplace, our identities in these spaces should not be at risk. 


\section{References}

Acker, J. (2004). Gender, capitalism, and globalization. Critical Sociology, 30, 117-141. doi:10.1163/156916304322981668

Alberts, J. K., Tracy, S. J., \& Trethewey, A. (2011). An integrative theory of the division of domestic labor: Threshold level, social organizing, and sensemaking. Journal of Family Communication, 11, 21-38. doi:10.1080/15267431.2011.534334

Alexander, S., \& Ryan, M. (1997). Social constructs of feminism: A study of undergraduates at a women's college. College Student Journal, 31, 555-568.

Allen, K. R. (2000). A conscious and inclusive family studies. Journal of Marriage and the Family, 62, 4-17. doi:10.1111/j.1741-3737.2000.00004.x

Alvesson, M., \& Billing, Y. D. (2009). Understanding gender and organizations $\left(2^{\text {nd }} e d.\right)$. London: Sage.

Amato, P. R. (1998). More than money? Men's contributions to their children's lives. In A. Booth \& A. C. Crouter (Eds.), Men in families: When do they get involved? What difference does it make (pp. 241-278). Mahwah, NJ: Erlbaum.

Ammons, S. K., \& Markham, W. T. (2004). Working at home: Experiences of skilled white collar workers. Sociological Spectrum, 24, 191-238. doi:10.1080/02732170490271744

Aron, A., Aron E. N., \& Smollan, D. (1992). Inclusion of other in the self scale and the structure of interpersonal closeness. Journal of Personality and Social Psychology, 63, 596-612. doi:10.1037/0022-3514.63.4.596

Aronson, P. (2003). Feminists or "postfeminists"? Young women's attitudes toward feminism and gender relations. Gender \& Society, 17, 903-922. doi:10.1177/0891243203257145

Annor, F. (2014). Managing work and family demands: The perspectives of employed parents in 
Ghana. International Perspectives on Social Policy, Administration, and Practice, 1, 1736. doi:10.1007/978-3-319-01237-7_2

Athay, M. M. (2012). Satisfaction with life scale (SWLS) in caregivers of clinically-referred youth: Psychometric properties and mediation analysis. Administration and Policy in Mental Health and Mental Health Services Research, 39, 41-50. doi:10.1007/s10488-011-0390-8

Bagger, J., \& Love, J. (2010). Methodological considerations in conducting cross-national workfamily survey research. In S. Sweet \& J. Casey (Eds.), Work and family encyclopedia. Chestnut Hill, MA: Sloan Work and Family Research Network.

Baines, S., \& Gelder, U. (2003). What is family friendly about the workplace in the home? The case of self-employed parents and their children. New Technology, Work and Employment, 18, 223-234. doi:10.1111/1468-005X.00123

Bandura, A. (1977). Social learning theory. New York, NY: General Learning Press.

Barber, B. L., \& Eccles, J. S. (1992). Long-term influence of divorce and single parenting on adolescent family-and-work related values, behaviors, and aspirations. Psychological Bulletin, 111, 108-126. doi:10.1037/0033-2909.111.1.108

Barge, J. K., \& Schlueter, D. W. (2004). Memorable messages and newcomer socialization. Western Journal of Communication, 68, 233-257. doi:10.1080/10570310409374800

Bassoff, E. S. (1987). Mothering adolescent daughters: A psychodynamic perspective. Journal of Counseling and Development, 65, 471-474. doi:10.1002/j.1556-6676.1987.tb00758.x

Baxter, J. (2005). To marry or not to marry: Marital status and the household division of labor. Journal of Family Issues, 36, 300-321. doi:10.1177/0192513X04270473

Baxter, J., Hewitt, B., \& Western, M. (2005). Post-familial families and the domestic division of 
labor. Journal of Comparative Family Studies, 36, 583-600.

doi:hdl.handle.net/10620/3071

Bazeley, P. (2007). Qualitative data analysis with Nvivo (2 ${ }^{\text {nd }}$ ed.) London, England: Sage.

Bedu-Addo, P. K. A. (2010). Work-family interference among Ghanaian women in higher status occupations (Doctoral dissertation). Retrieved from http://eprints.nottingham.ac.uk/id/eprint/11529

Bernauer, J. A., Lichtman, M., Jacobs, C., \& Robinson, S. (2013). Blending the old and the new: Qualitative analysis as critical thinking and using Nvivo with a generic approach. The Qualitative Report (How To Art. 2), 18, 1-10. Retrieved from http://www.nova.edu/ssss/QR/QR18/bernauer2.pdf

Bewes, T. (1997). Cynicism and postmodernity. New York, NY: Verso.

Bianchi, S., Robinson, J., \& Milkie, M. (2006). Changing rhythms of American family life. New York, NY: Russell Sage Foundation.

Booth-Butterfield, M., \& Sidelinger, R. (1998). The influence of family communication on the college-aged child: Openness, attitudes, and actions. Communication Quarterly, 46, 295308. doi:10.1080/01463379809370103

Brim, O., \& Wheeler, S. (1966). Socialization after childhood. New York: John Wiley and Sons. Bullis, C. (1993). Organizational socialization research: Enabling, constraining, and shifting perspectives. Communication Monographs, 60, 10-17. doi:10.1080/03637759309376289

Buzzanell, P. M., \& D’Enbeau, S. (2009). Stories of caregiving: Intersections of popular gender, academic research, and one woman's experiences. Qualitative Inquiry, 15, 1199-1224. doi: $10.1177 / 1077800409338025$

Byron, K. (2005). A meta-analytic review of work-family conflict and its antecedents. Journal of 
Vocational Behavior, 67, 169-198. doi:10.1016/j.jvb.2004.08.009

Cayanus, J. K., Martin, M. M., \& Goodboy, A. K. (2009). The relation between teacher selfdisclosure and student motives to communicate. Communication Research Reports, 26, 105-113. doi:10.1080/08824090902861523

Chelsey. N. (2005). Blurring boundaries? Linking technology use, spillover, individual distress, and family satisfaction. Journal of Marriage and Family, 67, 1237-1248. doi:10.1111/j.1741-3737.2005.00213.x

Chromy, J. R. (2008). Snowball sampling. In P. J. Lavrakas (Ed.), Encyclopedia of survey research methods (pp. 824-825). Thousand Oaks, CA: Sage.

Clark, S. C. (2000). Work/family border theory: A new theory of work/family balance. Human Relations, 53,747-770. doi:10.1177/0018726700536001

Clark, S. C. (2002). Communicating across the work/home border. Community, Work, and Family, 5, 23-48. doi:10.1080/13668800020006802

Colaner, W. C., Halliwell, D., \& Guignon, P. (2014). "What do you say to your mother when your mother's standing beside you?" Birth and adoptive family contributions to adoptive identity via relational identity and relational-relational identity gaps. Communication Monographs, 81, 469-494. doi:10.1080/03637751.2014.95808

Colon, N. J. (2011). Who dropped the ball: Examining the relationship between race, memorable messages about academic achievement, and graduation rates for football student-athletes (Unpublished doctoral dissertation). Michigan State University, East Lansing, MI.

Cooke-Jackson, A., Orbe, M. P., Johnson, A. L., \& Kauffman, L. (2014). Abstinence memorable messages narratives: A new exploratory research study into young adult sexual narratives. Health Communication, 30, 1201-1212. doi:10.1080/10410236.2014.924045 
Cranmer, G. A. (2015). Exploring the anticipatory socialization stage of division I studentathletes: The content, characteristics, and functions of memorable messages (Unpublished doctoral dissertation). West Virginia University, Morgantown, WV.

Creswell, J. W. (2013). Qualitative inquiry \& research design: Choosing among five approaches ( $3^{\text {rd }}$ ed.). Los Angeles: Sage.

Csikszentmihalyi, M., \& Schneider, B. (2000). Becoming adult: How teenagers prepare for the world of work. New York, NY: Basic Books.

Dallimore, E. J. (2003). Memorable messages as discursive formations: The gendered socialization of new university faculty. Women's Studies in Communication, 26, 214-265. doi:10.108007491409200310162460

Day, R., \& Lamb, M. (2004). Conceptualizing and measuring father involvement: Pathways, problems, and progress. In R. Day \& M. Lamb (Eds.), Conceptualizing and measuring father involvement (pp. 1-16). Mahwah, NJ: Erlbaum.

Delle, E., \& Arkoful, H. K. (2014). Work and family at war: Does individual difference matter? International Journal of Business and Social Science, 5, 82-90.

D’Enbeau, S., \& Buzzanell, P. M. (2010). Caregiving and female embodiment: Scrutinizing (professional) female bodies in media, academe, and the neighborhood bar. Women and Language, 33, 29-52.

Diener, E. (2000). Subjective well-being. American Psychologist, 55, 34-43. doi:10.1037/0003-066X.55.1.34

Diener, E., Emmons, R. A., Larsen, R. J., \& Griffin, S. (1985). The satisfaction with life scale. Journal of Personality Assessment, 49, 71-75. doi:10.1207/s15327752jpa4901_13

Docan-Mogan, S. (2010). "They don't know what it's like to be in my shoes": Topic avoidance 
about race in transracially adoptive families. Journal of Social and Personal Relationships, 28, 336-355. doi:10.1177/0265407510382177

Downing, N. E., \& Roush, K. L. (1985). From passive acceptance to active commitment: A model of feminist identity development for women. The Counseling Psychologist, 13, 695-709. doi:10.1177/0011000085134013

Drummond, D. K., \& Orbe, M. P. (2009). “Who are you trying to be?” Identity gaps within intraracial encounters. Qualitative Research Reports in Communication, 10, 81-87. doi:10.1080/17459430903236098

Dunleavy, V. O., \& Yang, Q. (2015). Memorable messages and newcomer socialization on campus: Messages about body image among student athletes, sorority members, and freshmen. Communication Research Reports, 32, 225-238.

doi:10.1080/08824096.2015.1052902

Eby, L. T., Casper, W. J., Lockwood, A., Bordeaux, C., \& Brinley, A. (2005). Work and family research in IO/OB: Content analysis and review of the literature (1980-2002). Journal of Vocational Behavior, 66, 124-197. doi:10.1016/j.jvb.2003.11.003

Ekman, P., \& Friesen, W. V. (1974). Detecting deception from the body or face. Journal of Personality and Social Psychology, 29, 288-298. doi:10.1037/h0036006

Ellis, J. B., \& Smith, S. W. (2004). Memorable messages as guides to self-assessment of behavior: A replication and extension diary study. Communication Monographs, 71, 97119. doi:10.1080/03634520410001691456

Erikson, E. H. (1968). Identity: Youth and crisis. New York, NY: W.W. Norton \& Company. Etaugh, C., \& Folger, D. (1998). Perceptions of parents whose work and parenting behaviors deviate from role expectations. Sex Roles, 39, 215-223. doi:10.1023/A:1018850404838 
Etchezahar, E., Jaume, L., Prado-Gascó, V., \& Brussino, S. (2014). Validación argentina de la Escala de Orientación a la Dominancia Social. Revista Latinoamericana De Psicología, 46, 35-43.

Faulkner, S. L., \& Ruby, P. D. (2015). Feminist identity in romantic relationships: A relational dialectics analysis of e-mail discourse as collaborative found poetry. Women's Studies in Communication, 38, 206-226. doi:10.1080/07491409.2015.1025460

Finkenauer, C., \& Hazam, H. (2000). Disclosure and secrecy in marriage: Do both contribute to marital satisfaction? Journal of Social and Personal Relationships, 17, 245-263. doi:10.1177/0265407500172005

Fischer, C. L. (2014). Coping together, side by side: Enriching mother-daughter communication across the breast cancer journey. New York, NY: Hampton Press.

Fischer, L. R. (1991). Between mothers and daughters. Marriage and Family Review, 16, 237248. doi:10.1300/J002v16n03_02

Fisher, C. D. (2010). Happiness at work. International Journal of Management Review, 12, 384412. doi:10.1111/j.1468-2370.2009.00270.x

Flores, L. Y., Carrubba, M. D., \& Good, G. E. (2006). Feminism and Mexican American adolescent women: Examining the psychometric properties of two measures. Hispanic Journal of Behavioral Sciences, 28, 48-64. doi:10.1177/0739986305283222.

Flouri, E. (2005). Fathering and child outcomes. Hoboken, NJ: John Wiley \& Sons.

Ford, L. A., \& Ellis, B. H. (1998). A preliminary analysis of memorable support and nonsupport messages received by nurses in acute care settings. Health Communication, 10, 37-63. doi:10.1207/s15327027hc1001_3

Fowler, C., \& Soliz, J. (2013). Communicative responses to the painful self-disclosures of 
familial and non-familial older adults. International Journal of Aging and Human Development, 77, 163-188. doi:10.2190/AG.77.3.a

Freeman, S. J. M. (1997). Parental influences on women's careers. In D. Dunn (Ed.), Workplace/women's place: An anthology (pp. 32-43). Los Angeles, CA: Roxbury.

Frone, M. R. (2000). Work-family conflict and employee psychiatric disorders: The national comorbidity survey. Journal of Applied Psychology, 85, 888-896. doi:10.I037//0021-90I0.85.6.888

Fung, H. H., \& Carstensen, L. L. (2003). Sending memorable messages to the old: Age differences in preferences and memory for advertisements. Journal of Personality and Social Psychology, 85, 163-178. doi:10.1037/0022-3514.85.1.163

Galinsky, E. (1999). Ask the children: What America's children really think about working parents. New York, NY: Morrow.

Galvin, K. (2006). Gendered communication in families. In B. Dow \& J. T. Wood (Eds.), Handbook of gender and communication (pp. 41-55). Thousand Oaks, CA: Sage.

Galvin, T. (Ed.). (2000). Industry report 2000: A comprehensive analysis of employee-sponsored training in the United States. Training: The human side of business, 37, 45-95

Gerstmann, E. A., \& Kramer, D. A. (1997). Feminist identity development: Psychometric analyses of two feminist identity scales. Sex Roles, 36, 327-348. doi:10.1007/BF02766651

Giddens, A. (1979). Central problems in social theory: Action, structure, and contradiction in analysis. Berkley, CA: University of California Press.

Gilchrist, E. S., \& Camara, S. (2012). Cultural dis/continuity in African American and Ghanaian mothers' voices and identities. Journal of Intercultural Communication Research, 41, 81- 
108. doi:10.1080/17475759.2011.651152

Golden, A. G., \& Geisler, C. (2007). Work-life boundary management and the personal digital assistant. Human Relations, 60, 519-551. doi:10.1177/0018726707076698

Goodnow, J. J., Bowes, J. M., Warton, P. M., Dawes, L. J., \& Taylor, A. J. (1991). Would you ask someone else to do this task? Parents and children's ideas about household work requests. Developmental Psychology, 27, 817-828. doi:10.1037/0012-1649.27.5.817

Gordon, R. M. (1998). The Medea complex and the parental alienation syndrome: When mothers damage their daughters' ability to love a man. In G. H. Fenchel (Ed.), The motherdaughter relationship: Echoes through time (pp. 207-225). Northvale, NJ: Jason Aronson.

Graen, G. B., \& Uhl-Bien, M. (1995). Relationship-based approach to leadership: Development of leader-member exchange (LMX) theory of leadership over 25 years: Applying a multilevel multi-domain perspective. Leadership Quarterly, 2, 219-247. doi:10.1016/1048-9843(95)90036-5

Harter, L. M., \& Krone, K. J. (2001). Exploring the identities of future physicians: Toward an understanding of the ideological socialization of osteopathic medical students. Southern Journal of Communication, 67, 66-84. doi:10.1080/10417940109373219

Harwood, J. (2000). Communicative predictors of solidarity in the grandparent-grandchild relationship. Journal of Social and Personal Relationships, 17, 743-766. doi:10.1177/0265407500176003

Harwood, J., Giles, H., \& Palomares, N. A. (2005). Intergroup theory and communication processes. In J. Harwood \& H. Giles (Eds.), Intergroup communication: Multiple perspectives (Vol. 2, pp. 1-20). New York, NY: Peter Lang. 
Harwood, J., Hewstone, M., Paolini, S., \& Voci, A. (2005). Grandparent-grandchild contact and attitudes towards older adults: Moderator and mediator effects. Personality and Social Psychology Bulletin, 31, 393-406. doi:10.1177/0146167204271577

Harwood, J., Soliz, J., \& Lin, M. C. (2006). Communication accommodation theory: An intergroup approach to family relationships. In D. O. Braithwaite \& L. Baxter (Eds.), Engaging theories in family communication: Multiple perspectives (pp. 19-34). Thousand Oaks, CA: Sage.

Hayes, A. F. (2013). Introduction to mediation, moderation, and conditional process analysis: A regression based approach. New York, NY: Guilford Press.

Hecht, M. L. (1978). The conceptualization and measurement of interpersonal communication satisfaction. Human Communication Research, 4, 253-264.

doi:10.1111/j.1468-2958.1978.tb00614.x

Hecht, M. L. (1993). 2002-A research odyssey: Toward the development of a communication theory of identity. Communication Monographs, 60, 76-82. doi:10.1080/03637759309376297

Hecht, M. L., \& Faulkner, S. L. (2000). Sometimes Jewish, sometimes not: The closeting of Jewish American identity. Communication Studies, 51, 372-387. doi:10.1080/10510970009388532

Hecht, M. L., Faulkner, S. L., Meyer, C. R., Niles, T. A., Golden, D., \& Cutler, M. (2002). Looking through Northern Exposure at Jewish American identity and the communication theory of identity. Journal of Communication, 52, 852-869. doi:10.1111/j.1460-2466.2002.tb02577.x

Hecht, M. L., Warren, J., Jung, E., \& Krieger, J. (2005). Communication theory of identity. In 
W. B. Gudykunst (Ed.), Theorizing about intercultural communication (pp. 257-278). Thousand Oaks, CA: Sage.

Heisler, J. M. (2000). The socialization of gender roles through parental memorable message (Unpublished doctoral dissertation). Michigan State University, East Lansing, MI.

Heisler, J. M., \& Ellis, J. B. (2008). Motherhood and the construction of "mommy identity:" Messages about motherhood and face negotiation. Communication Quarterly, 56, 445467. doi:10.1080/01463370802448246

Herman, N. (1989). Too long a child: The mother-daughter dyad. London, England: Free Association Books.

Hernández, L., \& Kahn, J. H. (2013, February). Parent-adolescent agreement on adolescent selfdisclosure. Poster session presented at the National Association of School Psychologists Convention, Seattle, WA.

Hinton-Johnson, K. (2004). African American mothers and daughters: Socialization, distance, and conflict. The Alan Review, 31, 45-49.

Hochschild, A. R. (1989). The second shift: Working families and the revolution at home. New York: Penguin Press.

Holladay, S. J. (2002). "Have fun while you can," "You're only as old as you feel," and "Don't ever get old!": An examination of memorable messages about aging. Journal of Communication, 52, 681-697. doi:10.1111/j.1460-2466.2002.tb02568.x

Honeycutt, J. M., \& Cantrill, J. G. (2001). Cognition, communication, and romantic relationships. Mahwah, NJ: Erlbaum.

hooks, B. (2000). Feminism is for everybody: Passionate politics. Cambridge, MA: South End 
Press.

Huston, T. L., McHale, S. M., \& Crouter, A. C. (1986). When the honeymoon's over: Changes in the marital relationship over the first year. In R. Gilmour \& S. Duck (Eds.), The emerging field of personal relationships (pp. 109-132). Hillsdale, NJ: Erlbaum.

Hussy, D. (2010). Nonprobability sampling. In N. Salkind (Ed.), Encyclopedia of research design (pp. 922-926). Thousand Oaks, CA: Sage.

Jack, D. C. (1999). Silencing the self: Inner dialogue and outer realities. In T. Joiner \& J. C. Coyne (Eds.), Interactional nature of depression (pp. 221-246). Washington, DC: American Psychological Association.

Johnson, A. L., Orbe, M. P., \& Cooke-Jackson, A. (2014). “Let's talk about sex”: Exploring HBCU student memorable message narratives. Howard Journal of Communications, 25, 303-323. doi:10.1080/10646175.2014.925309

Jung, E. (2011). Identity gap: Mediator between communication input and outcome variables. Communication Quarterly, 59, 315-338. doi:10.1080/01463373.2011.583501

Jung, E., \& Hecht, M. L. (2004). Elaborating the Communication Theory of Identity: Identity gaps and communication outcomes. Communication Quarterly, 52, 265-283. doi:10.1080/01463370409370197

Jung, E., \& Hecht, M. L. (2008). Identity gaps and level of depression among Korean immigrants. Health Communication, 23, 313-325. doi:10.1080/10410230802229688

Jung, E., Hecht, M. L., \& Wadsworth, B. C. (2007). The role of identity in international students' psychological well-being in the United States: A model of depression level, identity gaps, discrimination, and acculturation. International Journal of Intercultural Relations, 31, 605-624. doi:10.1016/j.jintrel.2007.04.001 
Kam, J. A., \& Hecht, M. L. (2009). Investigating the role of identity gaps among communicative and relational outcomes within the grandparent-grandchild relationship: The young-adult grandchildren's perspective. Western Journal of Communication, 73, 456-480. doi:10.1080/10570310903279067

Kassing, J. W., \& Pappas, M. E. (2007). “Champions are built in the off season”: An exploration of high school coaches' memorable messages. Human Communication, 10, 537-546.

Kaufman, G. (2005). Gender role attitudes and college students' work and family expectations. Gender Issues, 22, 58-71. doi:10.1007/s 12147-005-0015-1

Keating, D. M., Shaw, A. S., \& Smith, S. W. (2012, November). The intersection offamily communication patterns and parental memorable messages about family communication. Paper presented at the annual meeting of the National Communication Association, Orlando, FL.

Keeley, M. P. (2004). Final conversations: Survivors' memorable messages concerning religious faith and spirituality. Health Communication, 16, 87-104. doi:10.1207/S15327027HC1601_6

Kellas, J. K. (2010). Transmitting relational worldviews: The relationship between motherdaughter memorable messages and adult daughters' romantic relational schemata. Communication Quarterly, 58, 458-479. doi:10.1080/01463373.2010.525700

Kellner, D. (1992). Popular culture and the construction of postmodern identities. In S. Lash \& J. Friedman (Eds.), Modernity and identity (pp. 141-177). Cambridge, UK: Blackwell.

Kelly, E. (2006). Work-family policies: The U.S. in international perspective. In M. PittCatsouphes, E. Kossek, \& S. Sweet (Eds.) Work and family handbook: Multi-disciplinary perspectives, methods, and approaches (pp. 99-124). Mahwah, NJ: Erlbaum. 
Kirby, E. L. (2000). Should I do as you say, or do as you do? Mixed messages about work and family. The Electronic Journal of Communication/La Revue de Electronique de Communication, 10(1-2). Retrieved from http://www.cios.org/EJCPUBLIC/010/3/010313.html

Kirby, E. L., \& Buzzanell, P. M. (2014). Communicating work-life issues. In L. L. Putnam \& D. K. Mumby (Eds.), The SAGE handbook of organizational communication: Advances in theory, research, and methods ( $3^{\text {rd }}$ ed., pp. 351-373). Thousand Oaks, CA: Sage.

Kirby, E. L., Golden, A. G., Medved, C. E., Jorgenson, J., \& Buzzanell. P. M. (2003). An organizational communication challenge to the discourse of work and family research: From problematics to empowerment. In P. Kalbfleisch (Ed.), Communication yearbook 27 (pp. 1-43). Mahwah, NJ: Erlbaum.

Kissi-Abrokwah, B., Andoh-Robertson, T., Tutu-Danquah, C., \& Agbesi, C. S. (2015). Examining work and family conflict among female bankers in Accra Metropolis, Ghana. Journal of Education and Practice, 6, 61-88.

Knapp, M. L., Stohl, C., \& Reardon, K. K. (1981). “Memorable” messages. Journal of Communication, 31, 27-42. doi:10.1111/j.1460-2466.1981.tb00448.x

Kohler, J. K., Grotevant, H. D., \& McRoy, R. G. (2002). Adopted adolescents' preoccupation with adoption: The impact on adoptive family relationships. Journal of Marriage and Family, 64, 93-104. doi:10.1111/j.1741-3737.2002.00093.x

Kossek, E. E., Lautsch, B. A., \& Eaton S. C. (2006). Telecommuting, control, and boundary management: Corelates of policy used and practice, job control, and work-family effectiveness. Journal of Vocational Behavioral, 68, 347-367. doi:10.1016/j.jvb.2005.07.002 
Kranstuber, H., Carr, K., \& Hosek, A. M. (2012). "If you can dream it, you can achieve it", Parent memorable messages as indicators of college student success. Communication Education, 61, 44-66. doi:10.1080/03634523.2011.620617

La Sorsa, V. A., \& Fodor, I. G. (1990). Adolescent daughter/mid-life mother dyad: A new look at separation and self-definition. Psychology of Women Quarterly, 14, 593-606. doi:10.1111/j.1471-6402.1990.tb00233.x

Lauckner, C., Smith, S., Kotowski, M., Nazione, S., Stohl, C., Prestin, A., . . Nabi, R. (2012). An initial investigation into naturally occurring loss- and gain-framed memorable breast cancer messages. Communication Quarterly, 60, 1-16. doi:10.1080/01463373.2012.642269

Laurenceau, J. P., Barrett, L. F., \& Pietromonaco, P. R. (1998). Intimacy as an interpersonal process: The importance of self-disclosure, partner disclosure, and perceived partner responsiveness in interpersonal exchanges. Journal of Personality and Social Psychology, 74(5), 1238-1251.

Lee, G. (2008). Network sampling. In P. J. Lavrakas (Ed.), Encyclopedia of survey research methods (pp. 507-508). Thousand Oaks, CA: Sage

Lefever, S., Dal, M., \& Matthiasdottir, A. (2007). Online data collection in academic research: Advantages and limitations. British Journal of Educational Technology, 38, 574-582. doi:10.1111/j.1467-8535.2006.00638.x

Liu, H., Elliott, S., \& Umberson, D. J. (2010). Marriage in young adulthood. In J. E. Grant \& M. N. Potenza, (Eds.), Young adult mental health (pp. 169-180). New York, NY: Oxford University Press.

Lucas, K. (2011). Socialization messages in blue-collar families: Communicative pathways to 
social mobility and reproduction. Western Journal of Communication, 75, 95-121. doi:10.1080/10570314.2010.536964

Martin, C. L., \& Ruble, D. (2004). Children's search for gender cues: Cognitive perspectives on gender development. Current Directions in Psychological Science, 13, 67-70. doi:10.1111/ j.0963-7214.2004.00276.x

McCann, R. M., Ota, H., Giles, H., \& Caraker, R. (2003). Accommodation and nonaccommodation across the lifespan: Perspectives from Thailand, Japan, and the United States of America. Communication Reports, 16, 69-92. doi:10.1080/08934210309384492

McKinney, C., \& Renk, K. (2008). Differential parenting between mothers and fathers: Implications for late adolescents. Journal of Family Issues, 29, 806-827. doi:10.1177/0192513X07311222

Medved, C. E. (2004). The everyday accomplishment of work and family: Exploring practical actions and commonsense rules in everyday routines. Communication Studies, 55, 128154. doi:10.1080/10510970409388609

Medved, C. E. (2007). Investigating family labor in communication studies: Threading across historical and contemporary discourses. Journal of Family Communication, 7, 225-243. doi:10.1080/15267430701392172

Medved, C. E. (2009). Crossing and transforming occupational and household gendered divisions of labor. In C. Beck (Ed.), Communication yearbook, 33 (pp. 457-482). Thousand Oaks, CA: Sage.

Medved, C. E. (2010). Communication work-life research. In S. Sweet \& J. Casey (Eds.), Work and family encyclopedia. Chestnut Hill, MA: Sloan Work and Family Research Network. 
Retrieved from https://workfamily.sas.upenn.edu/wfrn-repo/object/3kb6k5cb4ft7918c

Medved, C. E., Brogan, S. M., McClanahan, A. M., Morris, J. F., \& Shepherd, G. J. (2006).

Family and work socializing communication: Messages, gender, and ideological implications. Journal of Family Communication, 6, 161-180.

doi:10.1207/s15327698jfc0603_1

Medved, C. E., \& Graham, E. E. (2006). Communicating contradictions: (Re)producing dialectical tensions through work, family, and balance socialization messages. In L. H. Turner \& R. West (Eds.), Family communication sourcebook (pp. 353-372). Thousand Oaks, CA: Sage.

Miller-Day, M. A. (2004). Communication among grandmothers, mothers, and adult daughters: A qualitative study of maternal relationships. Mahwah, NJ: Erlbaum.

Miller-Day, M. (2008). Talking to youth about drugs: What do late adolescents say about parental strategies? Family Relations, 57, 1-12. doi:10.1111/j.1741-3729.2007.00478.x

Morley, L. (1993). Women's studies as empowerment of "non-traditional" learners in community and youth work train-ing: A case study. In M. Kennedy, C. Lubelska, \& V. Walsh (Eds.), Making connections: Women's studies, women's movements, women's lives (pp. 118-141). London, England: Taylor \& Francis.

Moradi, B., \& Subich, L. M. (2002). Perceived sexist events and feminist identity development attitudes: Links to women's psychological distress. The Counseling Psychologist, 30, 4465. doi:10.1177/0011000002301003

Morman, M. T., \& Floyd, K. (2002). A “changing culture of fatherhood": Effects on the affectionate communication, closeness, and satisfaction in men's relationships with their fathers and their sons. Western Journal of Communication, 66, 395-411. 
doi:10.1080/10570310209374746

Morman, M. T., \& Floyd, K. (2009). Affection received from fathers as a predictor of men's affection with their own sons: Tests of the modeling and compensation hypotheses. Communication Monographs, 67, 347-361. doi:10.1080/03637750009376516

Morrison, M., \& Moir, J. (1998). The role of computer software in the analysis of qualitative data: Effective clerk, research assistant, or Trojan horse? Journal of Advanced Nursing, $28,106-116$.

Nazione, S., LaPlante, C., Smith, S. W., Cornacchione, J. R., Russell, J., \& Stohl, C. (2011). Memorable messages for navigating college life. Journal of Applied Communication Research, 39, 123-143. doi:10.1080/00909882.2011.556138

Nelson, D. A., \& Coyne, S. M. (2009). Children's intent attributions and feelings of distress: Associations with maternal and paternal parenting practices. Journal of Abnormal Child Psychology, 37, 223-237.

Nielson, L. (2007). College daughters' relationships with fathers: A 15 year study. College Student Journal, 41, 112-121.

Odenweller, K., Rittenour, C. E., Myers, S. A., \& Brann, M. (2013). Father-son family communication patterns and gender ideologies: A modeling and compensation analysis. Journal of Family Communication, 13, 340-357. doi:10.1080/15267431.2013.823432

Olson Buchanan, J. B., \& Boswell, W. R. (2006). Blurring boundaries: Correlates of integration and segmentation between work and nonwork. Journal of Vocational Behavioral, 68, 432-445. doi:10.1016/j.jvb.2005.10.006

Onayli, S., \& Erdur-Baker, O. (2013). Mother daughter relationship and daughter self-esteem. Social and Behavioral Sciences, 84, 327-331. doi:10.1016/j.sbspro.2013.06.560 
Orbe, M. P. (2004). Negotiating multiple identities within multiple frames: An analysis of firstgeneration college students. Communication Education, 53, 131-149. doi:10.10/03634520410001682401

Orr, D. (2000). Mothers as moral educators: Teaching language and nurturing souls. In A. O’Reilly \& S. Abbey (Eds.), Mothers and daughters: Connection, empowerment, and transformation (pp. 161-174). Lanham, MD: Rowman \& Littlefield.

Pearson, J. C. (1989). Communication in the family: Seeking satisfaction in changing times. New York, NY: Harper and Row.

Pecchioni, L. L., \& Nussbaum, J. F. (2001). Mother-adult daughter discussions of caregiving prior to dependency: Exploring conflicts among European-American women. Journal of Family Communication, 1, 133-150. doi:10.1207/S15327698JFC0102_03

Petronio, S. (2000). The boundaries of privacy: Praxis of everyday life. In S. Petronio (Ed.), Balancing the secrets of private disclosures (pp. 37-49). Mahwah, NJ: Erlbaum.

Petry, N. M. (2002). A comparison of young, middle-aged, and older adult treatment-seeking pathological gamblers. The Gerontologist, 42, 92-99.

Pettigrew, J. (2013). "I'll take what I can get": Identity development in the case of a stepfather. Journal of Divorce \& Remarriage, 54, 25-42. doi:10.1080/10502556.2012.725360

Piotrkowski, C. S., \& Stark, E. (1987). Children and adolescents look at their parents' jobs. New Directions for Child Development, 35, 3-19. doi:10.1002/cd.23219873503

Postmes, T., Haslam, S. A., \& Jans, L. (2013). A single-item measure of social identification: Reliability, validity, and utility. British Journal of Social Psychology, 52, 597-617. doi:10.111/bjso.12006

Pratto, F., Sidanius, J., Stallworth, L. M., \& Malle, B. F. (1994). Social dominance orientation: A 
personality variable predicting social and political attitudes. Journal of Personality and Social Psychology, 67, 741-763. doi:10.1037/0022-3514.67.4.741

Punyanunt-Carter, N. (2008). Father-daughter relationships: Examining family communication patterns and interpersonal communication satisfaction. Communication Research Reports, 25, 23-33. doi:10.1080/08824090701831750

Raskin, O. M. (2006). Women, work, and family: Three studies of role and identity among working mothers. American Behavioral Scientist, 49, 134-1381. doi: $10.77 / 0002764206286560$

Rastogi, M. (1995). Adult daughters'perception of the mother-daughter relationship: A crosscultural comparison (Unpublished doctoral dissertation). Texas Tech University, Lubbock, TX.

Rastogi, M. (2002). The Mother-Adult Daughter Questionnaire (MAD): Developing a culturally sensitive instrument. The Family Journal: Counseling and Therapy for Couples and Families, 10, 145-155. doi:10.1177/1066480702102004

Richards, L. (2005). Handling qualitative data. London, England: Sage.

Riggio, H. R., \& Desrochers, S. J. (2006). Maternal employment: Relations with young adults' work and family expectations and self-efficacy. American Behavioral Scientist, 49, 13281353. doi:10.1177/0002764206286558

Rittenour, C. E., \& Colaner, C. W. (2012). Finding female fulfillment: Intersecting role-based and morality-based identities of motherhood, feminism, and generativity as predictors of women's self-satisfaction and life satisfaction. Sex Roles, 67, 351-362. doi:10.1007/s11199-012-0186-7

Rittenour, C. E., Colaner, C. W., \& Odenweller, K. G. (2014). Mother's identities and gender 
socialization of daughters. Southern Communication Journal, 79, 215-234.

doi:10.1080/1041794X.2014.895408

Rittenour, C. E., \& Soliz, J. (2009). Communicative and relational dimensions of shared family identity and relational intentions in mother-in-law/daughter-in-law relationships: Developing a conceptual model for mother-in-law/daughter-in-law research. Western Journal of Communication, 73, 67-90. doi:10.1080/10570310802636334

Rokeach, M. (1973). The nature of human values. New York, NY: Free Press.

Roloff, M. E., \& Johnson, D. I. (2001). Reintroducing taboo topics: Antecedents and consequences of putting topics back on the table. Communication Studies, 52, 37-50. doi:10.1080/10510970109388539

Rubin, L. (1994). Families on the faultline: America's working class speaks about the family, the economy, race, and ethnicity. New York, NY: Harper Collins.

Rudman, L. A., \& Fairchild, K. (2007). The $F$ word: Is feminism incompatible with beauty and romance? Psychology of Women Quarterly, 31, 125-136. doi:10.1111/j.1471-6402.2007.00346.x

Rudman, L. A., \& Phelan, J. E. (2007). The interpersonal power of feminism for romantic relationships. Sex Roles, 57, 787-799. doi:10.1007/s11199-007-9319-9

Rusbult, C. E., Martz, J. M., \& Agnew, C. R. (1998). The Investment Model Scale: Measuring commitment level, satisfaction level, quality of alternatives, and investment size. Personal Relationships, 5, 357-391. doi:10.1111/j.1475-6811.1998.tb00177.x

Saldaña, J. (2009). The coding manual for qualitative researchers (2 ${ }^{\text {nd }}$ ed.). Thousand Oaks, CA: Sage.

Schick, V. R., Zucker, A. N., \& Bay-Cheng, L. Y. (2008). Safer, better sex through feminism: 
The role of feminist ideology in women's sexual well-being. Psychology of Women Quarterly, 32, 225-232. doi:10.1111/j.1471-6402.2008.00431.x.

Schieffelin, B. B., \& Ochs, E. (1986). Language socialization. Annual Review of Anthropology, 15, 163-191. doi:10.1146/annurev.an.15.100186.001115

Shockley, K. M., \& Singla, N. (2011). Reconsidering work-family interactions and satisfaction: A meta-analysis. Journal of Management, 37, 861-886. doi:10.1177/0149206310394864

Sigel, R. (1996). Ambition and accommodation: How women view gender relations. Chicago, IL: University of Chicago Press.

Smith, S. W., Ellis, J. B., \& Yoo, H. (2001). Memorable messages as guides to self-assessment of behavior: The role of instrumental values. Communication Monographs, 68, 325-339. doi:10.1080/03637750128072

Smith, S. W., Hamel, L. M., Kotowski, M. R., Nazione, S., LaPlante, C., Atkin, C. K., .. . Skubisz, C. (2010). Action tendency emotions evoked by memorable breast cancer messages and their association with prevention and detection behaviors. Health Communication, 25, 737-746. doi:10.1080/10410236.2010.521916

Smith, S. W., Munday, S., LaPlante, C., Kotowski, M. R., Atkin, C. K., Skubisz, C., \& Stohl, C. (2009). Topics and sources of memorable breast cancer messages: Their impact on prevention and detection behaviors. Journal of Health Communication, 14, 293-307. doi:10.1080/10810730902805903

Socha, T. J., \& Yingling, J. (2010). Families communicating with children. Oxford, England: Polity Press

Soliz, J. (2007). Communicative predictors of a shared family identity: Comparison of grandchildren's perceptions of family-of-origin grandparents and stepgrandparents. 
Journal of Family Communication, 7, 177-194. doi:10.1080/15267430701221636

Soliz, J., \& Harwood, J. (2006). Shared family identity, age salience, and intergroup contact: Investigation of the grandparent-grandchild relationship. Communication Monographs, 73, 87-107. doi:10.1080/03637750500534388

Soliz, J., Ribarsky, E., Harrigan, M. M., \& Tye-Williams, S. (2010). Perceptions of communication with gay and lesbian family members: Predictions of relational satisfaction and implications for outgroup attitudes. Communication Quarterly, 58, 7795. doi:10.1080/01463370903538622

Soliz, J., \& Rittenour, C. E. (2009). Communicative and relational dimensions of shared family identity and relational intentions in mother-in-law/daughter-in-law relationships: Developing a conceptual model for mother-inlaw/daughter-in-law research. Western Journal of Communication, 73, 67-90. doi:10.1080/10570310802636334

Soliz, J., \& Rittenour, C. E. (2012). Family as an intergroup arena. In H. Giles (Ed.), The handbook of intergroup communication (pp. 331-343). New York, NY: Routledge.

Soliz, J., Thorson, A. R., \& Rittenour, C. E. (2009). Communicative correlates of satisfaction, family identity, and group salience in multiracial/ethnic families. Journal of Marriage and Family, 71, 819-832. doi:10.1111/j.1741-3737.2009.00637.x

Soliz, J., Thorson, A. R., Rittenour, C. E. \& Murry, V. M. (2009). Communicative correlates of satisfaction, family identity, and group salience in multiracial/ethnic families. Journal of Marriage and Family, 71, 819-832. doi:10.1111/j.1741-3737.2009.00637.x

Stafford, L., \& Bayer, C. L. (1993). Interaction between parents and children. Newbury Park, CA: Sage.

Stafford, L., Burggarf, C. S., \& Sharkey, W. F. (1987). Conversational memory: The effects of 
time, recall, mode, and memory expectancies on remembrances of natural conversations. Human Communication Research, 14, 203-229. doi:10.1111/j1468-2958.1987.tb00127.x

Starcher, S. C. (2015). Memorable messages from fathers to children through sports:

Perspectives from sons and daughters. Communication Quarterly, 63, 204-220. doi:10.1080/01463373.2015.1012221

Steimel, S. (2013). Communicating with volunteers: Memorable messages and volunteer identification. Communication Research Reports, 30, 12-21. doi:10.1080/08824096.2012.746220

Stohl, C. (1986). The role of memorable messages in the process of organizational socialization. Communication Quarterly, 34, 231-249. doi:10.1080/01463378609369638

Swim, J. K., \& Campbell, B. (2003). Sexism: Attitudes, beliefs, and behaviors. In R. Brown \& S. Gaertner (Eds.), Blackwell handbook of social psychology: Intergroup Processes (pp. 218-237). Oxford, UK: Blackwell.

Toller, P. W., Suter, E. A., \& Trautman, T. C. (2004). Gender role identity and attitudes toward feminism. Sex Roles, 51, 85-90. doi:10.1023/B:SERS.0000032316.71165.45

Tracy, S. J. (2013). Qualitative research methods: Collecting evidence, crafting analysis, communicating impact. Hoboken, NJ: Wiley-Blackwell.

Tracy, S. J., \& Rivera, K. D., (2010). Endorsing equity and applauding stay-at-home moms: How male voices on work-life reveal aversive sexism and flickers of transformation. Management Communication Quarterly, 24, 3-43. doi:10.1177/0893318909352248

Tuck, B., Rolfe, J., \& Adair, V. (1994). Adolescents' attitude towards gender roles within work and its relationship to gender type and parental occupation. Sex Roles, 31, 547-58. doi:10.1007/BF01544279 
Urban, E. L., \& Orbe, M. P. (2010). Identity gaps of contemporary U.S. immigrants:

Acknowledging divergent communicative experiences. Communication Studies, 61, 304320. doi:10.1080/10510971003757147

Vogt, P. W. (2005). Purposive sample. In P. W. Vogt (Ed.), Dictionary of statistics and methodology (p. 253). Thousand Oaks, CA: Sage.

Wadsworth, B. C., Hecht, M. L., \& Jung, E. (2008). The role of identity gaps, discrimination, and acculturation in international students' educational satisfaction in American classrooms. Communication Education, 57, 64-87. doi:10.1080/03634520701668407

Waldron, V. R., Kloeber, D., Goman, C., Piemonte, N., \& Danaher, J. (2014). How parents communicate right and wrong: A study of moral messages recalled by emerging adults. Journal of Family Communication, 14, 374-397. doi:10.1080/15267431.2014.646032

Wang, T. R. (2012). Understanding the memorable messages first-generation college students receive from on-campus mentors. Communication Education, 61, 335-357. doi:10.1080/03634523.2012.691978

Wiggins, V. R. (2014). Mother and adult daughter relationships and the impact on emotional health, self-efficacy, and spiritual well-being. (Unpublished doctoral dissertation). Walden University, Minneapolis, MN.

Williams, A., \& Giles, H. (1996). Intergeneration conversations: Young adults' retrospective accounts. Human Communication Research, 23, 220-250. doi:10.1111/j.1468-2958.1996.tb00393.x

Williams, A., \& Harwood, J. (2004). Intergenerational communication. In J. F. Nussbaum \& J. Coupland (Eds.), Handbook of communication and aging research (2 ${ }^{\text {nd }}$ ed., pp. 115-137). Mahwah, NJ: Erlbaum. 
Williams, A., \& Nussbaum, J. F. (2001). Intergenerational communication across the lifespan. Mahwah, NJ: Erlbaum.

Williams, K., \& Umberson, D. (2004). Marital status, marital transitions, and health: A gendered life course perspective. Journal of Health and Social Behavior 45, 81-98. doi: $10.1177 / 002214650404500106$

Witte, T. H., \& Sherman, M. F. (2002). Silencing the self and feminist identity development. Psychological Reports, 90, 1075-1083. doi:10.2466/PR0.90.3.1075-1083

Yang, N. (2005). Individualism-collectivism in work-family interfaces: A Sino-US comparison. In S. A. Y. Poelmans (Ed.), Work and family: An international research perspective (pp. 287-218). Mahwah, NJ: Erlbaum.

Youniss, J., \& Smollar, J. (1985). Adolescent relations with mothers, fathers, and friends. Chicago, IL: University of Chicago Press. 


\section{Appendix A}

\section{Online Questionnaire - Mother}

I am interested in learning about a memorable message that you received from your mother regarding work/family. For the purpose of this study, the mother you choose to write about can be biological or non-biological and alive or deceased. Either way, please note that you will be reporting on the same person throughout the rest of the survey.

A memorable message is a message that is vividly remembered and believed to have had a large impact on how we behave, the attitudes we hold, and the decisions we make or anticipate making in the future.

A memorable message can be a 'piece of advice' or some 'words of wisdom' you received. In fact, the message may have influenced how you behaved at work, the expectations you created for the organization, the career decisions you made, or what work and family means to you. Please take a moment to reflect on your conversations with your mother. After you have thought about one memorable message from your mother about work/family, please complete this section of the questionnaire about this message.

Please go ahead and write the details of one memorable message you recall your mother giving you about work/family. Be sure to include where the message was communicated and who said what.

1. How confident are you that the wording you provided is the same wording that your mother used in communicating the memorable message to you?

\begin{tabular}{|l|l|c|c|c|}
\hline Very Unconfident & Unconfident & $\begin{array}{c}\text { Neither Unconfident } \\
\text { nor Confident }\end{array}$ & Confident & Very Confident \\
\hline & & & & \\
\hline
\end{tabular}


2. My mother communicated the memorable message to me in a setting. Public Private

3. My mother communicated the memorable message to me in a/an conversation. Formal/planned informal/unplanned

4. Why do you think your mother communicated this memorable message to you?

5. If you had an 18year old daughter, how likely would you be to pass the memorable message on to your daughter?

\begin{tabular}{|l|l|l|l|l|}
\hline Very Likely & Unlikely & Undecided & Likely & Very Likely \\
\hline & & & & \\
\hline
\end{tabular}

Directions: Read each statement carefully and select one of the five answers that best describes your present agreement or disagreement with the statement.

\begin{tabular}{|c|c|c|c|c|c|c|}
\hline 1 & 2 & 3 & 4 & 5 & 6 & 7 \\
\hline $\begin{array}{l}\text { Strongly } \\
\text { disagree }\end{array}$ & Disagree & $\begin{array}{c}\text { Somewhat } \\
\text { Disagree }\end{array}$ & $\begin{array}{c}\text { Neither } \\
\text { Agree nor } \\
\text { Disagree }\end{array}$ & $\begin{array}{c}\text { Somewhat } \\
\text { Agree }\end{array}$ & Agree & $\begin{array}{c}\text { Strongly } \\
\text { Agree }\end{array}$ \\
\hline
\end{tabular}

6.

7. The memorable message is consistent with my mother's lifestyle.

8. The memorable message is consistent with my mother's expectations.

9. The memorable message is consistent with my own personal values. The memorable message is consistent with my mother's actions.

10. The memorable message is consistent with my mother's behavior.

11. The memorable message is consistent with my mother's expressions/sayings.

12. The memorable message is consistent with my mother's attitude. 
13. How if at all, did this memorable message from your mother shape your expectations, and/or values about work/family?

Directions: The following question concern your relationship with your mother. Please select the option that best describes your relationship with your mother.

14. I consider my mother and I to be . (c)
A. very close
B. close
C. somewhat close
D. not very close
E. not close at all

Directions: For the following statements, refer to the scale below and choose the answer that describes you best.

\begin{tabular}{|c|c|c|c|c|}
\hline 1 & 2 & 3 & 4 & 5 \\
\hline Very false & Somewhat false & Maybe & Somewhat true & Very true \\
\hline
\end{tabular}

15. I can share my intimate secrets with my mother. (c)

16. My mother can share her intimate secrets with me. (c)

17. I can share my personal feelings with my mother. (c)

18. My mother can share her personal feelings with me. (c)

19. I can share my opinions and values with my mother. (c)

20. My mother can share her opinions and values with me. (c)

21. If my mother ever needs anything, I help in whatever way I can even if it means making huge sacrifices. (c)

22. If I ever need any kind of help, I do not hesitate to ask my mother for advice. (i)

23. I often depend on my mother for advice. (i)

24. My mother will always love me regardless of what I do. (c)

25. I feel the need to consult my mother when making a hard decision. (i)

Note: statements marked (c) are items on the Connectedness subscale and statements marked $(i)$ are items on the Interdependence subscale 
Directions: The following questions concern actions that either you or your mother engages in to show respect for each other while communicating. Using the scale below, please indicate the extent to which you agree with the following statements.

\begin{tabular}{|c|c|c|c|c|c|c|}
\hline 1 & 2 & 3 & 4 & 5 & 6 & 7 \\
\hline $\begin{array}{c}\text { Strongly } \\
\text { Disagree }\end{array}$ & Disagree & $\begin{array}{c}\text { Somewhat } \\
\text { Disagree }\end{array}$ & $\begin{array}{c}\text { Neither Agree } \\
\text { nor Disagree }\end{array}$ & $\begin{array}{c}\text { Strongly } \\
\text { Agree }\end{array}$ & Agree & $\begin{array}{c}\text { Strongly } \\
\text { Agree }\end{array}$ \\
\hline
\end{tabular}

26. My mother is respectful to me and my opinions

27. In our interactions, my mother takes my views and my opinions into account.

28. I feel respect for my mother's knowledge and wisdom.

29. I avoid certain ways of talking with my mother.*

30 . I don't always say what I think to my mother.*

31. In my interactions with my mother, I don't act like myself.*

Note: *Items were reverse coded.

\section{Directions: I would like you to think about your relationship with your mother over the last month. Please report the number that most closely describes your feelings toward your mother over the past month.}

\begin{tabular}{|r|r|l|l|l|l|l|l|l|l|}
\hline 32. & Miserable: & 1 & 2 & 3 & 4 & 5 & 6 & 7 & $:$ Enjoyable \\
\hline 33. & Hopeful: & 1 & 2 & 3 & 4 & 5 & 6 & 7 & $:$ Discouraging* \\
\hline 34. & Free: & 1 & 2 & 3 & 4 & 5 & 6 & 7 & $:$ Tied Down* \\
\hline 35. & Empty: & 1 & 2 & 3 & 4 & 5 & 6 & 7 & $:$ Full \\
\hline 36. & Interesting: & 1 & 2 & 3 & 4 & 5 & 6 & 7 & $:$ Boring* \\
\hline 37. & Rewarding: & 1 & 2 & 3 & 4 & 5 & 6 & 7 & $:$ Disappointing* \\
\hline 38. & $\begin{array}{r}\text { Doesn't give me } \\
\text { much chance: }\end{array}$ & 1 & 2 & 3 & 4 & 5 & 6 & 7 & $:$ Brings out the best in \\
me
\end{tabular}

Note: *Items were reverse coded. Two items (free-tied down and hard-easy) were dropped to score the measure. 
Directions: Think about conversations you have with your mother about work/family. Using the scale, answer the following questions by indicating the number that best represents your perception of your mother.

\begin{tabular}{|c|c|c|c|c|}
\hline 1 & 2 & 3 & 4 & 5 \\
\hline Not at all & Very little & Some & A good amount & A great deal \\
\hline
\end{tabular}

42. How much do you express your feelings about work/ family to your mother?

43. How personal is the information you disclose about work/family to your mother?

44. How much personal information do you disclose about work/family to your mother?

45. How much of your mother's feelings about work/family does she express to you?

46. How personal is the information about work/family that your mother discloses to you?

47. How much personal information about work/family does your mother disclose to you?

Item 48

Directions: Please select the picture that best describes your current relationship with your mother.
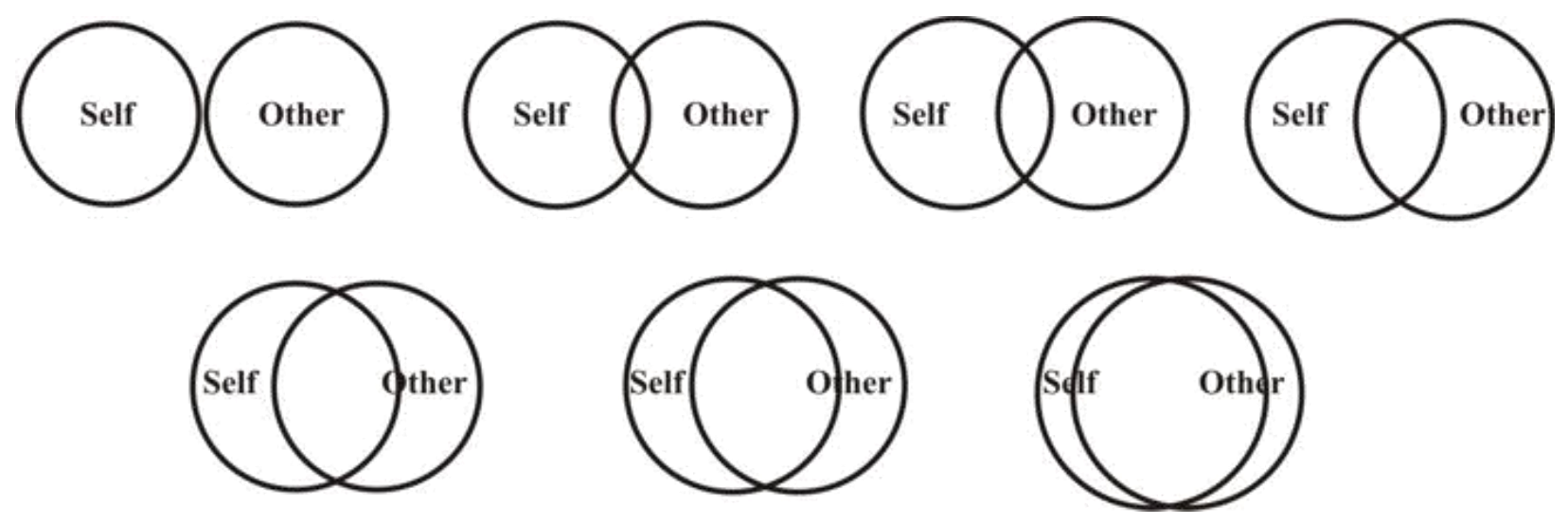
Directions: Read each statement carefully and decide to what degree you think it presently describes you. Using the scale below, record your responses.

\begin{tabular}{|c|c|c|c|c|c|c|}
\hline 1 & 2 & 3 & 4 & 5 & 6 & 7 \\
\hline $\begin{array}{l}\text { Strongly } \\
\text { Disagree }\end{array}$ & Disagree & $\begin{array}{c}\text { Somewhat } \\
\text { Disagree }\end{array}$ & $\begin{array}{c}\text { Neither Agree } \\
\text { nor Disagree }\end{array}$ & $\begin{array}{c}\text { Strongly } \\
\text { Agree }\end{array}$ & Agree & $\begin{array}{c}\text { Strongly } \\
\text { Agree }\end{array}$ \\
\hline
\end{tabular}

49. I don't think there is any need for an Equal Rights Amendment; women are doing well.

50. I I I don't see much point in questioning the general expectation that men should be masculine and women should be feminine.

51. ___ One thing I especially like about being a woman is that men will offer me their seat on a crowded bus or open doors for me because I am a woman.

52. I_ve never really worried or thought about what it means to be a woman in this society.

53. I I do not want to have equal status with men.

54. If_ If I were married and my husband was offered a job in another state, it would be my obligation as his spouse to move in support of his career.

55. __ I think that most women will feel most fulfilled by being a wife and mother.

56. I I think that men and women had it better in the 1950s when married women were housewives and their husbands supported them.

57. Generally, I think that men are more interesting than women.

58._I I I t _ I think that rape is sometimes the woman's fault.

59. I_ I am not sure what is meant by the phrase "women are oppressed under patriarchy."

60. I I think it's lucky that women aren't expected to do some of the more dangerous jobs that men are expected to do, like construction work or race car driving.

61. Men and women are simply not the equals of each other.

62. Men are just more worthy than women.

63. It Is not a problem if men have more of a chance in life than women.

64. If_ If women and men were treated more equally we would have fewer problems in this country.

65. We should try to treat men and women as equals as much as possible (All humans should be treated equally). 
Directions: Read each statement carefully and indicate your agreement with each item.

\begin{tabular}{|c|c|c|c|c|c|c|}
\hline 1 & 2 & 3 & 4 & 5 & 6 & 7 \\
\hline $\begin{array}{c}\text { Strongly } \\
\text { Disagree }\end{array}$ & Disagree & $\begin{array}{c}\text { Somewhat } \\
\text { Disagree }\end{array}$ & $\begin{array}{c}\text { Neither Agree } \\
\text { nor Disagree }\end{array}$ & $\begin{array}{c}\text { Strongly } \\
\text { Agree }\end{array}$ & Agree & $\begin{array}{c}\text { Strongly } \\
\text { Agree }\end{array}$ \\
\hline
\end{tabular}

66. In most ways, my life is close to my ideal.

67. The conditions of my life are excellent.

68. I am satisfied with my life.

69. So far I have gotten the important things I want in life.

70. If I could live my life over, I would change almost nothing.

Directions: The following questions concern your communication with your mother. Using the scale, indicate the extent to which you agree with each of the statements.

\begin{tabular}{|c|c|c|c|c|c|c|}
\hline 1 & 2 & 3 & 4 & 5 & 6 & 7 \\
\hline $\begin{array}{c}\text { Strongly } \\
\text { Disagree }\end{array}$ & Disagree & $\begin{array}{c}\text { Somewhat } \\
\text { Disagree }\end{array}$ & $\begin{array}{c}\text { Neither Agree } \\
\text { nor Disagree }\end{array}$ & $\begin{array}{c}\text { Strongly } \\
\text { Agree }\end{array}$ & Agree & $\begin{array}{c}\text { Strongly } \\
\text { Agree }\end{array}$ \\
\hline
\end{tabular}

71. I feel that my mother sees me as I see myself. *

72. I am different from the way my mother sees me.

73. I agree with how my mother describes me.*

74. I fee 1 that my mother has wrong images of me.

75. I feel that my mother has correct information about me.*

76. I feel that my mother portrays me not based on information provided by myself but information from other sources.

77. I feel that my mother stereotypes me.

78. I fee 1 that my mother does not realize that I have been changing and still portray me based on my past images.

79. I I I fee 1 that my mother knows who I used to be when they portray me.*

80. When my mother talks about me, I often wonder if she talk about me or someone else.

81. I feel that there is no difference between who I think I am and who my mother thinks I am.*

Note: *Items were reverse coded. 
Directions: The following questions concern your communication with your mother. Using the scale, indicate the extent to which you agree with each of the statements.

\begin{tabular}{|c|c|c|c|c|c|c|}
\hline 1 & 2 & 3 & 4 & 5 & 6 & 7 \\
\hline $\begin{array}{l}\text { Strongly } \\
\text { Disagree }\end{array}$ & Disagree & $\begin{array}{c}\text { Somewhat } \\
\text { Disagree }\end{array}$ & $\begin{array}{c}\text { Neither Agree } \\
\text { nor Disagree }\end{array}$ & $\begin{array}{c}\text { Strongly } \\
\text { Agree }\end{array}$ & Agree & $\begin{array}{c}\text { Strongly } \\
\text { Agree }\end{array}$ \\
\hline
\end{tabular}

82. When I communicate with my mother, she gets to know "real me."*

83. I feel that I can communicate with my mother in a way that is consistent with who I really am.*

84. I feel that I can be myself when communicating with my mother.*

85. I express myself in a certain way that is not the real me when communicating with my mother.

86. I do not reveal important aspects of myself in communication with my mother.

87. When communicating with my mother, I often lose sense of who I am.

88. When communicating with my mother, I often lose sense of who I am.

89. I sometimes mislead my mother about who I really am.

90. There is a difference between the real me and the impression I give my mother about me.

91. I speak truthfully to my mother about myself.*

92. I freely express the real me in communication with my mother.*

Note: *Items were reverse coded.

Directions: The following questions are about the mother you reported on in the survey. Please select the appropriate answer.

93. The mother you reported on is

Alive

Deceased

94. I reported on a mother. Biological Non-biological

95. The mother I reported on is years old.

96. Which of the following best describes your mother's relationship status? Single Engaged Married 
Divorced

Widowed

In a long term relationship

Directions: Read each statement carefully and decide to what degree you think it presently describes you. Using the scale below, record your responses.

\begin{tabular}{|c|c|c|c|c|c|c|}
\hline 1 & 2 & 3 & 4 & 5 & 6 & 7 \\
\hline $\begin{array}{l}\text { Strongly } \\
\text { Disagree }\end{array}$ & Disagree & $\begin{array}{c}\text { Somewhat } \\
\text { Disagree }\end{array}$ & $\begin{array}{c}\text { Neither Agree } \\
\text { nor Disagree }\end{array}$ & $\begin{array}{c}\text { Strongly } \\
\text { Agree }\end{array}$ & Agree & $\begin{array}{c}\text { Strongly } \\
\text { Agree }\end{array}$ \\
\hline
\end{tabular}

97. I don't think there is any need for an Equal Rights Amendment; women are doing well.

98. I I I don't see much point in questioning the general expectation that men should be masculine and women should be feminine.

99. One thing I especially like about being a woman is that men will offer me their seat on a crowded bus or open doors for me because I am a woman.

100. I_ve never really worried or thought about what it means to be a woman in this society.

101. I I do not want to have equal status with men.

102. If I were married and my husband was offered a job in another state, it would be my obligation as his spouse to move in support of his career.

103. I think that most women will feel most fulfilled by being a wife and mother.

104. I think that men and women had it better in the 1950s when married women were housewives and their husbands supported them.

105. Generally, I think that men are more interesting than women.

106. I think that rape is sometimes the woman's fault.

107. I am not sure what is meant by the phrase "women are oppressed under patriarchy."

108. I think it's lucky that women aren't expected to do some of the more dangerous jobs that men are expected to do, like construction work or race car driving.

109. Men and women are simply not the equals of each other.

110. Men are just more worthy than women.

111. It is not a problem if men have more of a chance in life than women.

112. If women and men were treated more equally we would have fewer problems in this country.

113. We should try to treat men and women as equals as much as possible (All humans should be treated equally). 


\section{Appendix B}

\section{Online Questionnaire - Father}

I am interested in learning about a memorable message that you received from your father regarding work/family. For the purpose of this study, the father you choose to write about can be biological or non-biological and alive or deceased. Either way, please note that you will be reporting on the same person throughout the rest of the survey.

A memorable message is a message that is vividly remembered and believed to have had a large impact on how we behave, the attitudes we hold, and the decisions we make or anticipate making in the future.

A memorable message can be a 'piece of advice' or some 'words of wisdom' you received. In fact, the message may have influenced how you behaved at work, the expectations you created for the organization, the career decisions you made, or what work and family means to you. Please take a moment to reflect on your conversations with your father. After you have thought about one memorable message from your mother about work/family, please complete this section of the questionnaire about this message.

Please go ahead and write the details of one memorable message you recall your father giving you about work/family. Be sure to include where the message was communicated and who said what.

1. How confident are you that the wording you provided is the same wording that your father used in communicating the memorable message to you?

\begin{tabular}{|l|l|c|c|c|}
\hline Very Unconfident & Unconfident & $\begin{array}{c}\text { Neither Unconfident } \\
\text { nor Confident }\end{array}$ & Confident & Very Confident \\
\hline & & & & \\
\hline
\end{tabular}


2. My father communicated the memorable message to me in a setting. Public Private

3. My father communicated the memorable message to me in a/an conversation. Formal/planned informal/unplanned

4. Why do you think your father communicated this memorable message to you?

5. If you had an 18year old daughter, how likely would you be to pass the memorable message on to your daughter?

\begin{tabular}{|l|l|l|l|l|}
\hline Very Likely & Unlikely & Undecided & Likely & Very Likely \\
\hline & & & & \\
\hline
\end{tabular}

Directions: Read each statement carefully and select one of the five answers that best describes your present agreement or disagreement with the statement.

\begin{tabular}{|c|c|c|c|c|c|c|}
\hline 1 & 2 & 3 & 4 & 5 & 6 & 7 \\
\hline $\begin{array}{c}\text { Strongly } \\
\text { disagree }\end{array}$ & Disagree & $\begin{array}{c}\text { Somewhat } \\
\text { Disagree }\end{array}$ & $\begin{array}{c}\text { Neither } \\
\text { Agree nor } \\
\text { Disagree }\end{array}$ & $\begin{array}{c}\text { Somewhat } \\
\text { Agree }\end{array}$ & Agree & $\begin{array}{c}\text { Strongly } \\
\text { Agree }\end{array}$ \\
\hline
\end{tabular}

6.

7. The memorable message is consistent with my father's lifestyle. The memorable message is consistent with my father's expectations.

8. The memorable message is consistent with my own personal values.

9. The memorable message is consistent with my father's actions.

10. The memorable message is consistent with my father's behavior.

11. The memorable message is consistent with my father's expressions/sayings.

12. The memorable message is consistent with my father's attitude. 
13. How if at all, did this memorable message from your father shape your expectations, and/or values about work/family?

Directions: The following question concern your relationship with your father. Please select the option that best describes your relationship with your father.

14. I consider my father and I to be (c)
A. very close
B. close
C. somewhat close
D. not very close
E. not close at all

Directions: For the following statements, refer to the scale below and choose the answer that describes you best.

\begin{tabular}{|c|c|c|c|c|}
\hline 1 & 2 & 3 & 4 & 5 \\
\hline Very false & Somewhat false & Maybe & Somewhat true & Very true \\
\hline
\end{tabular}

15. I can share my intimate secrets with my father. (c)

16. __ My father can share her intimate secrets with me. (c)

17. I I can share my personal feelings with my father. (c)

18. __ My father can share her personal feelings with me. (c)

19. I I can share my opinions and values with my father. (c)

20. __ My father can share her opinions and values with me. (c)

21. If my father ever needs anything, I help in whatever way I can even if it means making huge sacrifices. (c)

22. ___ If I ever need any kind of help, I do not hesitate to ask my father for advice. (i)

23. I often depend on my father for advice. (i)

24. My father will always love me regardless of what I do. (c)

25 . I feel the need to consult my father when making a hard decision. (i)

Note: statements marked (c) are items on the Connectedness subscale and statements marked $(i)$ are items on the Interdependence subscale 
Directions: The following questions concern actions that either you or your father engages in to show respect for each other while communicating. Using the scale below, please indicate the extent to which you agree with the following statements.

\begin{tabular}{|c|c|c|c|c|}
\hline 1 & 2 & 3 & 4 & 5 \\
\hline Strongly Disagree & Disagree & Neutral & Agree & Strongly Agree \\
\hline
\end{tabular}

26. My father is respectful to me and my opinions

27. In our interactions, my father takes my views and my opinions into account.

28. I feel respect for my father's knowledge and wisdom.

29. I avoid certain ways of talking with my father.*

30. I don't always say what I think to my father.*

31. In my interactions with my father, I don't act like myself.*

Note: *Items were reverse coded.

Directions: I would like you to think about your relationship with your father over the last month. Please report the number that most closely describes your feelings toward your father over the past month.

\begin{tabular}{|r|r|c|c|c|c|c|c|c|l|}
\hline 32. & Miserable: & 1 & 2 & 3 & 4 & 5 & 6 & 7 & $:$ Enjoyable \\
\hline 33. & Hopeful: & 1 & 2 & 3 & 4 & 5 & 6 & 7 & $:$ Discouraging* \\
\hline 34. & Free: & 1 & 2 & 3 & 4 & 5 & 6 & 7 & $:$ Tied Down* \\
\hline 35. & Empty: & 1 & 2 & 3 & 4 & 5 & 6 & 7 & $:$ Full \\
\hline 36. & Interesting: & 1 & 2 & 3 & 4 & 5 & 6 & 7 & $:$ Boring* \\
\hline 37. & Rewarding: & 1 & 2 & 3 & 4 & 5 & 6 & 7 & $:$ Disappointing* \\
\hline 38. & $\begin{array}{r}\text { Doesn't give me } \\
\text { much chance: }\end{array}$ & 1 & 2 & 3 & 4 & 5 & 6 & 7 & $:$ Brings out the best in \\
me
\end{tabular}

Note: *Items were reverse coded. 
Directions: Think about conversations you have with your father about work/family. Using the scale, answer the following questions by indicating the number that best represents your perception of your father.

\begin{tabular}{|c|c|c|c|c|c|c|}
\hline 1 & 2 & 3 & 4 & 5 & 6 & 7 \\
\hline $\begin{array}{c}\text { Strongly } \\
\text { Disagree }\end{array}$ & Disagree & $\begin{array}{c}\text { Somewhat } \\
\text { Disagree }\end{array}$ & $\begin{array}{c}\text { Neither Agree } \\
\text { nor Disagree }\end{array}$ & $\begin{array}{c}\text { Strongly } \\
\text { Agree }\end{array}$ & Agree & $\begin{array}{c}\text { Strongly } \\
\text { Agree }\end{array}$ \\
\hline
\end{tabular}

42. How much do you express your feelings about work/ family to your father?

43. How personal is the information you disclose about work/family to your father?

44. How much personal information do you disclose about work/family to your father?

45. How much of your father's feelings about work/family does he express to you?

46. How personal is the information about work/family that your father discloses to you?

47. How much personal information about work/family does your father disclose to you?

Item 48

Directions: Please select the picture that best describes your current relationship with your father.

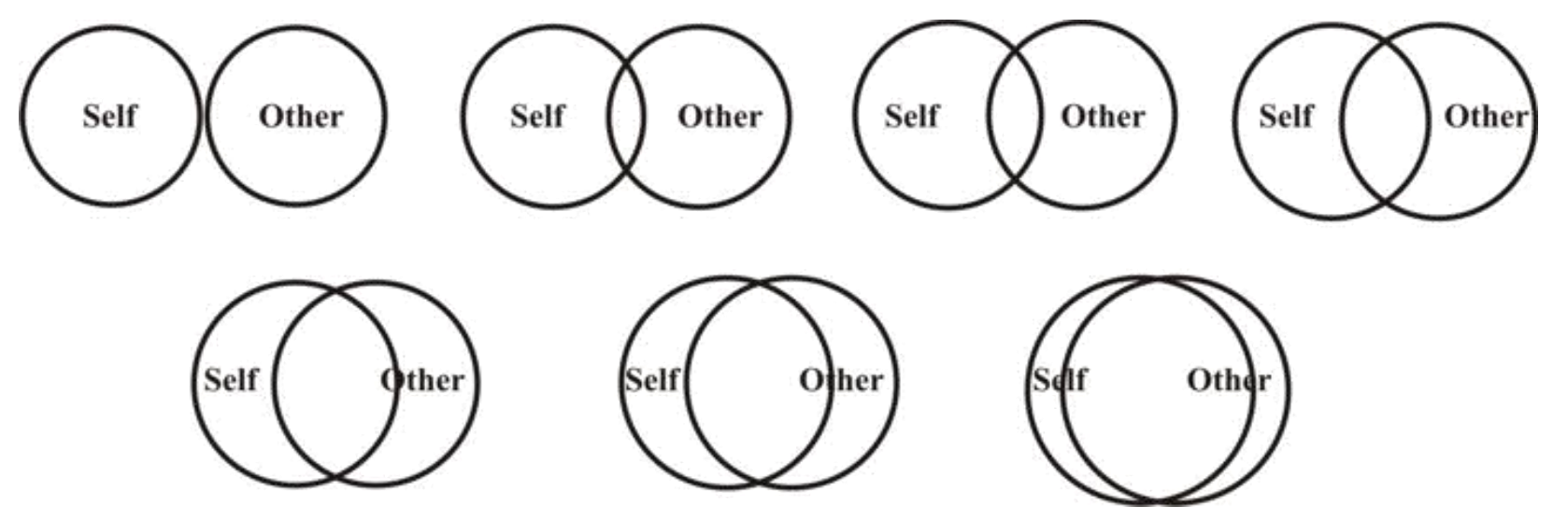


Directions: Read each statement carefully and indicate your agreement with each item.

\begin{tabular}{|c|c|c|c|c|c|c|}
\hline 1 & 2 & 3 & 4 & 5 & 6 & 7 \\
\hline $\begin{array}{c}\text { Strongly } \\
\text { Disagree }\end{array}$ & Disagree & $\begin{array}{c}\text { Somewhat } \\
\text { Disagree }\end{array}$ & $\begin{array}{c}\text { Neither Agree } \\
\text { nor Disagree }\end{array}$ & $\begin{array}{c}\text { Strongly } \\
\text { Agree }\end{array}$ & Agree & $\begin{array}{c}\text { Strongly } \\
\text { Agree }\end{array}$ \\
\hline
\end{tabular}

49. In most ways, my life is close to my ideal.

50 . The conditions of my life are excellent.

51. I am satisfied with my life.

52. So far I have gotten the important things I want in life.

53. If I could live my life over, I would change almost nothing.

Directions: The following questions concern your communication with your father. Using the scale, indicate the extent to which you agree with each of the statements.

\begin{tabular}{|c|c|c|c|c|c|c|}
\hline 1 & 2 & 3 & 4 & 5 & 6 & 7 \\
\hline $\begin{array}{c}\text { Strongly } \\
\text { Disagree }\end{array}$ & Disagree & $\begin{array}{c}\text { Somewhat } \\
\text { Disagree }\end{array}$ & $\begin{array}{c}\text { Neither Agree } \\
\text { nor Disagree }\end{array}$ & $\begin{array}{c}\text { Strongly } \\
\text { Agree }\end{array}$ & Agree & $\begin{array}{c}\text { Strongly } \\
\text { Agree }\end{array}$ \\
\hline
\end{tabular}

54. I feel that my father sees me as I see myself. *

55. I am different from the way my father sees me.

56. I agree with how my father describes me.*

57. I fee 1 that my father has wrong images of me.

58. I feel that my father has correct information about me.*

59. I feel that my father portrays me not based on information provided by myself but information from other sources.

60. I feel that my father stereotypes me.

61. I fee 1 that my father does not realize that I have been changing and still portray me based on my past images.

62. I I f fee 1 that my father knows who I used to be when they portray me.*

63. When my father talks about me, I often wonder if he talk about me or someone else.

64. I feel that there is no difference between who I think I am and who my father thinks I am.*

Note: *Items were reverse coded. 
Directions: The following questions concern your communication with your father. Using the scale, indicate the extent to which you agree with each of the statements.

\begin{tabular}{|c|c|c|c|c|c|c|}
\hline 1 & 2 & 3 & 4 & 5 & 6 & 7 \\
\hline $\begin{array}{c}\text { Strongly } \\
\text { Disagree }\end{array}$ & Disagree & $\begin{array}{c}\text { Somewhat } \\
\text { Disagree }\end{array}$ & $\begin{array}{c}\text { Neither Agree } \\
\text { nor Disagree }\end{array}$ & $\begin{array}{c}\text { Strongly } \\
\text { Agree }\end{array}$ & Agree & $\begin{array}{c}\text { Strongly } \\
\text { Agree }\end{array}$ \\
\hline
\end{tabular}

65. When I communicate with my father, he gets to know "real me."*

66. I feel that I can communicate with my father in a way that is consistent with who I really am.*

67. I feel that I can be myself when communicating with my father.*

68. I express myself in a certain way that is not the real me when communicating with my father.

69. I do not reveal important aspects of myself in communication with my father.

70. When communicating with my father, I often lose sense of who I am.

71. When communicating with my father, I often lose sense of who I am.

72. I sometimes mislead my father about who I really am.

73. There is a difference between the real me and the impression I give my father about me.

74. I speak truthfully to my father about myself.*

75. I freely express the real me in communication with my father.*

Note: *Items were reverse coded.

Directions: The following questions are about the mother you reported on in the survey. Please select the appropriate answer.

76. The mother you reported on is

Alive

Deceased

77. I reported on a mother. Biological Non-biological

78. The mother I reported on is years old.

79. Which of the following best describes your mother's relationship status?

Single

Married

Widowed
Engaged

Divorced

In a long term relationship 


\title{
Appendix C
}

\author{
Paper Questionnaire - Mother
}

\section{Dear Participant,}

You are requested to participate in a study designed to learn about memorable messages regarding work/career and family that young adult daughters receive from their parents. A memorable message is a piece of advice or some words of wisdom you received. In fact, the messages may have influenced your ideas/behavior/expectations about work and family or the career decisions you made. This research study is being conducted by Principal Investigator Christine E. Rittenour, Ph.D. and co-investigator Rita Daniels, PhD Candidate. This research will fulfill requirements toward earning a Ph.D. in Communication Studies for the co-investigator.

Participants of this research project must (a) be female, (b) be at least 18 to 35 years old, (c) have had contact with both mother and father (either biological or non-biological and alive or deceased) to be able to report on their relationship. Participation in this research project consists of completing an online survey that should take approximately $\mathbf{3 0}$ minutes. Please read each question carefully and answer all components of the questions if you can. You can stop completing the questionnaire at any point without fear of penalty.

Your involvement in this project will be kept anonymous. Participation in this study is voluntary. There are no known risks associated with participation in this study. Completing the survey indicates that you have agreed to participate in this study. The study has been approved by West Virginia University Institutional Review Board (\#1508782424). If you would like more information about this research project, please contact Rita Daniels at either (+1) 304-293-3905 or ridaniels@mix.wvu.edu.

Thank you for your participation.

Sincerely,

Christine E. Rittenour, Ph.D.

Associate Professor

Department of Communication Studies

West Virginia University

108 Armstrong Hall

P O Box 6293

Morgantown, WV 26506-6293

Phone: (304) 293-3905

Fax: (304) 293-8667

Christine.Rittenour@mail.wvu.edu

Rita Daniels, M.A.

Ph.D. Candidate/Graduate Teaching Assistant

Department of Communication Studies

West Virginia University 113 Armstrong Hall

Morgantown, WV 26506-6293 
$3 / 24 / 2016$

Qualtrics Survey Software

Phone: (304) 293-3905

Fax: (304) 293-8667

ridaniels@mail.wvu.edu

By continuing with this online survey, you agree to these terms of consent.

Kindly respond to the following demographic questions about you.

How old are you?

years

Which of the following describes your ethnicity/race.

-Black/African American Mative American/American Indian Asian/Pacific Islander

Hispanic/Latino(a) Please specify if not listed White / Caucasian

Which of the following best describes your relationship status?

$$
\text { single }
$$

engriged

married divorced

widowed

in a long term relationship

What is the highest level of education you have completed?

some high school / GED professional certificate some college credits

What is your current employment status? bachelor's degree

- graduate degree (e.g., master's,
$\square$ employed
$\square$ homemaker
O student
D self-employed
out of work but currently looking for work
(1) unable to work
D out of work and not currently looking for work

Which of the following best describes the area in which you live?

urban

- rural

$$
\text { suburban }
$$

https://wvu.qualtrics.com/ControlPanel/Ajax.php?action=GetSurveyPrintPreview 
Which of the following best describes your parent/s (whether biological or non-biological) who are primarily responsible for raising you?
father and father
O mother and father
mother and mother
father
o mother

questions on mothers

I am interested in learning about a memorable message that you received from your mother regarding work/family. For the purpose of this study, the mother you choose to write about can be biological or non-biological and alive or deceased. Either way, please note that you will be reporting on the same person throughout the rest of the survey.

A memorable message is a message that is vividly remembered and believed to have had a large impact on how we behave, the attitudes we hold, and the decisions we make or anticipate making in the future.

A memorable message can be a 'piece of advice' or some 'words of wisdom' you received. In fact, the message may have influenced how you behaved at work, the expectations you created for the organization, the career decisions you made, or what work and family means to you. Please take a moment to reflect on your conversations with your mother. After you have thought about one memorable message from your mother about work/family, please complete this section of the questionnaire about this message.

Please go ahead and write the details of one memorable message you recall your mother giving you about work/family. Be sure to include where the message was communicated and who said what.

\section{Please use the attached sheet on the next page.}

How confident are you that the wording you provided is the same wording that your mother used in communicating the memorable message to you?

\begin{tabular}{|c|c|c|c|c|}
\hline Very Unconfident & Unconfident & $\begin{array}{l}\text { Neither Unconfident nor } \\
\text { Confident }\end{array}$ & Confident & VeryConfident \\
\hline 0 & 0 & 0 & 0 & 0 \\
\hline
\end{tabular}


Please go ahead and write the details of one memorable message you recall your mother giving you about work/family. Be sure to include where the message was communicated and who said what.

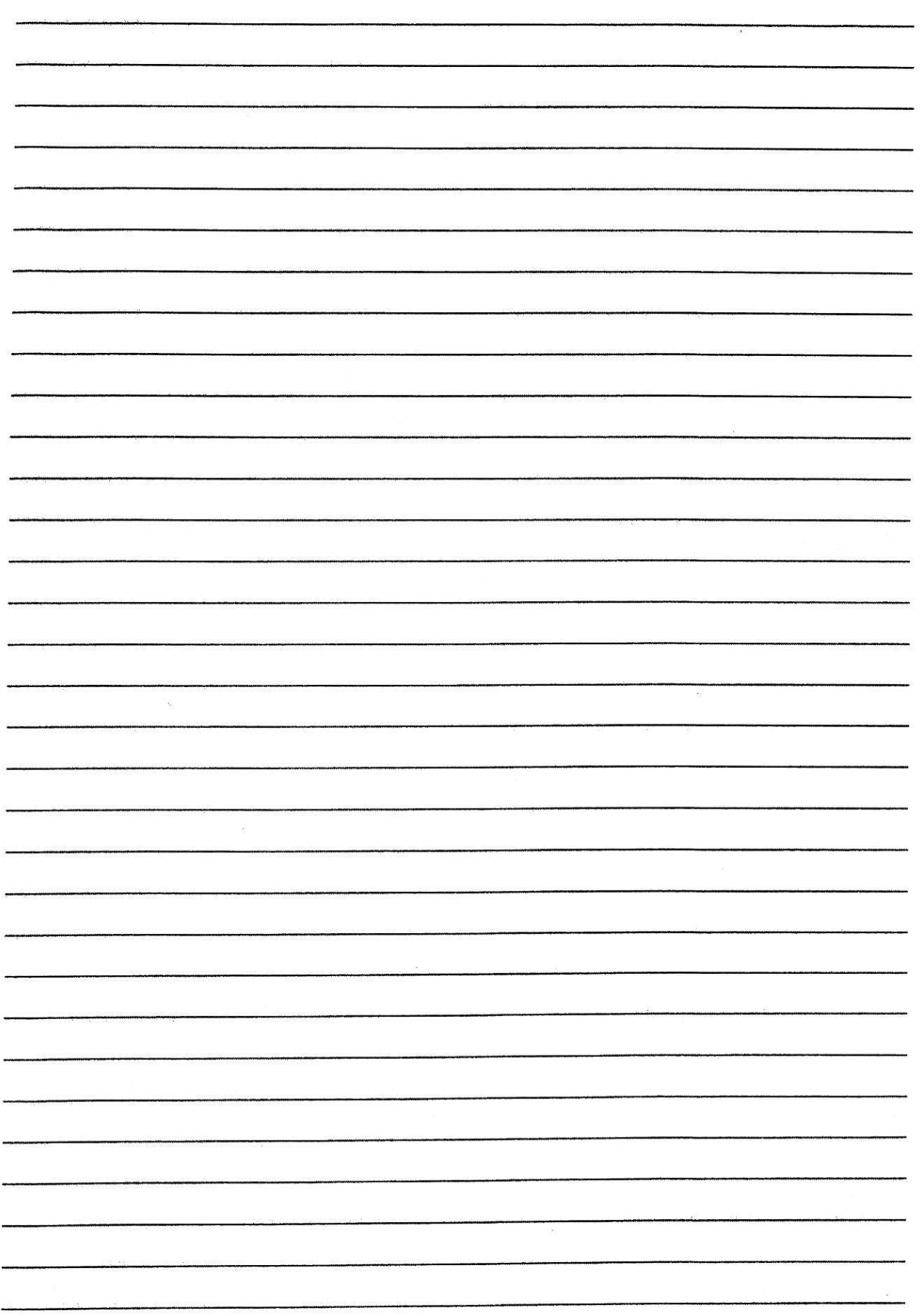


My mother communicated the memorable message to me in a setting.

public private

My mother communicated the memorable message to me in a/an conversation.

- formal/planned informal /unplanned

Why do you think your mother communicated this memorable message to you?

If you had an 18year old daughter, how likely would you be to pass the memorable message on to your daughter?

Very Unlikely

0
Unlikely

0
Undecided

0
Likely

0
Very Likely

0

The memorable message you wrote is consistent with your

\begin{tabular}{l|ccccccc} 
& $\begin{array}{c}\text { Strongly } \\
\text { Disagree }\end{array}$ & Disagree & $\begin{array}{c}\text { Somewhat } \\
\text { Disagree }\end{array}$ & $\begin{array}{c}\text { Neither } \\
\text { Agree nor } \\
\text { Disagree }\end{array}$ & $\begin{array}{c}\text { Somewhat } \\
\text { Agree }\end{array}$ & $\begin{array}{c}\text { Agree } \\
\text { Strongly } \\
\text { Agree }\end{array}$ \\
\hline mother's lifestyle & 0 & 0 & 0 & 0 & 0 & 0 & 0 \\
mother's expectations & 0 & 0 & 0 & 0 & 0 & 0 & 0 \\
own personal values & 0 & 0 & 0 & 0 & 0 & 0 & 0 \\
mother's actions & 0 & 0 & 0 & 0 & 0 & 0 & 0 \\
mother's behavior & 0 & 0 & 0 & 0 & 0 & 0 & 0 \\
mother's expressions/sayings & 0 & 0 & 0 & 0 & 0 & 0 & 0 \\
mother's attitude & 0 & 0 & 0 & 0 & 0 & 0 & 0
\end{tabular}

How if at all, did this memorable message from your mother shape your expectations, and/or values about work/family?

The following question concern your relationship with your mother. Please select the option that best describes your relationship with your mother.

\begin{tabular}{l|ccccc} 
& not close at all & not very close & somewhat close & close & very close \\
\hline $\begin{array}{l}\text { I consider my mother and I to } \\
\text { be }\end{array}$ & 0 & 0 & 0 & 0 & 0
\end{tabular}


For the following statements, refer to the scale below and choose the answer that best describes you.

\begin{tabular}{l|ccccc} 
& Strongly Disagree & Disagree & $\begin{array}{c}\text { Neither Agree nor } \\
\text { Disagree }\end{array}$ & Agree & Strongly Agree \\
\hline \begin{tabular}{l|cccc} 
Ican share my intimate secrets \\
with my mother.
\end{tabular} & 0 & 0 & 0 & 0 & 0 \\
$\begin{array}{l}\text { My mother can share her } \\
\text { intimate secrets with me. }\end{array}$ & 0 & 0 & 0 & 0 & 0 \\
$\begin{array}{l}\text { I can share my personal } \\
\text { feelings with my mother. }\end{array}$ & 0 & 0 & 0 & 0 & 0 \\
$\begin{array}{l}\text { My mother can share her } \\
\text { personal feelings with me. }\end{array}$ & 0 & 0 & 0 & 0 & 0 \\
$\begin{array}{l}\text { I can share my opinions and } \\
\text { values with my mother. }\end{array}$ & 0 & 0 & 0 & 0 & 0 \\
$\begin{array}{l}\text { My mother can share her } \\
\text { opinions and values with me. }\end{array}$ & 0 & 0 & 0 & 0 & 0 \\
$\begin{array}{l}\text { If my mother ever needs } \\
\text { anything, Ihelp in whatever } \\
\text { way I can even if it means } \\
\text { making huge sacrifices. }\end{array}$ & 0 & 0 & 0 & 0 & 0 \\
$\begin{array}{l}\text { If lever need any kind of help, } \\
\text { do nothesitate to ask my } \\
\text { mother for advice. }\end{array}$ & 0 & 0 & 0 & 0 & 0 \\
$\begin{array}{l}\text { loften depend on my mother } \\
\text { for advice. }\end{array}$ & 0 & 0 & 0 & 0 & 0 \\
$\begin{array}{l}\text { My mother will always love me } \\
\text { regardless of what Ido. }\end{array}$ & 0 & 0 & 0 & 0 & 0 \\
$\begin{array}{l}\text { I feel the need to consult my } \\
\text { mother when making a hard } \\
\text { decision. }\end{array}$ & 0 & 0 & 0 & 0 & 0
\end{tabular}

The following questions concern actions that either you or your mother engage in to show respect for each other while communicating. Please refer to the scale below to choose the appropriate answer.

\begin{tabular}{l|ccccccc} 
& $\begin{array}{c}\text { Strongly } \\
\text { Disagree }\end{array}$ & Disagree & $\begin{array}{c}\text { Somewhat } \\
\text { Disagree }\end{array}$ & $\begin{array}{c}\text { Neither } \\
\text { Dgree nor } \\
\text { Disagree }\end{array}$ & $\begin{array}{c}\text { Somewhat } \\
\text { Agree }\end{array}$ & $\begin{array}{c}\text { Agree } \\
\begin{array}{l}\text { Strongly } \\
\text { Agree }\end{array}\end{array}$ \\
\hline $\begin{array}{l}\text { My mother is respectful to me } \\
\text { and my opinions. }\end{array}$ & 0 & 0 & 0 & 0 & 0 & 0 & 0 \\
$\begin{array}{l}\text { In our interactions, my mother } \\
\text { takes my views and my } \\
\text { opinions into account. }\end{array}$ & 0 & 0 & 0 & 0 & 0 & 0 & 0 \\
$\begin{array}{l}\text { I feel respect for my mother's } \\
\text { knowledge and wisdom. }\end{array}$ & 0 & 0 & 0 & 0 & 0 & 0 & 0 \\
$\begin{array}{l}\text { Iavoid certain ways of talking } \\
\text { with my mother. }\end{array}$ & 0 & 0 & 0 & 0 & 0 & 0 & 0 \\
$\begin{array}{l}\text { I don't always say what I think } \\
\text { to my mother. }\end{array}$ & 0 & 0 & 0 & 0 & 0 & 0 & 0 \\
$\begin{array}{l}\text { In my interactions with my } \\
\text { mother, I don't actl like myself. }\end{array}$ & 0 & 0 & 0 & 0 & 0 & 0 & 0
\end{tabular}

I would like you to think about your relationship with your mother over the last month. Please select the bubble closest to the word that best describes your feelings toward your mother over 
the past month.

$$
\begin{array}{r|llllllll}
\text { Miserable } & 0 & 0 & 0 & 0 & 0 & 0 & 0 & \text { Enjoyable } \\
\text { Hopeful } & 0 & 0 & 0 & 0 & 0 & 0 & 0 & \text { Discouraging } \\
\text { Free } & 0 & 0 & 0 & 0 & 0 & 0 & 0 & \text { Tied Down } \\
\text { Empty } & 0 & 0 & 0 & 0 & 0 & 0 & 0 & \text { Full } \\
\text { Interesting } & 0 & 0 & 0 & 0 & 0 & 0 & 0 & \text { Boring } \\
\text { Rewarding } & 0 & 0 & 0 & 0 & 0 & 0 & 0 & \text { Disappointing } \\
\text { Doesn't give me much chance } & 0 & 0 & 0 & 0 & 0 & 0 & 0 & \text { Brings out the best in me } \\
\text { Lonely } & 0 & 0 & 0 & 0 & 0 & 0 & 0 & \text { Friendly } \\
\text { Hard } & 0 & 0 & 0 & 0 & 0 & 0 & 0 & \text { Easy } \\
\text { Worthwhile } & 0 & 0 & 0 & 0 & 0 & 0 & 0 & \text { Useless }
\end{array}
$$

\begin{tabular}{|c|c|c|c|c|c|}
\hline & Not at all & Very little & Some & A good amount & A great deal \\
\hline $\begin{array}{l}\text { How much do you express your } \\
\text { feelings about work/family to } \\
\text { your mother? }\end{array}$ & 0 & 0 & 0 & 0 & 0 \\
\hline $\begin{array}{l}\text { How personal is the } \\
\text { information you disclose about } \\
\text { work/family to your mother? }\end{array}$ & 0 & 0 & 0 & 0 & 0 \\
\hline $\begin{array}{l}\text { How much personal } \\
\text { information do you disclose } \\
\text { about work/family to your } \\
\text { mother? }\end{array}$ & 0 & 0 & 0 & 0 & 0 \\
\hline $\begin{array}{l}\text { How much of your mother's } \\
\text { feelings about work/family does } \\
\text { she express to you? }\end{array}$ & 0 & 0 & 0 & 0 & 0 \\
\hline $\begin{array}{l}\text { How personal is the } \\
\text { information about work/family } \\
\text { that your mother discloses to } \\
\text { you? }\end{array}$ & 0 & 0 & 0 & 0 & 0 \\
\hline $\begin{array}{l}\text { How much personal } \\
\text { information about work/family } \\
\text { does your mother disclose to } \\
\text { you? }\end{array}$ & 0 & 0 & 0 & 0 & 0 \\
\hline
\end{tabular}

Think about conversations you have with your mother about work/family. Using the scale below, answer the following questions by indicating the option that best represents your perception for your mother.

Please click on the picture that best describes your current relationship with your mother. "Self" refers to you and "Other" refers to your mother. Select only one picture. 


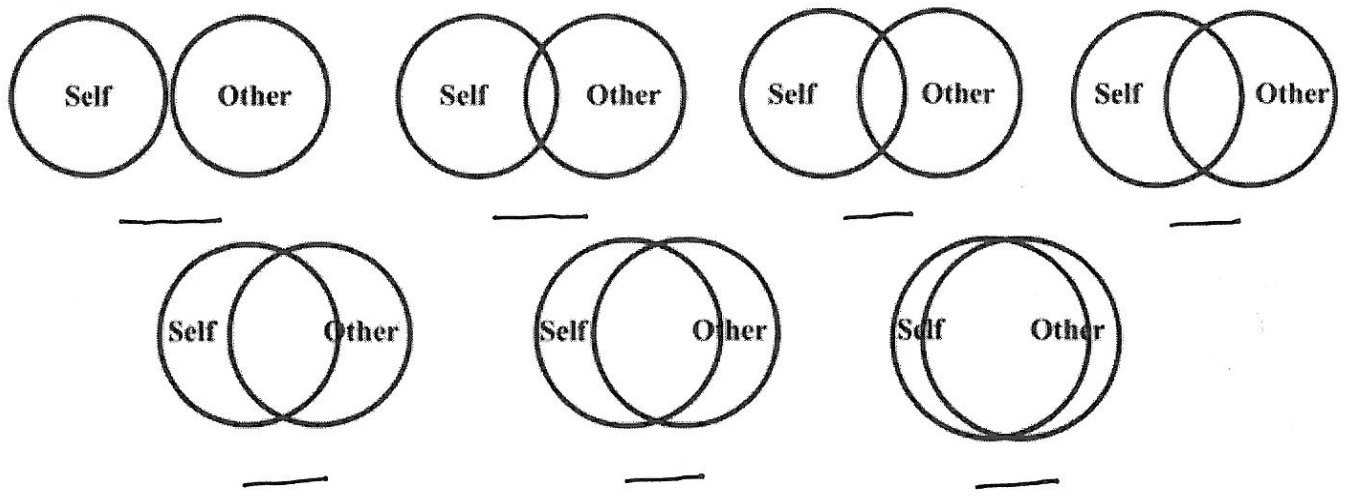

Read each statement carefully and decide to what degree you think it presently describes you. Using the scale below, record your responses.

\begin{tabular}{|c|c|c|c|c|c|c|c|}
\hline & $\begin{array}{l}\text { Strongly } \\
\text { Disagree }\end{array}$ & Disagree & $\begin{array}{l}\text { Somewhat } \\
\text { Disagree }\end{array}$ & $\begin{array}{l}\text { Neither } \\
\text { Agree nor } \\
\text { Disagree }\end{array}$ & $\begin{array}{l}\text { Somewhat } \\
\text { Agree }\end{array}$ & Agree & $\begin{array}{l}\text { Strongly } \\
\text { Agree }\end{array}$ \\
\hline $\begin{array}{l}\text { I don't think there is any need } \\
\text { for an Equal Rights } \\
\text { Amendment; women are doing } \\
\text { well. }\end{array}$ & 0 & 0 & 0 & 0 & 0 & 0 & 0 \\
\hline $\begin{array}{l}\text { I don't see much point in } \\
\text { questioning the general } \\
\text { expectation that men should } \\
\text { be masculine and women } \\
\text { should be feminine. }\end{array}$ & 0 & 0 & 0 & 0 & 0 & 0 & 0 \\
\hline $\begin{array}{l}\text { One thing I especially like } \\
\text { about being a woman is that } \\
\text { men will offer me their seat on } \\
\text { a crowded bus or open doors } \\
\text { for me because I am a woman. }\end{array}$ & 0 & 0 & 0 & 0 & 0 & 0 & 0 \\
\hline $\begin{array}{l}\text { I've never really worried or } \\
\text { thought about what it means to } \\
\text { be a woman in this society. }\end{array}$ & 0 & 0 & 0 & 0 & 0 & 0 & 0 \\
\hline $\begin{array}{l}\text { Ido not want to have equal } \\
\text { status with men. }\end{array}$ & 0 & 0 & 0 & 0 & 0 & 0 & 0 \\
\hline $\begin{array}{l}\text { If I were married and my } \\
\text { husband was offered a job in } \\
\text { another state, it would be my } \\
\text { obligation as his spouse to } \\
\text { move in support of his career. }\end{array}$ & 0 & 0 & 0 & 0 & 0 & 0 & 0 \\
\hline $\begin{array}{l}\text { I think that most women will } \\
\text { feel most fuffliled by being a } \\
\text { wife and mother. }\end{array}$ & 0 & 0 & 0 & 0 & 0 & 0 & 0 \\
\hline $\begin{array}{l}\text { I think that men and women } \\
\text { had it better in the } 1950 \text { s when } \\
\text { married women were } \\
\text { housewives and their } \\
\text { husbands supported them. }\end{array}$ & 0 & 0 & 0 & 0 & 0 & 0 & 0 \\
\hline $\begin{array}{l}\text { Generally, I think that men are } \\
\text { more interesting than women. }\end{array}$ & 0 & 0 & 0 & 0 & 0 & 0 & 0 \\
\hline $\begin{array}{l}\text { Ithink that rape is sometimes } \\
\text { the woman's fault. }\end{array}$ & 0 & 0 & 0 & 0 & 0 & 0 & 0 \\
\hline $\begin{array}{l}\text { lam not sure what is meant by } \\
\text { the phrase "women are } \\
\text { oppressed under patriarchy." }\end{array}$ & 0 & 0 & 0 & 0 & 0 & 0 & 0 \\
\hline I think it's lucky that women & & & & & & & \\
\hline
\end{tabular}


3/24/2016

Qualtrics Survey Software

aren't expected to do some of the more dangerous jobs that men are expected to do, like construction work or race car driving.

Men and women are simply not the equals of each other.

Men are just more worthy than women.

It is not a problem if men have more of a chance in life than

women.

If women and men were treated more equally we would have fewer problems in this country.

We should try to treat men and women as equals as much as possible (All humans should be treated equally).

$\begin{array}{lllllll}0 & 0 & 0 & 0 & 0 & 0 & 0 \\ 0 & 0 & 0 & 0 & 0 & 0 & 0 \\ 0 & 0 & 0 & 0 & 0 & 0 & 0 \\ 0 & 0 & 0 & 0 & 0 & 0 & 0 \\ 0 & 0 & 0 & 0 & 0 & 0 & 0 \\ 0 & 0 & 0 & 0 & 0 & 0 & 0\end{array}$

The following statements pertain to your satisfaction with your current life. Read each statement carefully and indicate your degree of agreement with each statement by selecting the appropriate option.

\begin{tabular}{|c|c|c|c|c|c|c|c|}
\hline & $\begin{array}{l}\text { Strongly } \\
\text { Disagree }\end{array}$ & Disagree & $\begin{array}{l}\text { Somewhat } \\
\text { Disagree }\end{array}$ & $\begin{array}{l}\text { Neither } \\
\text { Agree nor } \\
\text { Disagree }\end{array}$ & $\begin{array}{l}\text { Somewhat } \\
\text { Agree }\end{array}$ & Agree & $\begin{array}{c}\text { Strongly } \\
\text { Agree }\end{array}$ \\
\hline $\begin{array}{l}\text { In most ways, my life is close to } \\
\text { my ideal. }\end{array}$ & 0 & 0 & 0 & 0 & 0 & 0 & 0 \\
\hline $\begin{array}{l}\text { The conditions of my life are } \\
\text { excellent. }\end{array}$ & 0 & 0 & 0 & 0 & 0 & 0 & 0 \\
\hline lam satisfied with my life. & 0 & 0 & 0 & 0 & 0 & 0 & 0 \\
\hline $\begin{array}{l}\text { So far I have gotten the } \\
\text { important things I want in life. }\end{array}$ & 0 & 0 & 0 & 0 & 0 & 0 & 0 \\
\hline $\begin{array}{l}\text { f I could live my life over, I } \\
\text { would change almost nothing. }\end{array}$ & 0 & 0 & 0 & 0 & 0 & 0 & 0 \\
\hline
\end{tabular}

The following questions concern your communication with your mother. Using the scale, please indicate the extent to which you agree with each of the statements.

\begin{tabular}{l|ccccccc} 
& $\begin{array}{c}\text { Strongly } \\
\text { Disagree }\end{array}$ & Disagree & $\begin{array}{c}\text { Somewhat } \\
\text { Disagree }\end{array}$ & $\begin{array}{c}\text { Neither } \\
\text { Agree nor } \\
\text { Disagree }\end{array}$ & $\begin{array}{c}\text { Somewhat } \\
\text { Agree }\end{array}$ & $\begin{array}{c}\text { Agree } \\
\begin{array}{l}\text { Strongly } \\
\text { Agree }\end{array}\end{array}$ \\
\begin{tabular}{l|cccccc} 
If feel that my mother sees me \\
as I see myself.
\end{tabular} & 0 & 0 & 0 & 0 & 0 & 0 & 0 \\
$\begin{array}{l}\text { lam different from the way my } \\
\text { mother sees me. }\end{array}$ & 0 & 0 & 0 & 0 & 0 & 0 & 0 \\
$\begin{array}{l}\text { lagree with how my mother } \\
\text { describes me. }\end{array}$ & 0 & 0 & 0 & 0 & 0 & 0 & 0 \\
$\begin{array}{l}\text { Ifeel that my mother has } \\
\text { wrong images of me. }\end{array}$ & 0 & 0 & 0 & 0 & 0 & 0 & 0 \\
$\begin{array}{l}\text { Ifeel that my mother has } \\
\text { correct information about me. }\end{array}$ & 0 & 0 & 0 & 0 & 0 & 0 & 0 \\
$\begin{array}{l}\text { Ifeel that my mother portrays } \\
\text { me not based on information } \\
\text { provided by myself but } \\
\text { information from other sources. }\end{array}$ & 0 & 0 & 0 & 0 & 0 & 0 & 0
\end{tabular}


3/24/2016

I feel that my mother stereotypes me.

I feel that my mother does not realize that I have been changing and still portrays me based on my past images.

I feel that my mother knows who l used to be when she portrays me.

When my mother talks about me, l often wonder if she is talking about me or someone else.

I feel that there is no difference between who I think I am and who my mother thinks I am.

$\begin{array}{ccccccc}0 & 0 & 0 & 0 & 0 & 0 & 0 \\ 0 & 0 & 0 & 0 & 0 & 0 & 0 \\ 0 & 0 & 0 & 0 & 0 & 0 & 0 \\ 0 & 0 & 0 & 0 & 0 & 0 & 0 \\ 0 & 0 & 0 & 0 & 0 & 0 & 0\end{array}$

The following questions concern your communication with your mother. Using the scale below, indicate the extent to which you agree with each of the statements.

\begin{tabular}{|c|c|c|c|c|c|c|c|}
\hline & $\begin{array}{l}\text { Strongly } \\
\text { Disagree }\end{array}$ & Disagree & $\begin{array}{l}\text { Somewhat } \\
\text { Disagree }\end{array}$ & $\begin{array}{l}\text { Neither } \\
\text { Agree nor } \\
\text { Disagree }\end{array}$ & $\begin{array}{l}\text { Somewhat } \\
\text { Agree }\end{array}$ & Agree & $\begin{array}{l}\text { Strongly } \\
\text { Agree }\end{array}$ \\
\hline $\begin{array}{l}\text { When I communicate with my } \\
\text { mother, she gets to know the } \\
\text { "real me." }\end{array}$ & 0 & 0 & 0 & 0 & 0 & 0 & 0 \\
\hline $\begin{array}{l}\text { I feel that I can communicate } \\
\text { with my mother i a way that is } \\
\text { consistent with who I really am. }\end{array}$ & 0 & 0 & 0 & 0 & 0 & 0 & 0 \\
\hline $\begin{array}{l}\text { I feel that I can be myself when } \\
\text { communicating with my } \\
\text { mother. }\end{array}$ & 0 & 0 & 0 & 0 & 0 & 0 & 0 \\
\hline $\begin{array}{l}\text { lexpress myself in a certain } \\
\text { way that is not the real me } \\
\text { when communicating with my } \\
\text { mother. }\end{array}$ & 0 & 0 & 0 & 0 & 0 & 0 & 0 \\
\hline $\begin{array}{l}\text { I do not reveal important } \\
\text { aspects of myself in } \\
\text { communication with my } \\
\text { mother. }\end{array}$ & 0 & 0 & 0 & 0 & 0 & 0 & 0 \\
\hline $\begin{array}{l}\text { When communicating with my } \\
\text { mother, loften lose sense of } \\
\text { who l am. }\end{array}$ & 0 & 0 & 0 & 0 & 0 & 0 & 0 \\
\hline $\begin{array}{l}\text { I do not express the real me } \\
\text { when I think it is different from } \\
\text { my mother's expectation. }\end{array}$ & 0 & 0 & 0 & 0 & 0 & 0 & 0 \\
\hline $\begin{array}{l}\text { I sometimes mislead my } \\
\text { mother about who I really am. }\end{array}$ & 0 & 0 & 0 & 0 & 0 & 0 & 0 \\
\hline $\begin{array}{l}\text { There is a difference between } \\
\text { the real me and the impression } \\
\text { I give my mother about me. }\end{array}$ & 0 & 0 & 0 & 0 & 0 & 0 & 0 \\
\hline $\begin{array}{l}\text { I speak truthfully to my mother } \\
\text { about myself. }\end{array}$ & 0 & 0 & 0 & 0 & 0 & 0 & 0 \\
\hline $\begin{array}{l}\text { I freely express the real me in } \\
\text { communication with my } \\
\text { mother. }\end{array}$ & 0 & 0 & 0 & 0 & 0 & 0 & 0 \\
\hline
\end{tabular}

The following questions are about the mother you had in mind while completing this survey. Please select the appropriate answers. 


\section{The mother you reported on is}

0 alive

O deceased

I reported on a mother.
O biological
non-biological

The mother I reported on is years old.

Which of the following best describes your mother's relationship status?

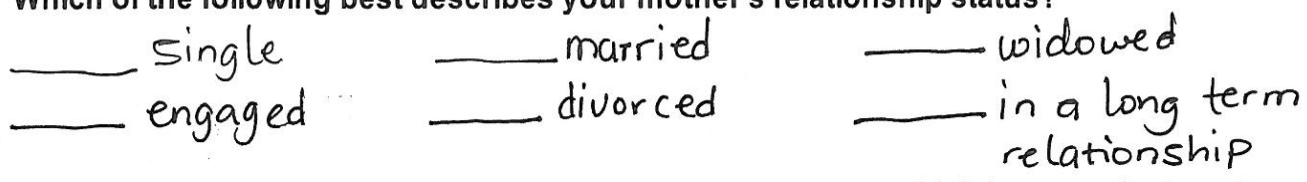

Read each statement carefully and decide to what degree you think it presently describes your mother. Using the scale below, record your responses.

\begin{tabular}{c|ccccc} 
Strongly & Neither & Somewhat Agree nor Somewhat & Som \\
Disagree Disagree & Disagree & Disagree & Agree & Agree & Agree
\end{tabular}

My mother doesn't think there

is any need for an Equal

Rights Amendment; women

are doing well.

My mother doesn't see much point in questioning the

general expectation that men

should be masculine and

women should be feminine.

One thing my mother

especially likes about being a

woman is that men will offer

her their seat on a crowded

bus or open doors for her

because she is a woman

My mother has never really

worried or thought about what

it means to be a woman in this

society.

My mother does not want to have equal status with men.

If my mother were married and her husband were offered a

job in another state, it would

be her obligation as his

spouse to move in support of

$\begin{array}{lllllll}0 & 0 & 0 & 0 & 0 & 0 & 0 \\ 0 & 0 & 0 & 0 & 0 & 0 & 0 \\ 0 & 0 & 0 & 0 & 0 & 0 & 0 \\ 0 & 0 & 0 & 0 & 0 & 0 & 0 \\ 0 & 0 & 0 & 0 & 0 & 0 & 0 \\ 0 & 0 & 0 & 0 & 0 & 0 & 0\end{array}$


158

3/24/2016

his career.

My mother thinks that most women will feel most fulfilled by being a wife and mother.

My mother thinks that men and women had it better in the 1950 s when married women were housewives and their husbands supported them.

Generally, my mother thinks that men are more interesting than women.

My mother thinks that rape is sometimes the woman's fault.

My mother is not sure what is meant by the phrase "women are oppressed under patriarchy."

My mother thinks it's lucky that women aren't expected to do some of the more dangerous jobs that men are expected to do, like construction work or race car driving.

My mother thinks men and women are simply not the equals of each other.

My mother thinks men are just more worthy than women.

My mother thinks it is not a problem if men have more of a chance in life than women.

My mother thinks that if men and women were treated more equally we would have fewer problems in this country.

My mother thinks we should try to treat men and women as equals as much as possible (All humans should be treated equally).
Qualtrics Survey Software

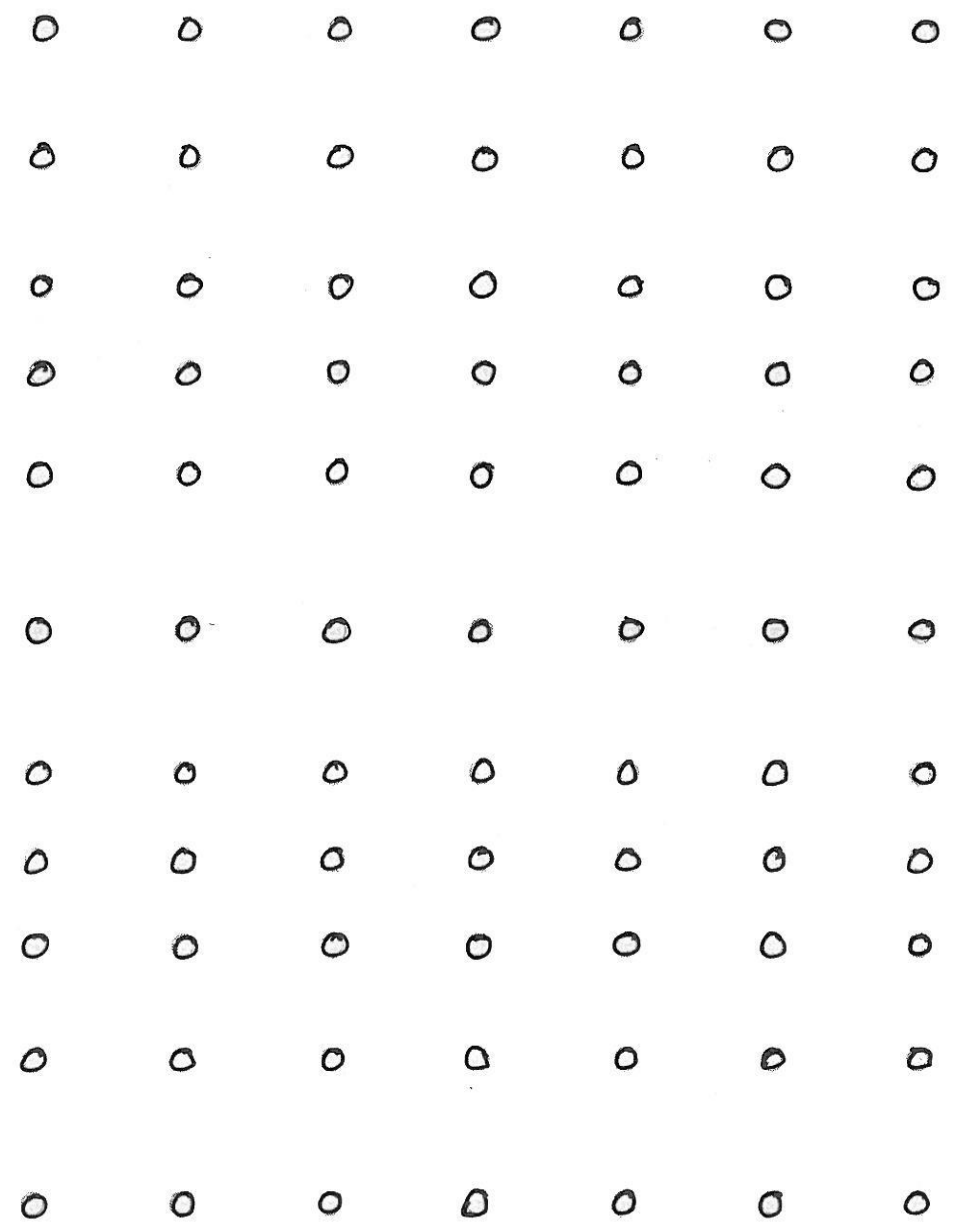

https://wvu.qualtrics.com/ControlPanel/Ajax.php?action=GetSurveyPrintPreview

$11 / 17$ 


\section{Appendix D}

Paper Questionnaire - Father

\section{Dear Participant,}

You are requested to participate in a study designed to learn about memorable messages regarding work/career and family that young adult daughters receive from their parents. A memorable message is a piece of advice or some words of wisdom you received. In fact, the messages may have influenced your ideas/behavior/expectations about work and family or the career decisions you made. This research study is being conducted by Principal Investigator Christine E. Rittenour, Ph.D. and co-investigator Rita Daniels, PhD Candidate. This research will fulfill requirements toward earning a Ph.D. in Communication Studies for the co-investigator.

Participants of this research project must (a) be female, (b) be at least 18 to 35 years old, (c) have had contact with both mother and father (either biological or non-biological and alive or deceased) to be able to report on their relationship. Participation in this research project consists of completing an online survey that should take approximately $\mathbf{3 0}$ minutes. Please read each question carefully and answer all components of the questions if you can. You can stop completing the questionnaire at any point without fear of penalty.

Your involvement in this project will be kept anonymous. Participation in this study is voluntary. There are no known risks associated with participation in this study. Completing the survey indicates that you have agreed to participate in this study. The study has been approved by West Virginia University Institutional Review Board (\#1508782424). If you would like more information about this research project, please contact Rita Daniels at either (+1) 304-293-3905 or ridaniels@mix.wvu.edu.

Thank you for your participation.

Sincerely,

Christine E. Rittenour, Ph.D.

Associate Professor

Department of Communication Studies

West Virginia University

108 Armstrong Hall

PO Box 6293

Morgantown, WV 26506-6293

Phone: (304) 293-3905

Fax: (304) 293-8667

Christine.Rittenour@mail.wvu.edu

Rita Daniels, M.A.

Ph.D. Candidate/Graduate Teaching Assistant

Department of Communication Studies

West Virginia University 113 Armstrong Hall

Morgantown, WV 26506-6293 
Phone: (304) 293-3905

Fax: (304) 293-8667

ridaniels@mail.wvu.edu

By continuing with this online survey, you agree to these terms of consent.

Kindly respond to the following demographic questions about you.

How old are you?

years

Which of the following describes your ethnicity/race.

Black/African American Asian / Pacific Islander Native American/American Hispanic/Latino(a) Please specify if not listed

Which of the following best describes your relationship status? single divorced engaged widowed married in a long term relationship

What is the highest level of education you have completed? some high school /GED bachelor's degree - professional certificate some college credits What is your current employment status?

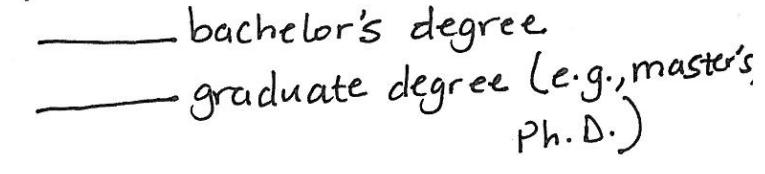
口 employed
$\square$ homemaker
D student
D self-employed
$\square$ out of work but currently looking for work
$\square$ unable to work
$\square$ out of work and not currently looking for work

Which of the following best describes the area in which you live? urban rural suburban 
Which of the following best describes your parent/s (whether biological or non-biological) who are primarily responsible for raising you?
father and father
mother and father
mother and mother
O father
mother

questions on $f$ athers

I am interested in learning about a memorable message that you received from your father regarding work/family. For the purpose of this study, the father you choose to write about can be biological or non-biological and alive or deceased. Either way, please note that you will be reporting on the same person throughout the rest of the survey.

A memorable message is a message that is vividly remembered and believed to have had a large impact on how we behave, the attitudes we hold, and the decisions we make or anticipate making in the future.

A memorable message can be a 'piece of advice' or some 'words of wisdom' you received. In fact, the message may have influenced how you behaved at work, the expectations you created for the organization, the career decisions you made, or what work and family means to you. Please take a moment to reflect on your conversations with your father. After you have thought about one memorable message from your father about work/family, please complete this section of the questionnaire about this message.

Please go ahead and write the details of one memorable message you recall your father giving you about work/family. Be sure to include where the message was communicated and who said what.

Please use the attached sheet on the next page. 
Please go ahead and write the details of one memorable message you recall your fother giving you about work/family. Be sure to include where the message was communicated and who said what. 
How confident are you that the wording you provided is the same wording that your father used in communicating the memorable message to you?

$\begin{array}{ccccc}\text { Very Unconfident } & \text { Unconfident } & \text { Neither Unconfident nor } & & \\ \text { Confident } & \text { Confident } & \text { VeryConfident }\end{array}$

My father communicated the memorable message to me in a setting.<smiles>CCN[PH](C)(C)C</smiles>

My father communicated the memorable message to me in a/an conversation. formal/planned
informal / unplanned

Why do you think your father communicated this memorable message to you?

If you had an 18year old daughter, how likely would you be to pass the message on to your daughter?

$\begin{array}{ccccc}\text { Very Unlikely } & \text { Unlikely } & \text { Undecided } & \text { Likely } & \text { Very Likely } \\ 0 & 0 & 0 & 0 & 0\end{array}$

The memorable message you wrote is consistent with your 
$3 / 24 / 2016$

Qualtrics Survey Sottware

\begin{tabular}{l|ccccccc} 
& $\begin{array}{c}\text { Strongly } \\
\text { Disagree }\end{array}$ & Disagree & $\begin{array}{c}\text { Somewhat } \\
\text { Disagree }\end{array}$ & $\begin{array}{c}\text { Neither } \\
\text { Dgree nor }\end{array}$ & $\begin{array}{c}\text { Somewhat } \\
\text { Disagree }\end{array}$ & $\begin{array}{c}\text { Agree } \\
\text { Agree }\end{array}$ \\
\hline father's lifestyle & 0 & 0 & 0 & 0 & 0 & 0 & 0 \\
father's expectations & 0 & 0 & 0 & 0 & 0 & 0 & 0 \\
own personal values & 0 & 0 & 0 & 0 & 0 & 0 & 0 \\
father's actions & 0 & 0 & 0 & 0 & 0 & 0 & 0 \\
father's behavior & 0 & 0 & 0 & 0 & 0 & 0 & 0 \\
father's expressions/sayings & 0 & 0 & 0 & 0 & 0 & 0 & 0 \\
father's attitude & 0 & 0 & 0 & 0 & 0 & 0 & 0
\end{tabular}

How if at all, did this memorable message from your father shape your expectations, and/or values about work/family?

The following question concerns your relationship with your father. Please select the option that best describes your relationship with your father.

\begin{tabular}{l|ccccc} 
& not close at all & not very close & somewhat close & close & very close \\
\hline I consider my father and I to be & 0 & 0 & 0 & 0 & 0
\end{tabular}

For the following statements, refer to the scale below and choose the answer that best describes you.

\begin{tabular}{l|ccccc} 
& Strongly Disagree & Disagree & $\begin{array}{c}\text { Neither Agree nor } \\
\text { Disagree }\end{array}$ & Agree & Strongly Agree \\
\hline \begin{tabular}{l|cccc} 
I can share my intimate secrets \\
with my father.
\end{tabular} & 0 & 0 & 0 & 0 & 0 \\
$\begin{array}{l}\text { My father can share his } \\
\text { intimate secrets with me. }\end{array}$ & 0 & 0 & 0 & 0 & 0 \\
$\begin{array}{l}\text { I can share my personal } \\
\text { feelings with my father. }\end{array}$ & 0 & 0 & 0 & 0 & 0 \\
$\begin{array}{l}\text { My father can share his } \\
\text { personal feelings with me. }\end{array}$ & 0 & 0 & 0 & 0 & 0 \\
$\begin{array}{l}\text { I can share my opinions and } \\
\text { values with my father. }\end{array}$ & 0 & 0 & 0 & 0 & 0 \\
$\begin{array}{l}\text { My father can share his } \\
\text { opinions and values with me. }\end{array}$ & 0 & 0 & 0 & 0 & 0 \\
$\begin{array}{l}\text { If my father ever needs } \\
\text { anything, Inelp in whatever } \\
\text { way I can even if it means } \\
\text { making huge sacrifices. }\end{array}$ & 0 & 0 & 0 & 0 & 0 \\
$\begin{array}{l}\text { Ifl lever need any kind of help, } \\
\text { do not hesitate to ask my father } \\
\text { for advice. }\end{array}$ & 0 & 0 & 0 & 0 & 0 \\
$\begin{array}{l}\text { lofien depend on my father for } \\
\text { advice. }\end{array}$ & 0 & 0 & 0 & 0 & 0 \\
$\begin{array}{l}\text { My father will always love me } \\
\text { regardless of whatl do. }\end{array}$ & 0 & 0 & 0 & 0 & 0
\end{tabular}


3/24/2016

I feel the need to consult my father when making a hard

Qualtrics Survey Software

$$
\text { decision. }
$$

0

0

0

0

The following questions concern actions that either you or your father engage in to show respect for each other while communicating. Please refer to the scale below to choose the

\begin{tabular}{|c|c|c|c|c|c|c|c|}
\hline & $\begin{array}{l}\text { Strongly } \\
\text { Disagree }\end{array}$ & Disagree & $\begin{array}{l}\text { Somewhat } \\
\text { Disagree }\end{array}$ & $\begin{array}{l}\text { Neither } \\
\text { Agree nor } \\
\text { Disagree }\end{array}$ & $\begin{array}{l}\text { Somewhat } \\
\text { Agree }\end{array}$ & Agree & $\begin{array}{l}\text { Strongly } \\
\text { Agree }\end{array}$ \\
\hline $\begin{array}{l}\text { My father is respectful to me } \\
\text { and my opinions. }\end{array}$ & 0 & 0 & 0 & 0 & 0 & 0 & 0 \\
\hline $\begin{array}{l}\text { In our interactions, my father } \\
\text { takes my views and my } \\
\text { opinions into account. }\end{array}$ & 0 & 0 & 0 & 0 & 0 & 0 & 0 \\
\hline $\begin{array}{l}\text { I feel respect for my father's } \\
\text { knowledge and wisdom. }\end{array}$ & 0 & 0 & 0 & 0 & 0 & 0 & 0 \\
\hline $\begin{array}{l}\text { I avoid certain ways of talking } \\
\text { with my father. }\end{array}$ & 0 & 0 & 0 & 0 & 0 & 0 & 0 \\
\hline $\begin{array}{l}\text { I don't always say what I think } \\
\text { to my father. }\end{array}$ & 0 & 0 & 0 & 0 & 0 & 0 & 0 \\
\hline $\begin{array}{l}\text { In my interactions with my } \\
\text { father, I don't act like myself. }\end{array}$ & 0 & 0 & 0 & 0 & 0 & 0 & 0 \\
\hline
\end{tabular}
appropriate answer.

I would like you to think about your relationship with your father over the last month. Please select the bubble closest to the word that best describes your feelings toward your father over the past month.

\begin{tabular}{r|lllllll|l} 
Miserable & 0 & 0 & 0 & 0 & 0 & 0 & 0 & Enjoyable \\
Hopeful & 0 & 0 & 0 & 0 & 0 & 0 & 0 & Discouraging \\
Free & 0 & 0 & 0 & 0 & 0 & 0 & 0 & Tied down \\
Empty & 0 & 0 & 0 & 0 & 0 & 0 & 0 & Full \\
Interesting & 0 & 0 & 0 & 0 & 0 & 0 & 0 & Boring \\
Rewarding & 0 & 0 & 0 & 0 & 0 & 0 & 0 & Disappointing \\
Doesn't give me much chance & 0 & 0 & 0 & 0 & 0 & 0 & 0 & Brings out the best in me \\
Lonely & 0 & 0 & 0 & 0 & 0 & 0 & 0 & Friendly \\
Hard & 0 & 0 & 0 & 0 & 0 & 0 & 0 & Easy \\
Worthwhile & 0 & 0 & 0 & 0 & 0 & 0 & 0 & Useless
\end{tabular}

Think about conversations you have with your father about work/family. Using the scale below, answer the following questions by indicating the option that best represents your perception for

\begin{tabular}{|c|c|c|c|c|c|}
\hline & Not at all & Very little & Some & A good amount & A great deal \\
\hline $\begin{array}{l}\text { How much do you express your } \\
\text { feelings about work/family to } \\
\text { your father? }\end{array}$ & 0 & 0 & 0 & 0 & 0 \\
\hline $\begin{array}{l}\text { How personal is the } \\
\text { information you disclose about } \\
\text { work/family to your father? }\end{array}$ & 0 & 0 & 0 & 0 & 0 \\
\hline $\begin{array}{l}\text { How much personal } \\
\text { information do you disclose } \\
\text { about work/family to your }\end{array}$ & 0 & 0 & 0 & 0 & 0 \\
\hline
\end{tabular}
your father. 


\section{father?}

How much of your father's feelings about work/family does he express to you?

How personal is the information about work/family that your father discloses to you?

How much personal information about work/family does your father disclose to you?
0
0
0
0
0
o
0
0
0
0
0
0
0
0
0

Please click on the picture that best describes your current relationship with your father. "Self" refers to you and "Other" refers to your father. Select only one picture.
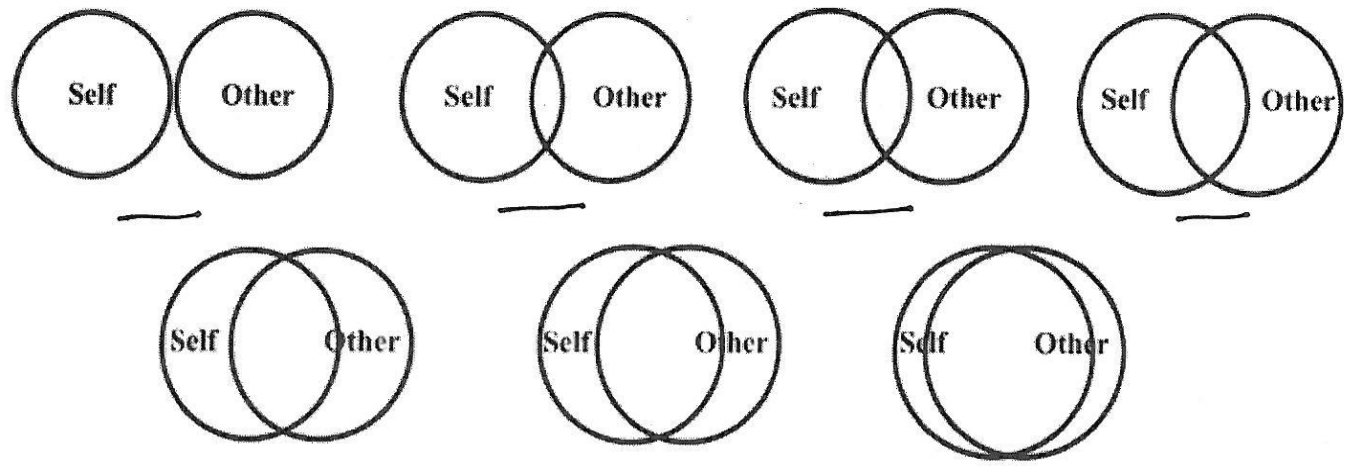

The following statements pertain to your satisfaction with your current life. Read each statement carefully and indicate your agreement with each statement by selecting the appropriate option.

\begin{tabular}{|c|c|c|c|c|c|c|c|}
\hline & $\begin{array}{l}\text { Strongly } \\
\text { Disagree }\end{array}$ & Disagree & $\begin{array}{l}\text { Somewhat } \\
\text { Disagree }\end{array}$ & $\begin{array}{c}\text { Neither } \\
\text { Agree nor } \\
\text { Disagree }\end{array}$ & $\begin{array}{l}\text { Somewhat } \\
\text { Agree }\end{array}$ & Agree & $\begin{array}{l}\text { Strongly } \\
\text { Agree }\end{array}$ \\
\hline $\begin{array}{l}\text { In most ways, my life is close to } \\
\text { my ideal. }\end{array}$ & 0 & 0 & 0 & 0 & 0 & 0 & 0 \\
\hline $\begin{array}{l}\text { The conditions of my life are } \\
\text { excellent. }\end{array}$ & 0 & 0 & 0 & 0 & 0 & 0 & 0 \\
\hline lam satisfied with my life. & 0 & 0 & 0 & 0 & 0 & 0 & 0 \\
\hline $\begin{array}{l}\text { So far I have gotten the } \\
\text { important things I want in life. }\end{array}$ & 0 & 0 & 0 & 0 & 0 & 0 & 0 \\
\hline $\begin{array}{l}\text { If I could live my life over, I } \\
\text { would change almost nothing. }\end{array}$ & 0 & 0 & 0 & 0 & 0 & 0 & 0 \\
\hline
\end{tabular}

The following questions concern your communication with your father. Using the scale, please indicate the extent to which you agree with each of the statements.

\begin{tabular}{|c|c|c|c|c|c|c|c|}
\hline & $\begin{array}{l}\text { Strongly } \\
\text { Disagree }\end{array}$ & Disagree & $\begin{array}{l}\text { Somewhat } \\
\text { Disagree }\end{array}$ & $\begin{array}{l}\text { Neither } \\
\text { Agree nor } \\
\text { Disagree }\end{array}$ & $\begin{array}{c}\text { Somewhat } \\
\text { Agree }\end{array}$ & Agree & $\begin{array}{l}\text { Strongly } \\
\text { Agree }\end{array}$ \\
\hline $\begin{array}{l}\text { I feel that my father sees me as } \\
\text { I see myself. }\end{array}$ & 0 & 0 & 0 & 0 & 0 & 0 & 0 \\
\hline $\begin{array}{l}\text { I am different from the way my } \\
\text { father sees me. }\end{array}$ & 0 & 0 & 0 & 0 & 0 & 0 & 0 \\
\hline
\end{tabular}


3/24/2016 describes me.

I feel that my father has wrong images of me.

I feel that my father has correct information about me.

I feel that my father portrays me not based on information provided by myself but information from other sources.

I feel that my father stereotypes me.

I feel that my father does not realize that I have been changing and still portrays me based on my past images.

I feel that my father knows who I used to be when he portrays me.

When my father talks about me, I often wonder if he is

talking about me or someone

else.

I feel that there is no difference between who I think I am and who my father thinks I am.
I agree with how my father

Qualtrics Survey Software

$\begin{array}{lllllll}0 & 0 & 0 & 0 & 0 & 0 & 0 \\ 0 & 0 & 0 & 0 & 0 & 0 & 0 \\ 0 & 0 & 0 & 0 & 0 & 0 & 0 \\ 0 & 0 & 0 & 0 & 0 & 0 & 0 \\ 0 & 0 & 0 & 0 & 0 & 0 & 0 \\ 0 & 0 & 0 & 0 & 0 & 0 & 0 \\ 0 & 0 & 0 & 0 & 0 & 0 & 0 \\ 0 & 0 & 0 & 0 & 0 & 0 & 0 \\ 0 & 0 & 0 & 0 & 0 & 0 & 0\end{array}$

The following questions concern your communication with your father. Using the scale, please indicate the extent to which you agree with each of the statements.

\begin{tabular}{|c|c|c|c|c|c|c|c|}
\hline & $\begin{array}{l}\text { Strongly } \\
\text { Disagree }\end{array}$ & Disagree & $\begin{array}{l}\text { Somewhat } \\
\text { Disagree }\end{array}$ & $\begin{array}{l}\text { Neither } \\
\text { Agree nor } \\
\text { Disagree }\end{array}$ & $\begin{array}{l}\text { Somewhat } \\
\text { Agree }\end{array}$ & Agree & $\begin{array}{l}\text { Strongly } \\
\text { Agree }\end{array}$ \\
\hline $\begin{array}{l}\text { When I communicate with my } \\
\text { father, he gets to know the } \\
\text { "real me." }\end{array}$ & 0 & 0 & 0 & 0 & 0 & 0 & 0 \\
\hline $\begin{array}{l}\text { I feel that I can communicate } \\
\text { with my father in a way that is } \\
\text { consistent with who I really am. }\end{array}$ & 0 & 0 & 0 & 0 & 0 & 0 & 0 \\
\hline $\begin{array}{l}\text { I feel that I can be myself when } \\
\text { communicating with my father. }\end{array}$ & 0 & 0 & 0 & 0 & 0 & 0 & 0 \\
\hline $\begin{array}{l}\text { lexpress myself in a certain } \\
\text { way that is not the real me } \\
\text { when communicating with my } \\
\text { father. }\end{array}$ & 0 & 0 & 0 & 0 & 0 & 0 & 0 \\
\hline $\begin{array}{l}\text { Ido not reveal important } \\
\text { aspects of myself in } \\
\text { communication with my father. }\end{array}$ & 0 & 0 & 0 & 0 & 0 & 0 & 0 \\
\hline $\begin{array}{l}\text { When communicating with my } \\
\text { father, Ioften lose sense of } \\
\text { who lam. }\end{array}$ & 0 & 0 & 0 & 0 & 0 & 0 & 0 \\
\hline $\begin{array}{l}\text { I do not express the real me } \\
\text { when I think it is different from } \\
\text { my father's expectation. }\end{array}$ & 0 & 0 & 0 & 0 & 0 & 0 & 0 \\
\hline $\begin{array}{l}\text { I sometimes mislead my father } \\
\text { about who I really am. }\end{array}$ & 0 & 0 & 0 & 0 & 0 & 0 & 0 \\
\hline $\begin{array}{l}\text { There is a difference between } \\
\text { the real me and the impression } \\
\text { I give my father about me. }\end{array}$ & 0 & 0 & 0 & 0 & 0 & 0 & 0 \\
\hline I speak truthfully to my father & 0 & 0 & 0 & 0 & 0 & 0 & 0 \\
\hline
\end{tabular}




\section{Appendix E}

\section{IRB-Approved Recruitment Script}

\section{Female Young Adults (18-35years old) Needed for Research Participation}

Dear participant,

You are requested to participate in a study designed to learn about work and family messages that young adult daughters receive from their parents. This research study is being conducted by Principal Investigator Christine E. Rittenour, Ph.D. and co-investigator Rita Daniels, Ph.D. candidate. This research will fulfill requirements toward earning a Ph.D. in Communication Studies for the co-investigator.

To qualify for participation, you must (a) be female, (b) be at least 18 to 35 years old and, (c) have had contact with either mother or father (either biological or non-biological and alive or deceased) to be able to report on their relationship. Participation in this research project consists of completing an online survey that should take approximately 30 minutes. The study has been approved by West Virginia University Institutional Review Board (\#1508782424).

To participate in this study, kindly send an email to ridaniels@mix.wvu.edu requesting participation. Your subject line for the email should read: research. A link to the online survey will be sent to you. If you do not fit the criteria, you may recruit a participant.

Thank you for your participation.

Sincerely,

Christine E. Rittenour, Ph.D.

Rita Daniels, M.A.

Associate Professor

Ph.D. Candidate 


\section{Appendix F}

\section{Participants’ Demographic Questions}

1. How old are you?

2. Which of the following describes your ethnicity/race?

Black/African America

Asian/Pacific Islander

Hispanic/Latino(a)

Native America/American Indian

White/Caucasian

Please specify if not listed

3. Which of the following best describes your relationship status?

Single
Engaged
Married
Divorced
Widowed
In a long term relationship

4. What is the highest level of education you have completed?

Some high school/GED

Professional certificate

Some college credits

Bachelor's degree

Graduate degree (e.g., Master's, Ph.D.)

5. What is your current employment status?

\section{Employed}

Homemaker

Student

Self-employed

Out of work but currently looking for work retired

Unable to work

Out of work and not currently looking for work 
6. Which of the following best describes the area in which you live?

Urban

rural

suburban

7. Which of the following best describes your parent/s (whether biological or non-biological) who are primarily responsible for raising you?

Father and father

Mother and father

Mother and mother

Father

Mother 


\section{Appendix G}

Journal

\section{$\underline{3 / 9 / 2016 ~ 12: 08 ~ P M}$}

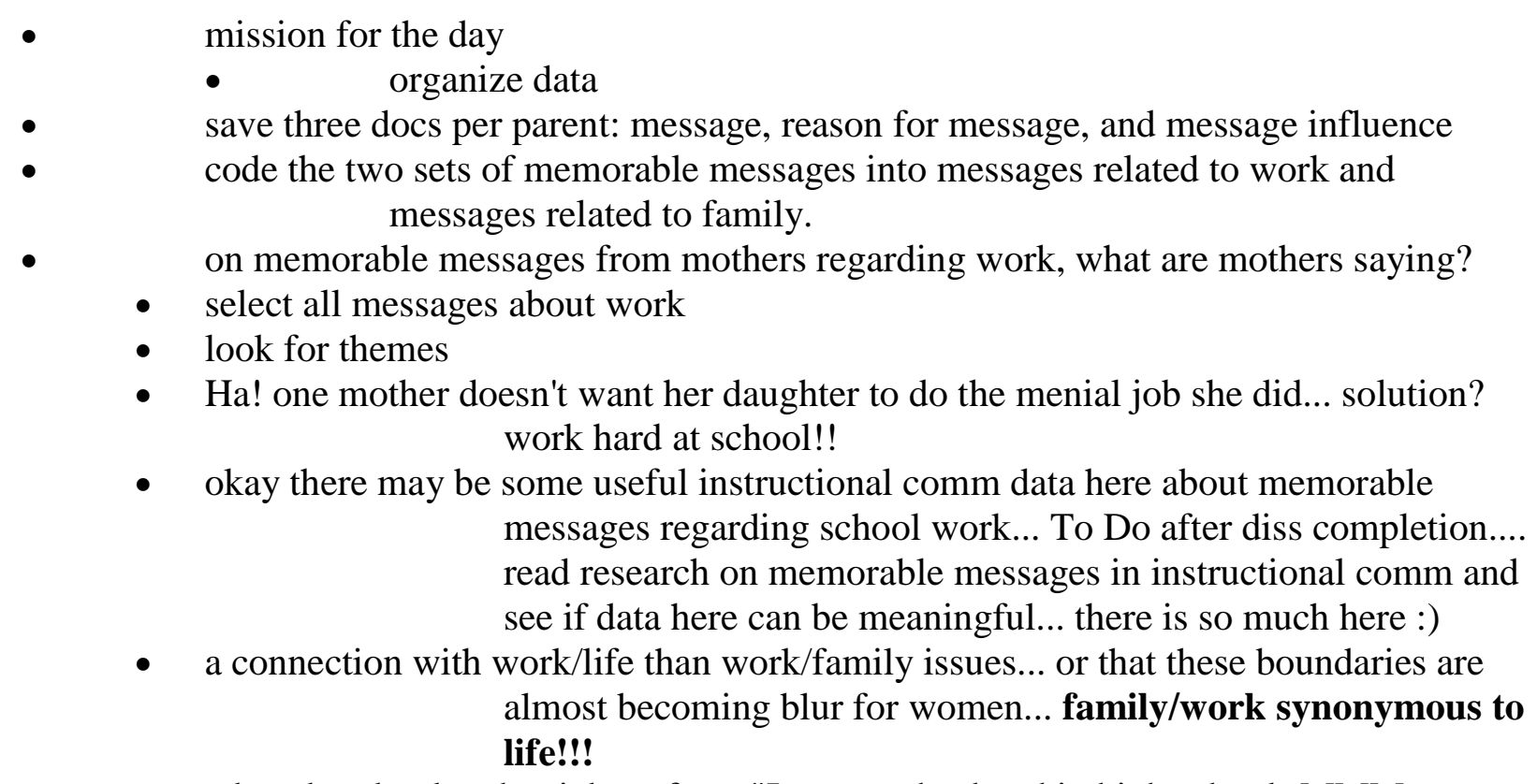

- take a break... lunch: pick up from "I met my husband in high school- MMM

$$
\text { - } \quad \text { okay, let's move on :) }
$$

- $\quad$ on memorable messages from mothers regarding family, what are mothers saying?

- $\quad$ select all messages about work

- $\quad$ look for themes

- $\quad$ on memorable messages from fathers regarding work, what are mothers saying?

$$
\begin{array}{ll}
\text { - } & \text { select all messages about work } \\
\text { look for themes }
\end{array}
$$

- $\quad$ on memorable messages from fathers regarding work, what are mothers saying?

$$
\begin{array}{ll}
- & \text { select all messages about work } \\
\text { - } & \text { look for themes }
\end{array}
$$

- $\quad$ create word cloud from each set of memorable message data

- $\quad$ explore to find important words; delete unimportant words from word cloud for clarity

- $\quad$ some words taken out: always, like

- $\quad$ run basic data analysis: word cloud/frequencies complete write-up

\section{- $\quad$ Thoughts on data = simply delish!!}

miscellaneous .... alright lady, review work done so far when you get back from teaching before you proceed.... lest you mess up the flow of work (that's what I don't need now :))....tadaaaaa! done for the day

$\frac{3 / 11 / 20162: 18 \mathrm{PM}}{-\quad \text { begin by reviewing the nodes that you have already created }}$ 
- $\quad$ okay, initial coding done... ugggh! why do i have too much junk? okay, now let's take coding from the superficial level to make a few inferences of what these amazing daughters are talking about in themes under "other"

- $\quad$ recode/categorize all messages that i can infer are related to work/family/work \& family.

- $\quad$ take note of frequency differences and report in manuscript.

- $\quad$ fathers seem to be blunt/straight forward with their messages about work both moms ad dads are concerned with happiness... read more on happiness (is it a construct studies in communication studies? ughhhh... that will be exciting to know... probe further for discussion) - $\quad$ nobody talks about happiness in relationships/marriage? Hehehe... isn't that too important, moms and dads?

- $\quad \mathrm{NB}$ : have a clear mind about the trends in the data... personal experience and ideals are irrelevant here, m'am :)

- $\quad$ okay got that!!! back into the data

3/12/16 5:30AM

- $\quad$ there is theoretical saturation too.... all messages are now beginning to fall in nodes created already. no new nodes...

- $\quad$ NB: no cross coding.... messages are coded for general idea and cannot belong to more than one node.

- $\quad$ Advantage: keeps coding and analysis clean and clear. no confusion about this.... always look for the general idea... message content should support general ideas too, well sometimes...either way, all messages get to be categorized.

- $\quad$ Disadvantage: over stretching the data and this could result in double themes that may not be necessarily existent.... no deception/confusion about memorable messages.... keep it clean and clear.

After diss though: let's see how cross coding how looks like, with its word cloud as well and then see if you would find a relationship.

- $\quad$ word cloud $=$ confirms similarity in words/ideas/thoughts highlighted in the nodes. - $\quad$ go back into diss and write up results.

- $\quad$ Remember: review journal and nodes for the last time to double check everything and make corrections where needed.

- $\quad$ after diss results write up

- $\quad$ renaming of themes for clarity... thanks to Christy

- $\quad$ frequency counts adjusted to reflect correction in messages recoded.

- $\quad$ okay: work done!!! i took much longer than i ever imagined :(.

- $\quad$ though my advisor wasn't a 'coder', her review of the codes also served as a check for coding. Thanks, Dr. Rittenour :) 